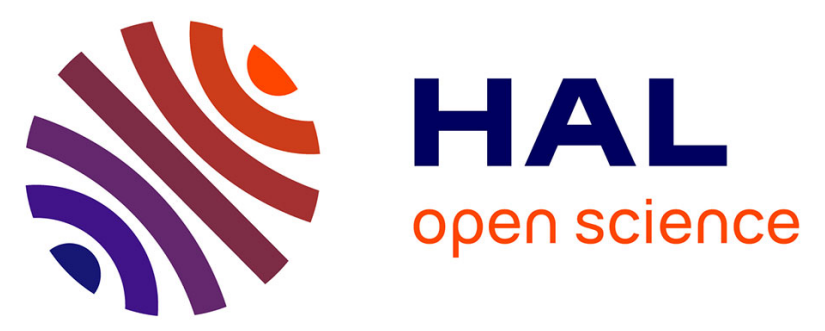

\title{
2-Substituted vs 4-substituted-9,9'-spirobifluorene host materials for green and blue phosphorescent OLEDs: a structure-property relationship study
}

Sebastien Thiery, Céline Declairieux, Denis Tondelier, Gijun Seo, Bernard

Geffroy, Olivier Jeannin, Rémi Métivier, Joëlle Rault-Berthelot, Cyril Poriel

\section{To cite this version:}

Sebastien Thiery, Céline Declairieux, Denis Tondelier, Gijun Seo, Bernard Geffroy, et al.. 2Substituted vs 4 -substituted-9,9'-spirobifluorene host materials for green and blue phosphorescent OLEDs: a structure-property relationship study. Tetrahedron, 2014, 70 (36), pp.6337 - 6351. 10.1016/j.tet.2014.05.081 . hal-01072178

HAL Id: hal-01072178

https://hal-univ-rennes1.archives-ouvertes.fr/hal-01072178

Submitted on 7 Oct 2014

HAL is a multi-disciplinary open access archive for the deposit and dissemination of scientific research documents, whether they are published or not. The documents may come from teaching and research institutions in France or abroad, or from public or private research centers.
L'archive ouverte pluridisciplinaire HAL, est destinée au dépôt et à la diffusion de documents scientifiques de niveau recherche, publiés ou non, émanant des établissements d'enseignement et de recherche français ou étrangers, des laboratoires publics ou privés. 


\section{2-substituted vs 4-substituted-9,9'-spirobifluorene host materials for green and blue phosphorescent OLEDs: A Structure-Property Relationship Study}

Sébastien Thiery, ${ }^{a}$ Céline Declairieux, ${ }^{c}$ Denis Tondelier, ${ }^{c}$ Gijun Seo, ${ }^{c}$ Bernard Geffroy, ${ }^{c, d}$ Olivier Jeannin, ${ }^{a}$ Rémi Métivier, ${ }^{b}$ Joëlle Rault-Berthelot, ${ }^{* a}$ Cyril Poriel ${ }^{* a}$

a. Université de Rennes 1-UMR CNRS 6226, "Institut des Sciences Chimiques de Rennes" MaCSE group. Bat 10C, Campus de Beaulieu, 35042 Rennes, France

b. PPSM, Institut d'Alembert, ENS Cachan, UMR CNRS 8531, 61 Avenue du Président Wilson, 94235 Cachan, France

c. LPICM, Ecole Polytechnique, UMR CNRS 7647, Route de Saclay, 91128, Palaiseau

d. LICSEN, CEA Saclay, IRAMIS/NIMBE, 91191 Gif sur Yvette

\section{$\underline{\text { Abstract }}$}

We report a structure-property relationship study of four 9,9'-spirobifluorene (SBF) derivatives (45Pm-SBF, 2-5Pm-SBF, 4-Ph-SBF and 2-Ph-SBF), substituted with either phenyl or pyrimidine at the $\mathrm{C} 2$ or $\mathrm{C} 4$ position of the SBF core. Structural, thermal, electrochemical and photophysical properties have been examined and correlated to theoretical calculations in order to study the influence of the nature and the position of the substituent. The emission properties of 4- vs 2substituted SBFs are noticeably different highlighting, in the excited state, the remarkable effect of substitution in ortho position of SBF. All compounds have been used as host material for green dopant in PhOLEDs with very high performances (2-5Pm-SBF: CE $>58 \mathrm{~cd} / \mathrm{A}, \mathrm{PE}>35 \mathrm{~lm} / \mathrm{W}, \mathrm{EQE}$ $>14 \%$ ). More importantly, the two 4-substituted SBFs have been used as host materials in blue PhOLEDs, displaying high performance and a decrease of $\mathrm{V}_{\mathrm{TH}}$ for 4-5Pm-SBF due to the incorporation of the electron-withdrawing pyrimidine.

\section{Grpahical Abstract}
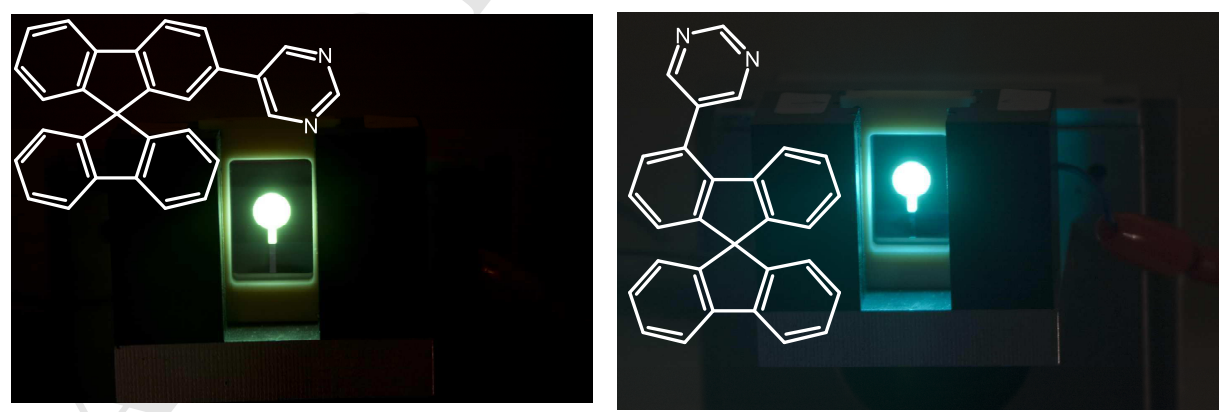

\section{Introduction}


In the past twenty years, the use of organic semiconducting materials for applications in "plastic electronics", such as field effect transistors (FETs), ${ }^{1}$ organic light emitting diodes (OLEDs), ${ }^{2,3}$ and organic photovoltaic (OPVs), ${ }^{4,5}$ has gained fantastic interest. ${ }^{6-8}$ Particularly, OLEDs have attracted much scientific and commercial interest because of their potential applications in organic flat-panel displays and solid-state lighting. However, as full colour displays and white lighting require materials that emit over a broad range of colour, the weak link of the technology remains the lack of efficient and stable blue light emitters. Moreover, due to the triplet exciton/singlet exciton ratio of $3 / 1$, the maximum achievable emission quantum yield is limited to $25 \%$ for fluorescent emitters. Among the significant progress recently made, phosphorescent organic emitting-diodes (PHOLEDs) which use heavy-metal complexes as emitters to harvest both singlet and triplet excitons are considered as the most promising technology because, theoretically the internal quantum efficiencies of these devices may reach $100 \%$. The fabrication of blue phosphorescent devices is however still challenging because the prerequisites for designing organic host materials are (i) a high triplet energy level (higher than $E_{T}$ of the blue dopant), (ii) a high glass-transition temperature ( $\mathrm{Tg}$ ) and (iii) matching HOMO/LUMO levels for hole and electron injection/transport. In this context, most of host materials for blue PhOLEDs are based on carbazole, triphenylamines, phosphine oxides or fluorene derivatives. ${ }^{9-11}$ However, novel host materials with good thermal and morphological stabilities to afford blue PhOLEDs with high efficiencies, stability and colour purity are still desirable. In this context, 9,9'-spirobifluorene (SBF) based semiconductors have experienced a fantastic development during the last thirty years, due to their use as chiral ligand, ${ }^{12,13}$ as electropolymerizable building block, ${ }^{14-17}$ as solid state laser ${ }^{18}$, in third-order nonlinear optics, ${ }^{19}$ in Metal Organic Frameworks ${ }^{20}$ but more importantly in organic electronics, leading to fantastic breakthroughs in the field. ${ }^{21-23}$ Thus, numbers of electron donating and /or withdrawing functionalities have been introduced on the SBF scaffold in order to make the electronic properties of the resulting dyes fitting with an application. ${ }^{21}$ For that purpose, electron-deficient heterocycles such as $1,3,4$-oxadiazoles, ${ }^{24}$ pyridine $^{25}$, quinoline, ${ }^{26}$ quinoxaline ${ }^{27}$ and pyridopyrazine ${ }^{28}$ connected at $\mathrm{C} 2$ and $\mathrm{C} 7$ positions of SBF were reported in literature. Among those electron-deficient heterocycles, only few examples describing the fluorene substitution by pyrimidine units (see chart 1) have been reported to date. However, pyrimidine possesses many striking characteristics, as it is notably more electron-deficient than pyridine, which has been widely studied. ${ }^{29}$ Thus Bryce's group has for example demonstrated in 2003, that fluorene fluorophore $\mathrm{F} 3$ emits a pure blue emission in solution and thin films. ${ }^{30}$ However the electroluminescent spectrum of F3-based OLED mainly presents the known parasite green emission of dialkylfluorenes. ${ }^{31-33} \mathrm{~A}$ similar green emission is observed on PL spectrum of the liquid crystal F4. ${ }^{34}$ The introduction of a 9,9' Spirobifluorene unit (SBF) in TBPSF leads to improve the thermal, optical and electronic properties and this new blue emitter has been used as host for fluorescent blue, red or green organic dopants leading to efficient devices. ${ }^{35,36}$

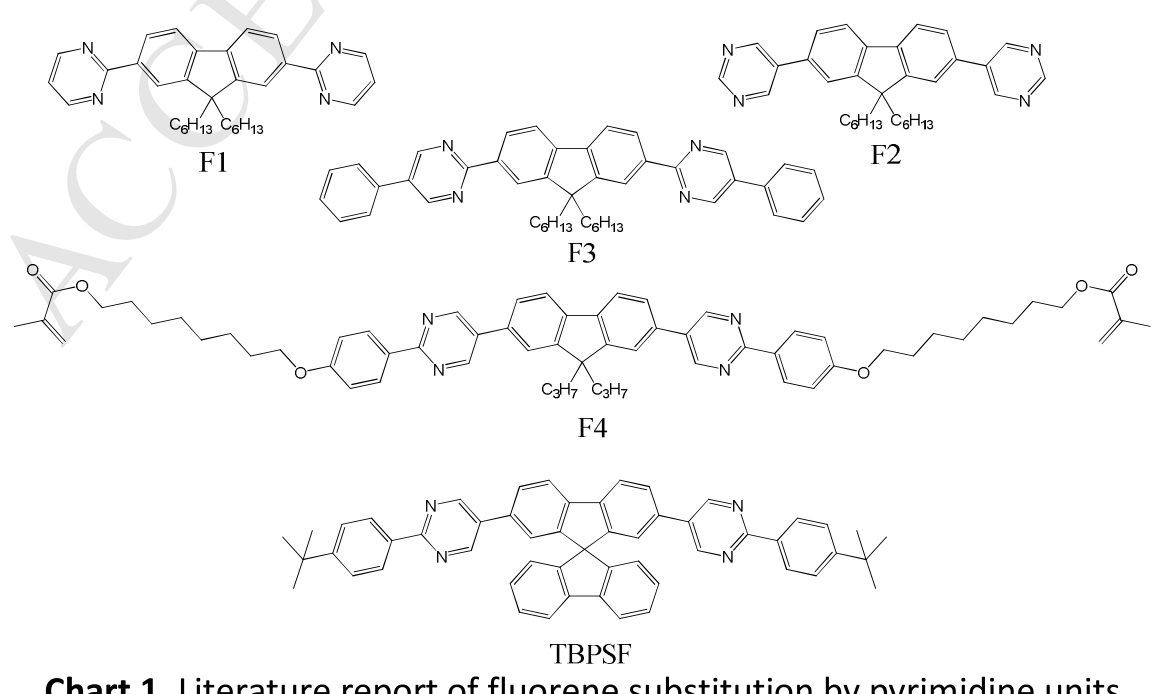

Chart 1. Literature report of fluorene substitution by pyrimidine units 
However, if 2-substituted SBFs have been impressively investigated for the last decades, it is far to be the case of the three other positional isomers, that are 1-, 3- or 4-substituted SBFs. Thus, for example, 4substituted SBFs have only been reported in a few instances ${ }^{37-42}$ but appears as a very appealing scaffold to design rigid SBF-based organic host materials for PhOLEDs. In our quest for robust derivatives with high $\mathrm{E}_{\mathrm{T}}$ which can be used as host materials for green and blue phosphorescent dyes, ${ }^{43}$ we wish to report herein the synthesis and the detailed study of the properties of two pyrimidine-substituted SBFs (4-5Pm-SBF and 2-5Pm-SBF, see chart 2). Moreover, in order to give a detailed description of the influence of the pyrimidine unit, the 2- and 4-phenyl-substituted SBFs (2-Ph-SBF and 4-Ph-SBF) have been also studied in detail (4-PhSBF has been previously reported). ${ }^{44}$ Thus, after synthetic considerations, the electrochemical, thermal and photo-physical properties will be discussed and coupled to a theoretical approach. The influence of the nature of the substituent (pyrimidine vs phenyl) and of its position (2- vs 4-) will be notably carefully investigated. Finally, the incorporation of these four semiconductors as host material for green and blue PhOLEDs will be presented.

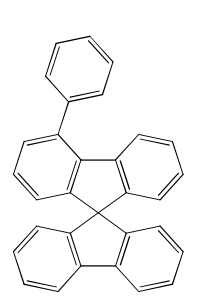

4-Ph-SBF
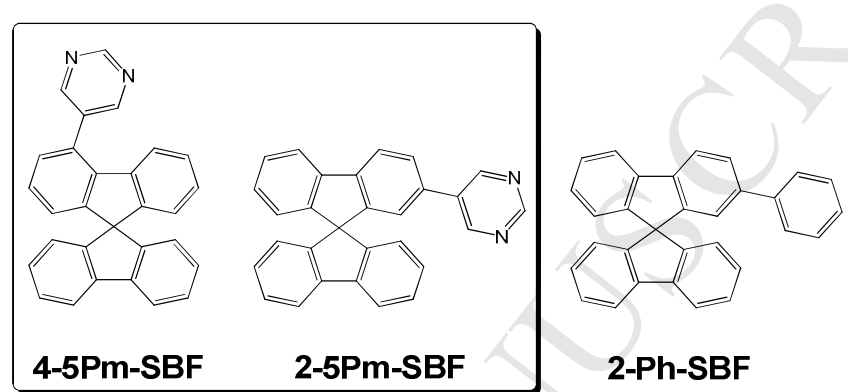

Chart 2. Molecules studied in this work

\section{Results and discussion}

The first step towards the synthesis of 4- and 2-substituted SBF was the access of the two key platforms 4- and 2-bromo-9,9'-spirobifluorene (see structures of 4-Br-SBF and 2-Br-SBF in scheme 1). As reported previously, ${ }^{37,44}$ 4-Br-SBF was synthesized by the mono lithium-halogen exchange of 2,2'dibromobiphenyl followed by the trapping of the corresponding lithiated intermediate with 9-fluorenone. The intramolecular electrophilic ring closure of the corresponding fluorenol (not isolated), in acidic media $(\mathrm{AcOH} / \mathrm{HCl})$, further provides $4-\mathrm{Br}-\mathrm{SBF}$ with $75 \%$ yield (2 steps). Finally, a subsequent Suzuki cross-coupling between 4-Br-SBF and either 5-pyrimidine boronic acid or phenylboronic acid was performed ( $\left.\mathrm{Pd}(\mathrm{dppf}) \mathrm{Cl}_{2} / \mathrm{K}_{2} \mathrm{CO}_{3} / \mathrm{DMF}\right)$ providing 4-5Pm-SBF or 4-Ph-SBF with significant good yields $(94 \%$ and $91 \%$ respectively). Similarly, access to $\mathbf{2 - B r - S B F}$ was performed by the lithium-halogen exchange of 2bromobiphenyl followed by the trapping of the corresponding lithiated intermediate with 2-bromo-9fluorenone. ${ }^{45}$ The intramolecular electrophilic ring closure of the corresponding fluorenol, in acidic media $(\mathrm{AcOH} / \mathrm{HCl})$, further provides $2-\mathrm{Br}-\mathrm{SBF}$ with $67 \%$ yield (2 steps), involved in a final Suzuki cross-coupling with either 5-pyrimidine boronic acid or phenylboronic acid to lead the corresponding 2-5Pm-SBF or 2-PhSBF with high yields ( $77 \%$ and $78 \%$ respectively). 


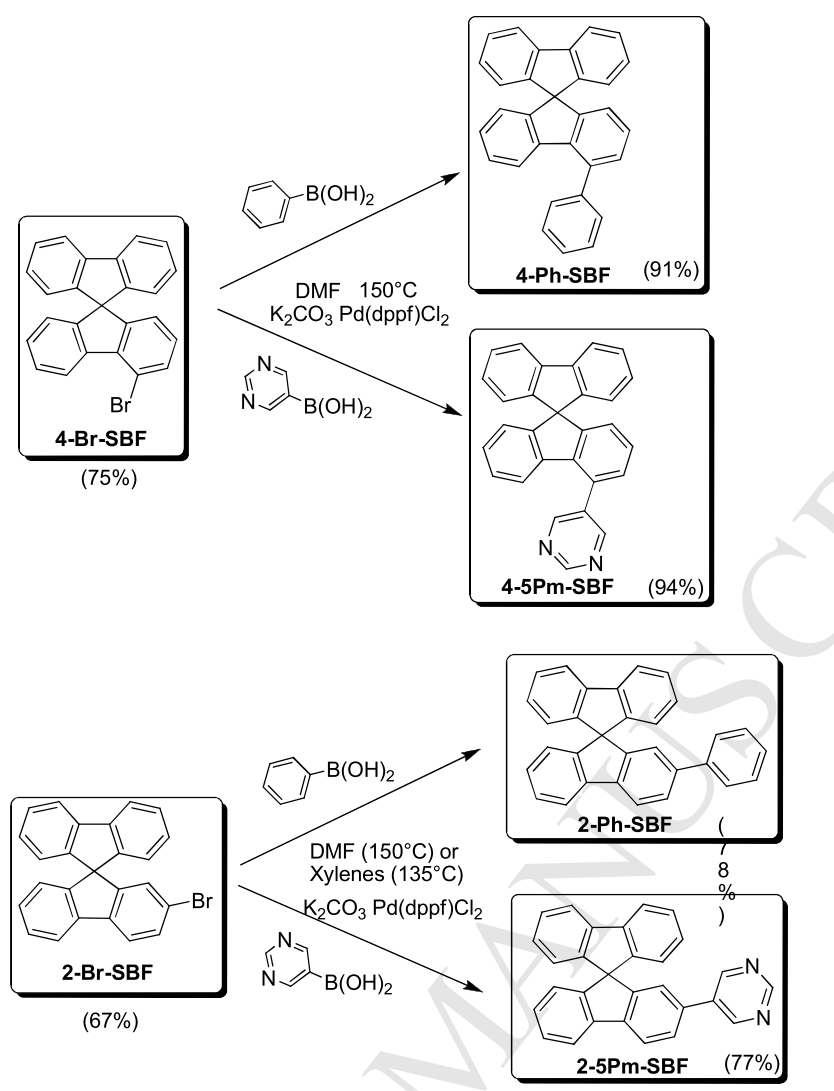

Scheme 1. Synthesis of the four dyes, 4-Ph-SBF, 4-5Pm-SBF, 2-Ph-SBF and 2-5Pm-SBF

\section{$\underline{\text { Structural Properties }}$}

Molecular structure of the four dyes was further confirmed by X-ray crystallography. The X-ray diffraction data of single crystals of 2-Ph-SBF (Figure 1, left) and 4-Ph-SBF (Figure 1, right) reveal an asymmetric unit containing two independent molecules 1 and 2 . As previously reported, ${ }^{44}$ in 4-Ph-SBF, the angle between the mean plane of the pendant phenyl ring and that of its attached phenyl ring of the fluorene is as large as $51.2^{\circ}$ in molecule 1 and $56.6^{\circ}$ in molecule 2.

In 2-Ph-SBF, the same angle appears to be noticeably smaller, ie $37.4^{\circ}$ for molecule 1 . Similar values have been reported in literature for 2-substituted SBF $\left(\mathrm{ca} 30^{\circ}\right)^{46,47}$ and seems hence to be a characteristic of such family of 2-substituted SBFs. This difference between the angle observed in 2-Ph-SBF and 4-Ph-SBF may be at the origin of the restricted $\pi$-conjugation of the latter and will have remarkable consequences on the electronic properties (see below). In addition, we note that the fluorene unit bearing the pendant phenyl ring in the molecule 1 of 2-Ph-SBF is folded with a deformation of ca $7.1^{\circ}$ between the mean planes of each phenyl unit. However, in the case of molecule 2 of 2-Ph-SBF, we surprisingly note that the pendant phenyl unit is almost coplanar with the fluorene unit with an angle between the mean plane of the pendant phenyl ring and that of its attached phenyl ring of the fluorene unit as low as $4.6^{\circ}$. In addition and oppositely to what was observed for molecule 1 , the fluorene bearing the phenyl unit is now almost perfectly flat with only a small deformation of $1.5^{\circ}\left(7.1^{\circ}\right.$ measured in molecule 1 , see above). Such structural feature appears highly surprising and is assigned to the packing of the molecule. Indeed, numbers of short $\mathrm{CH}$ and $\mathrm{CC}$ distances are detected in the packing diagram of 2-Ph-SBF and especially two short intermolecular $\mathrm{CH}$ distances of ca $2.8 \AA$ A between the pendant phenyl ring and its close neighbours (see $\mathrm{SI}$ ). 

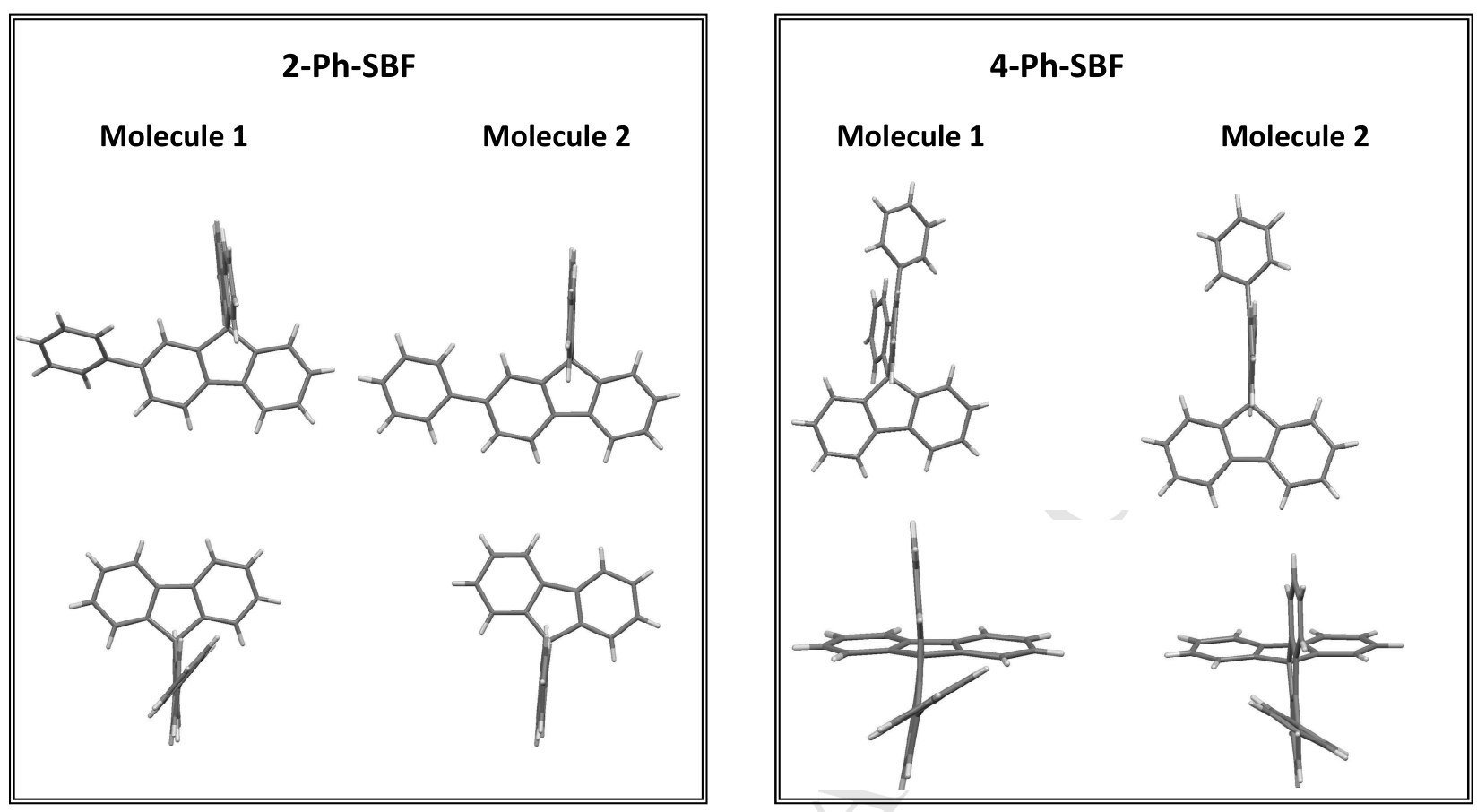

Figure 1. Molecular structure of the two molecules (molecule 1 and molecule 2) contained in 2-Ph-SBF (left) and 4-Ph$\mathrm{SBF}^{44}$ (right) single crystal asymmetric unit.

However, in the case pyrimidine based SBFs, ie 4-5Pm-SBF and 2-5Pm-SBF, we only managed to obtain single crystals of 2-5Pm-SBF good enough for X-Ray diffraction and hence the direct comparison is not possible. However, we are convinced that similar structural features structures occur in both 4-5Pm-SBF and 2-5Pm-SBF. Indeed, in 2-5Pm-SBF, the angle between the mean plane of the pyrimidine plane and that of its attached phenyl ring is recorded at $23.7^{\circ}$ (See $\mathrm{SI}$ ), lower than that recorded for its phenyl analogue 2Ph-SBF (37.4 $4^{\circ}$.

\section{Electrochemical Properties}

Electrochemical properties have been investigated by cyclic voltammetry $(\mathrm{CV})$ in $\mathrm{CH}_{2} \mathrm{Cl}_{2}$ in oxidation and reduction and are summarized in table 1. Pyrimidine-substituted SBF were studied in absence of $\mathrm{Al}_{2} \mathrm{O}_{3}$ as their rapid adsorption on $\mathrm{Al}_{2} \mathrm{O}_{3}$ leads to a strong decrease of the intensity of the oxidation and reduction waves.

All compounds present at least two successive oxidation waves (with maxima $E^{1}$ and $E^{2}$ ) before $2.2 \mathrm{~V}$ (figure 2). Except for 2-5Pm-SBF, the oxidation is accompanied by an electropolymerization process signed on the present $\mathrm{CVs}$ by a reduction wave at the back sweep. This polymerization process is more clearly observed along recurrent sweeps (see CVs in $\mathrm{SI}$ ). Compared one to another, polymerization process is highly efficient for 2-Ph-SBF and 4-Ph-SBF and largely less efficient for 4-5Pm-SBF. Moreover, the electroactivity of the corresponding polymers, ie Poly(2-Ph-SBF) and Poly(4-Ph-SBF) are similar with onset oxidation potentials at ca $1.1 \mathrm{~V}$ vs SCE (polymers HOMO: $-5.5 \mathrm{eV}$ ). In addition, the p-doping process reversibility of the two polymers occurs in a large potential range between 1 and $2 \mathrm{~V}$. Oppositely, Poly(4-5Pm-SBF) presents a $p$ - 
doping process only occurring since $1.35 \mathrm{~V}$ (polymer HOMO : $-5.75 \mathrm{eV}$ ) and appearing less intense and reversible.

Table1. Selected electrochemical, theoretical and optical data

\begin{tabular}{|c|c|c|c|c|c|c|c|c|c|}
\hline & \multicolumn{5}{|c|}{ Electrochemical studies } & \multicolumn{3}{|c|}{ Theoretical calculations } & \multirow{2}{*}{$\begin{array}{c}\text { Optical } \\
\text { studies } \\
\Delta \mathrm{E}^{\mathrm{opt}}(\mathrm{eV})^{\mathrm{e}}\end{array}$} \\
\hline & $\begin{array}{c}\mathrm{E}^{1}, \mathrm{E}^{2} \text { oxidation } \\
\text { peaks/ } \\
\mathrm{E}_{\text {onset }} \mathrm{ox}(\mathrm{V})^{\mathrm{a}}\end{array}$ & $\begin{array}{l}\text { Reduction peak/ } \\
E_{\text {onset }} \text { red }(V)^{a}\end{array}$ & $\begin{array}{l}\mathrm{HOMO}^{\mathrm{b}} \\
(\mathrm{eV})\end{array}$ & $\begin{array}{c}\text { LUMO }^{\mathrm{C}} \\
(\mathrm{eV})\end{array}$ & $\Delta \mathrm{E}^{\mathrm{el}}(\mathrm{eV})^{\mathrm{d}}$ & $\begin{array}{c}\text { HOMO } \\
(\mathrm{eV})\end{array}$ & $\begin{array}{c}\text { LUMO } \\
(\mathrm{eV})\end{array}$ & $\Delta \mathrm{E}^{\text {theo }}(\mathrm{eV}) / \mathrm{E}_{\mathrm{T}}$ & \\
\hline 4-5Pm-SBF & $\begin{array}{c}1.82,2.23 / \\
1.57\end{array}$ & $\begin{array}{l}-2.38 / \\
-2.17\end{array}$ & -5.97 & -2.23 & 3.74 & -6.16 & -1.65 & $4.51 / 2.80$ & 3.72 \\
\hline 4-Ph-SBF & $\begin{array}{c}1.68,1.88 / \\
1.55\end{array}$ & $\begin{array}{l}-2.75 / \\
-2.45\end{array}$ & -5.95 & -1.95 & 4.00 & -5.97 & -1.27 & $4.70 / 2.82$ & 3.82 \\
\hline 2-5Pm-SBF & $\begin{array}{c}1.75,2.00 / \\
1.56\end{array}$ & $\begin{array}{l}-2.33 / \\
-2.10\end{array}$ & -5.96 & -2.30 & 3.66 & -6.13 & -1.85 & $4.29 / 2.63$ & 3.66 \\
\hline 2-Ph-SBF & $\begin{array}{c}1.60,1.93 / \\
1.48\end{array}$ & $\begin{array}{c}\text { No peak in } \mathrm{CH}_{2} \mathrm{Cl}_{2} / \\
-2.3\end{array}$ & -5.88 & -2.10 & 3.78 & -5.87 & -1.48 & $4.39 / 2.62$ & 3.70 \\
\hline
\end{tabular}

a. Measured in $\mathrm{CH}_{2} \mathrm{Cl}_{2}+\mathrm{Bu}_{4} \mathrm{NPF}_{6} 0.2 \mathrm{M}$ at $100 \mathrm{mV} / \mathrm{s}$, b. Calculated from the onset oxidation potential $\mathrm{E}_{\text {onset }}{ }^{\text {ox }}$, c. Calculated from the onset reduction potential $\mathrm{E}_{\text {onset }}{ }^{\text {ed }}, \mathrm{d}: \Delta \mathrm{E}^{\mathrm{el}}=|\mathrm{HOMO}-\mathrm{LUMO}|$, e: Calculated from the onset of the absorption spectrum in solution in cyclohexane (see spectra figure 5 left) by using $\Delta \mathrm{E}^{\mathrm{opt}}=\mathrm{hc} / \lambda\left(\Delta \mathrm{E}^{\mathrm{opt}}(\mathrm{eV})=1237.5 / \lambda(\mathrm{nm})\right.$.
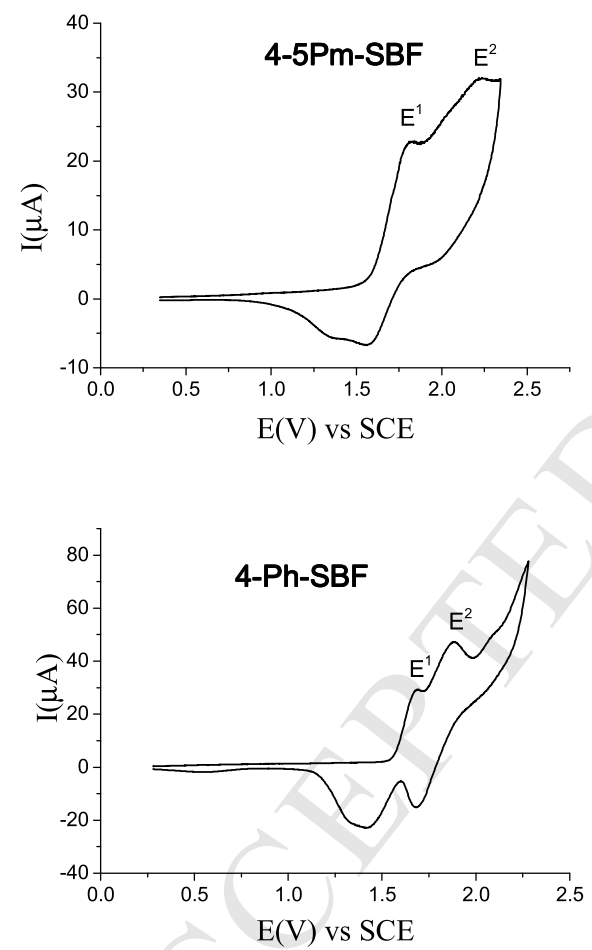
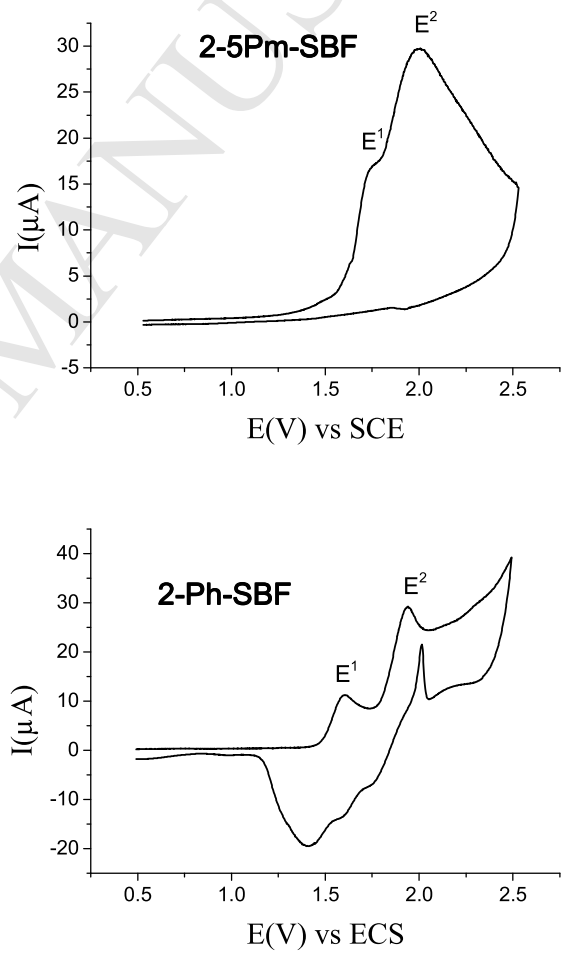

Figure 2. Cyclic voltammetry of 4-5Pm-SBF $\left(5 \times 10^{-3} \mathrm{M}\right)$ and 2-5Pm-SBF $\left(2 \times 10^{-3} \mathrm{M}\right)$ (top) and of 4-Ph-SBF $\left(5 \times 10^{-3} \mathrm{M}\right)$ and 2-Ph-SBF $\left(510^{-3} \mathrm{M}\right)$ (bottom) solutions in $\mathrm{CH}_{2} \mathrm{Cl}_{2}+\mathrm{Bu}_{4} \mathrm{NPF}_{6} 0.2 \mathrm{M}$, sweep-rate $100 \mathrm{mV} . \mathrm{s}^{-1}$. Platinum disk $(\varnothing: 1 \mathrm{~mm})$ working electrode.

From the onset oxidation of the CVs, we determined the HOMO levels ${ }^{48}$ of 4-5Pm-SBF at $-6.0 \mathrm{~V}$ close to that of 4-Ph-SBF (HOMO: $-5.95 \mathrm{eV}$ ) and of its constituting building block SBF (HOMO: $-5.94 \mathrm{eV})^{49}$ indicating that the substitution in ortho position leads to a $\pi$-conjugation interruption surely due to the large angle observed in the X-ray structure between the pendant unit and the fluorene core. In addition, we note that the substitution by a 5-pyrimidine or a phenyl group have both very weak effects on the HOMO level of the 4-substituted-SBFs. Indeed, as seen in theoretical calculations, the pendant substituent is not involved in the HOMO character of 4-substituted SBFs (Figure 3) being hence in accordance with our electrochemical conclusions. On the other hand, HOMO levels of 2-5Pm-SBF and 2-Ph-SBF calculated from their respective onset oxidation potentials are estimated at $-5.96 \mathrm{eV}$ and $-5.88 \mathrm{eV}$. The highest HOMO of 2- 
Ph-SBF compared to that of SBF signs an extension of the $\pi$-conjugation between the fluorene and the phenyl group in 2-Ph-SBF. This effect is however neutralized in 2-5Pm-SBF by the electron withdrawing effect of the pyrimidine group leading to an HOMO level identical to that of SBF. Thus, in the case of 2-PhSBF, the substituent is involved in the character of the HOMO (Figure 3), which is not the case for the HOMO of 2-5Pm-SBF. Cathodic exploration in dichloromethane, reveal that all compounds are reduced at negative potential in a non-reversible process close to the electrolytic medium reduction (see CVs in SI). However, when studied in THF, allowing reaching a more cathodic potential range, one or two reduction waves are observed before the reduction of the electrolytic solution (see CVs in SI). LUMO levels were determined from the onset reduction potential in $\mathrm{CH}_{2} \mathrm{Cl}_{2}$ at $-2.23 ;-1.95 ;-2.30$ and $-2.10 \mathrm{eV}$ for 4-5Pm-SBF ; 4-Ph-SBF : 2-5Pm-SBF and 2-Ph-SBF respectively (these values are close to that measured in THF, see in SI).

The lowest LUMO level is recorded for 2-5Pm-SBF as low as $-2.3 \mathrm{eV}, 0.41 \mathrm{eV}$ lower than the LUMO of SBF ($1.89 \mathrm{eV})^{44}$ signing the double effect of the extension of conjugation due to the substitution at the C2 of SBF and to the electron-withdrawing effect of the electron-deficient pyrimidinium group. Thus, we note that the pyrimidine unit is strongly involved in the LUMO character of 2-5Pm-SBF and even more strongly involved in the case of 4-5Pm-SBF (Figure 3). Thus, the LUMO level of 4-5Pm-SBF $(-2.23 \mathrm{eV}$ ) is shifted by $0.07 \mathrm{eV}$ compared to that of 2-5Pm-SBF. In addition, the LUMO level of 4-5Pm-SBF is shifted by $0.27 \mathrm{eV}$ compared to that of SBF, $(-1.96 \mathrm{eV})$ due to the effect of the incorporation of the electron-withdrawing pyrimidine fragment. Finally, due to the absence of $\pi$-conjugation between the phenyl and the C4fluorene, ${ }^{44}$ LUMO levels of 4-Ph-SBF is the highest of the present series, ie $-1.96 \mathrm{eV}$, and very close to that of SBF.

Finally, HOMO-LUMO gaps ( $\triangle \mathrm{E}^{\mathrm{el}}$ ) extend between $3.66 \mathrm{eV}$ for 2-5Pm-SBF to $4.00 \mathrm{eV}$ for 4-Ph-SBF. This trend in HOMO-LUMO gap changes is well reproduced by theoretical calculations (figure 3 ) with nevertheless a deviation of ca $0.7 \mathrm{eV}$.
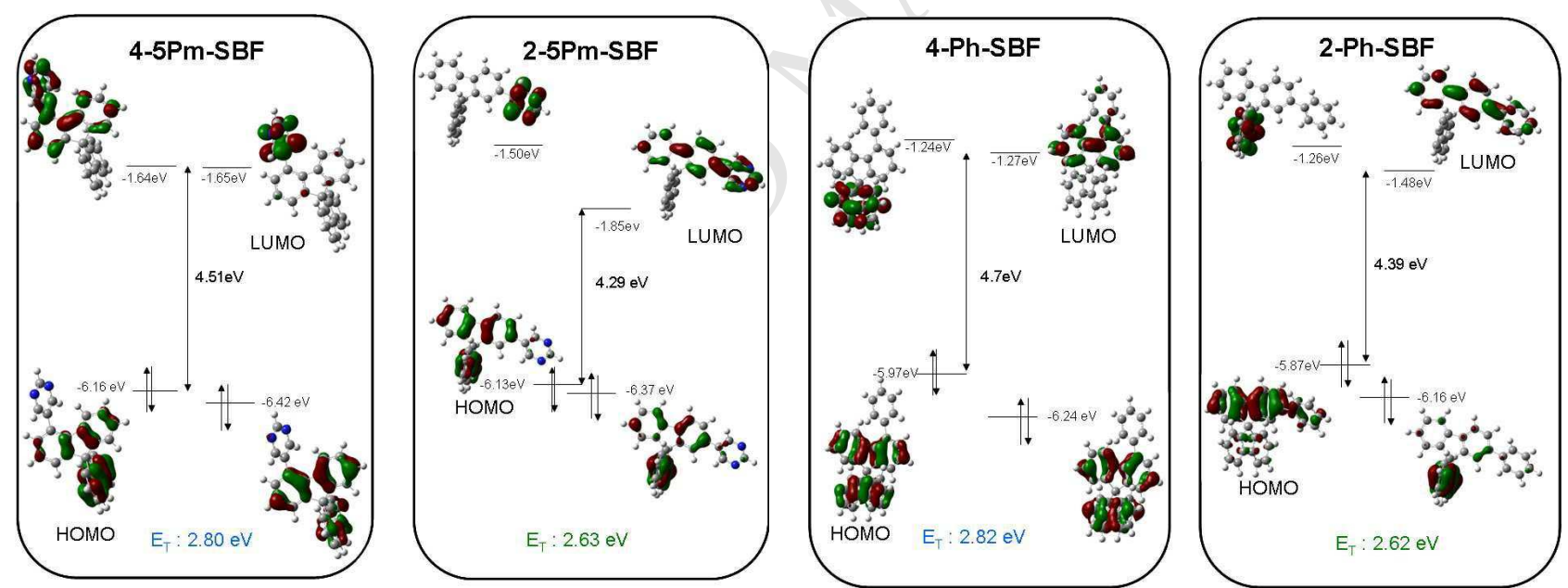

Figure 3. Calculated frontier molecular orbitals by DFT of 4-5Pm-SBF ; 4-Ph-SBF : 2-5Pm-SBF and 2-Ph-SBF, after geometry optimization at the B3LYP/6-311G+(d,p) level of theory, shown with an isovalue of 0.04 .

Geometry optimization of the four substituted dyes in the singlet and triplet states was performed using Density Functional Theory (DFT) at the Gaussian09 B3LYP/6-311+G(d,p) level of theory. There is a clear resemblance between the HOMO values determined by CVs and by theoretical calculations. 2-Ph-SBF is the easiest oxidizable molecule due to the extension of conjugation between the phenyl and the 2-substituted fluorene unit and its HOMO presents a phenyl-fluorene character, perfectly translating this extension of conjugation. 4-5Pm-SBF is the more difficult oxidizible molecule due to the withdrawing effect of the pyrimidine group on the fluorenyl core. However, it should be noted that 2-5Pm-SBF and 4-5Pm-SBF presents almost identical HOMO character and HOMO energy level ( $-6.13 \mathrm{eV}$ vs $-6.16 \mathrm{eV}$ resp) clearly meaning that the position of the pyrimidine group only has a weak influence on the HOMO energy levels and distribution. As exposed above, the more easily reduced molecule is 2-5Pm-SBF due to the double effect of the extension of conjugation and of the electron-accepting properties of the pyrimidine unit, its LUMO has hence a clear pyrimidine-fluorene character. In 4-5Pm-SBF, the LUMO exclusively has a pyrimidine character and its energy level is $0.2 \mathrm{eV}$ higher than that of 2-5Pm-SBF due to the absence of 
conjugation between the fluorene and the pyrimidine unit. This is a very important feature of the present chemical design and clearly highlights its efficiency. Thus, in 4-substituted SBFs, the HOMO character is almost identical with no (or weak) contribution of the substituent in accordance with our electrochemical conclusions (see above). In addition, it must be pointed out that the LUMO+1 of 4-5Pm-SBF is very close to its LUMO $(0.01 \mathrm{eV})$ with a 4-5Pm-fluorenyl and 4,5Pm character respectively. Thus, both 2-5Pm-SBF and 45Pm-SBF have a clear fluorene/pyrimidine character in their LUMO and LUMO+1 (almost degenerated with the LUMO which exclusively possess a pyrimidine character) respectively but present different energy levels. This highlights the importance of the torsion angle between the fluorene and the pyrimidine, which is surely at the origin of these different energy values. The computed triplet adiabatic $S_{0}$ to $T_{1}$ excitation energies, defined as the energy difference between total energy of the molecule in their respective singlet and triplet states, is of 2.80 and $2.82 \mathrm{eV}$ for 4-5Pm-SBF and 4-Ph-SBF and of 2.63 and $2.62 \mathrm{eV}$ for 2-5PmSBF and 2-Ph-SBF respectively. These calculations predict that 4-5Pm-SBF will be, as 4-Ph-SBF, ${ }^{44}$ a good candidate as host for blue and green phosphorescent dyes and both 2-5Pm-SBF and 2-Ph-SBF will be both only adapted to green dopants.

The thermal properties of all SBF derivatives were investigated by thermogravimetric analysis (TGA) and differential scanning calorimetry (DSC) and the results are summarized in table 2 . The $T d$ is defined as the temperature at which the sample has lost the first $5 \%$ of mass during heating.

Table 2. Thermal properties (melting point: m.p., decomposition temperature: $T_{d}$, glass transition: $T_{g}$, crystallization temperature: $T_{c}$, all obtained from the tangent to the transition peak) of the four SBF dyes.

\begin{tabular}{ccccc}
\hline & 4-5Pm-SBF & 4-Ph-SBF & 2-5PmSBF & 2-Ph-SBF \\
\hline m.p. $\left({ }^{\circ} \mathrm{C}\right)$ & 173 & $213^{\mathrm{b}}$ & $197-198$ & $100-108^{\mathrm{a}}$ \\
$\mathrm{T}_{\mathrm{d}}\left({ }^{\circ} \mathrm{C}\right)$ & 277 & 254 & 242 & 238 \\
$\mathrm{~T}_{\mathrm{g}}\left({ }^{\circ} \mathrm{C}\right)$ & 85 & 76 & 94 & 78 \\
$\mathrm{~T}_{\mathrm{c}}\left({ }^{\circ} \mathrm{C}\right)$ & - & 115 & - & - \\
\hline
\end{tabular}

a: This transition appears to be not very clear, occurring on a large range. b. from reference 44
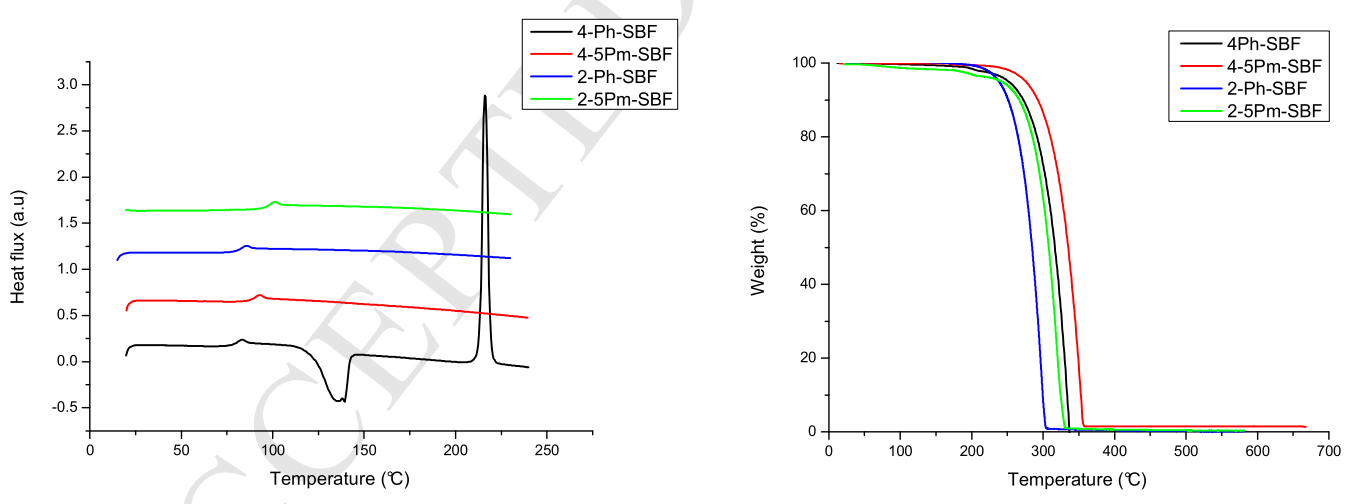

Figure 4. DSC curves from second heating cycle (Left) and TGA curves (right) of 4-Ph-SBF (black line), 4-5Pm-SBF (red line), 2-Ph-SBF (blue line), 2-5Pm-SBF (green line)

5\% decomposition ( $\left.T_{d}\right)$ of 4-Ph-SBF (Figure 4 right, black line) and 4-5Pm-SBF (Figure 4 right, red line) respectively occurs at $254^{\circ} \mathrm{C}$ and $277^{\circ} \mathrm{C}$, higher than the $T_{d}$ of $\operatorname{SBF}\left(234^{\circ} \mathrm{C}\right)^{44}$ showing the interest of the incorporation of a pendant phenyl or pyrimidine unit at the $\mathrm{C} 4$ of SBF. Decomposition temperature of the 2-substituted-SBF occurs at $242^{\circ} \mathrm{C}(2-5 \mathrm{Pm}-\mathrm{SBF})$ and $238^{\circ} \mathrm{C}$ (2-Ph-SBF) close to the $\mathrm{T}_{d}$ of SBF, clearly highlighting that the substitution in position 2 only has a weak effect on the thermal stability, whereas the substitution in position 4 leads to a more stiff structure being hence more thermally stable. Thus, we note that the position of the substitution has a clear influence on the $T_{d}$. On the other hand, 4-5Pm-SBF and 4-Ph-SBF respectively present melting transitions at 173 and $206^{\circ} \mathrm{C}$, whereas that of $2-5 \mathrm{Pm}-\mathrm{SBF}$ is detected at ca $197 / 198^{\circ}$ (see SI). It should be noted that the fusion of 2-Ph-SBF was very surprising appearing on a wide 
range of temperature. The substituent also has a clear influence on the whole thermal properties as the replacement of phenyl by pyrimidine leads to different glass transitions $\left(T_{g}\right)$. Thus, we note that lower $T_{g}$ (Figure 4, left) are detected (recorded on the second heating cycle of DSC, Figure 4 left) for phenylsubstituted SBF (76 and $78^{\circ} \mathrm{C}$ for 4-Ph-SBF and 2-Ph-SBF respectively) compared to pyrimidine-substituted SBF ( 85 and $94^{\circ} \mathrm{C}$ for $4-5 \mathrm{Pm}-\mathrm{SBF}$ and 2-5Pm-SBF respectively). The slightly higher $\mathrm{Tg}$ of pyrimidinesubstituted compounds compared to phenyl-substituted compounds may be the consequence of stronger intermolecular interactions due to $\mathrm{CH}^{\prime \prime} \mathrm{N}$ hydrogens bonding interactions ${ }^{50}{ }^{5 \mathrm{It}}$ is important to stress that all compounds present $T_{g}$ higher than those of classical host materials for PhOLEDs such as CBP $\left(62^{\circ} \mathrm{C}\right)^{51}$ or $m$ $\mathrm{CP}\left(55^{\circ} \mathrm{C}\right) .{ }^{10}$ Finally, it should be mentioned that 4-5Pm-SBF, 2-5Pm-SBF and 2-Ph-SBF do no present any cristallization phenomena, $T_{c}$, being hence highly promising for devices incorporation. $A$ cristallization transition was only recorded for 4-Ph-SBF but at high temperature, $115^{\circ} \mathrm{C}$, during the second heating cycle in DSC.

\section{Photophysical studies}

The UV-Vis absorption and emission spectra recorded in cyclohexane are presented figure 5 . All compounds present similar absorption bands in the range 260-315 with the same maxima at $308 \mathrm{~nm}$ similar to the main absorption band of SBF attributed to $\pi-\pi *$ transition of the fluorene unit in SBF. ${ }^{37,38,44}$
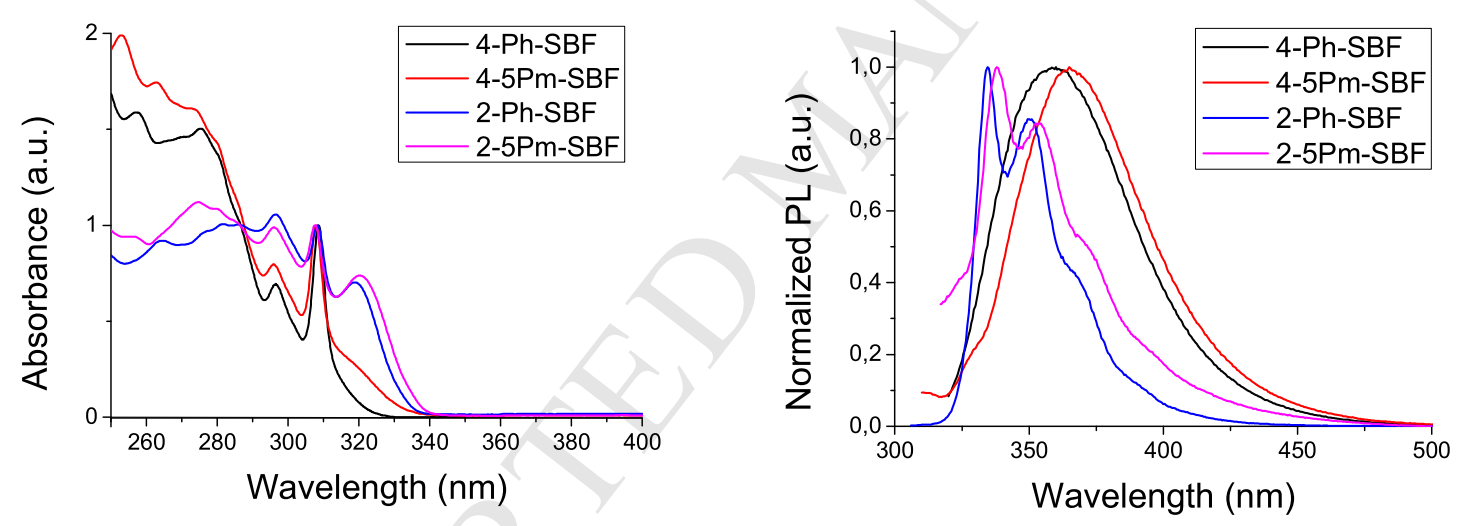

Figure 5. Normalized absorption (left) and emission (right, $\lambda_{\mathrm{exc}}=300 \mathrm{~nm}$ for 4-Ph-SBF, 4-5Pm-SBF and 2-Ph-SBF and 305 $\mathrm{nm}$ for 2-5Pm-SBF) spectra of the four dyes recorded in cyclohexane, $\mathrm{C}=10^{-6} \mathrm{M}$.

At higher wavelength, each compound possesses its own signature with a clear supplemental absorption peak at 320 or $319 \mathrm{~nm}$ for $\mathbf{2 - 5 P m - S B F}$ or 2-Ph-SBF signing an extension of the conjugation between the fluorene and the pyrimidine or the phenyl rings when the fluorene is substituted at $\mathrm{C} 2$ position. Literature reports a $\lambda_{\max }$ of $328 \mathrm{~nm}\left(\mathrm{CH}_{2} \mathrm{Cl}_{2}\right)$ for the disubstituted analogue 2,7-di-5Pm-9,9-dihexylfluorene (compound $F 2$ in chart 1) clearly showing an even more important extension of $\pi$-conjugation due to the presence of two pyrimidine units. ${ }^{30}$ It means that efficient $\pi$-conjugation occurs between fluorene and pyrimidine unit leading to a red shift of ca $8 / 10 \mathrm{~nm}$ per pyrimidine unit. In the case of 4-substituted SBF, we note the presence of wavelength tail between 315 and $340 \mathrm{~nm}$, which appears to be larger in the case of 4-5Pm-SBF than in the case of 4-Ph-SBF. This tail may be due to a more limited $\pi$-conjugation between the pyrimidine or the phenyl ring and the fluorene when substituted at the $\mathrm{C} 4$ position. It could also reflect a minor proportion of conformers of the molecules with a more planar structure, allowing a certain degree of $\pi$ conjugation between the pyrimidine or phenyl rings and the fluorene moiety. As these bands at low energy seem to be more intense for pyrimidine-based dyes than for phenyl-based dyes, one may conclude that more efficient $\pi$-conjugation seems to occur between fluorene and pyrimidine units. 
From the onset absorption wavelength, optical energy gap $\left(\Delta \mathrm{E}^{\mathrm{opt}}\right)$ varying from $3.66 \mathrm{eV}$ for 2-5Pm-SBF to $3.82 \mathrm{eV}$ for 4-Ph-SBF were determined (see table 1) with a variation following the same trend as that obtained from electrochemical measurement and theoretical calculations.

The experimental UV-vis spectra of the four dyes have been compared with predicted electronic absorption spectrum from TD-DFT calculations (see figures in SI) and compared to that of its constituting building block SBF. From those calculations one may observe that except 4-Ph-SBF, all compounds present an additional absorption band at a lower energy than that the main band observed in SBF (see Figures in SI). This additional band presents an oscillator strength value as high as 0.3552 for 2-Ph-SBF and 0.1677 for 2-5PmSBF, similar to that calculated for the neighbouring band (0.3346 for 2-Ph-SBF and 0.1553 for 2-5Pm-SBF), itself calculated close to the lowest energy band of SBF. This is in accordance with the experimental conclusions from absorption spectroscopy presented above. Looking at the detailed transitions, for 2-PhSBF and 2-5Pm-SBF, the lowest energy absorption band corresponds to an HOMO-LUMO transition involving the 2-substituted-fluorene unit (see figure 3). For 4-5Pm-SBF, the two calculated lowest energy bands present strongly less intense oscillator strength $(0.0198$ and 0.0303 for excited state 1 and 2 respectively) and the more important transitions involved in these two bands correspond to (i) HOMO vs LUMO transition (65\% in excited state 1 ) involving two different molecular fragments of the fluorophore (HOMO possessing a spirobifluorenyl character and LUMO possessing a pyrimidine character) presenting very low orbital overlap and hence a very strong charge transfer character and (ii) HOMO vs LUMO+1 transition (58.7\% in excited excited state 2) involving two fluorenyl units and hence an orbital overlap between them (HOMO possessing a spirobifluorenyl character and LUMO+1 possessing a pyrimidine/fluorenyl character). Finally, calculated UV-spectrum of 4-Ph-SBF is very similar to that calculated for SBF (see SI) and the lowest energy absorption bands with very weak oscillator strength (0.06 and 0.059 for calculated excited states 1 and 2) correspond to the HOMO vs LUMO and HOMO vs LUMO+1 transitions, corresponding mainly to fluorene-fluorene transitions.

Fluorescence spectra of the four dyes (figure 5, right) clearly show drastically different emission spectra depending on the substitution. The first type of emission spectra recorded for the 2-substituted-SBFs presents a well resolved emission spectra with maxima at 338/355 and 335/351 nm for 2-5Pm-SBF and 2Ph-SBF respectively, signing the extension of $\pi$-conjugation compared to SBF $\left(\lambda_{\max }=311 / 323 \mathrm{~nm}\right){ }^{49}$ Structured emission spectrum was also reported for 2,7-di-5Pm-9,9-dihexylfluorene (compound F2 in chart 1) with maxima at 361 and $378 \mathrm{~nm}$ due to an even more important extension of conjugation in the disubstituted-fluorenyl core. ${ }^{30} 4$-substituted SBFs presents structureless and large emission spectra centred at $365 \mathrm{~nm}$ for 4-5Pm-SBF and $358 \mathrm{~nm}$ for 4-Ph-SBF. This surprising loss of resolution was also observed for the rare examples of 4-substituted SBF found in literature, ie 4-diphenylphosphine oxide-SBF ( $\lambda_{\text {max }}: 346$ $\mathrm{nm})^{39}$, 4-dibenzofuran-SBF $\left(\lambda_{\max }: 369 \mathrm{~nm}\right)^{41}$ and 4-dibenzothiophene-SBF $\left(\lambda_{\text {max }}: 355 \mathrm{~nm}\right){ }^{42}$ This feature appears hence to be a unique characteristic of 4-substituted SBF derivatives as 2-substituted SBF analogues (and 9,9'dialkylfluorene as well) always present well resolved emission bands assigned to the double bond character of the $\mathrm{C}-\mathrm{C}$ bond linking the pendant substituent and the fluorene core in the excited state..$^{52-55}$

In addition, there is also an intriguing red shift observed between 4-substituted-SBF and 2-substituted-SBF derivatives (shift of $27 \mathrm{~nm}$ for 5Pm-SBFs and of $23 \mathrm{~nm}$ for Ph-SBFs). It is clear that the position of the substitution ( $C 2$ vs $C 4$ ) is at the origin of this spectacular effect. We could assume that the $C 4$ substitution of phenyl or pyrimidine fragments on the fluorene do not affect dramatically the $\pi$-conjugation in the ground state (absorption spectra are only slightly altered with a low energy tail, as described above), but contribute to a strong planarization in the excited state leading to an impressive Stokes shift. More detailed theoretical and spectroscopic investigations need to be conducted to unravel this critical issue.

The emission quantum yields (Фsol) were determined in cyclohexane by using standard procedures with quinine sulphate as reference. On one hand, phenyl-substituted SBFs appear to be efficiently fluorescent with Фsol of 0.42 and 0.87 and lifetimes of 4.20 ns and 1.56 ns for 4-Ph-SBF and 2-Ph-SBF, respectively. On the other hand, a quenching of fluorescence is observed for pyrimidine-substituted SBFs with Фsol of 0.04 and 0.02 and lifetimes of $0.61 \mathrm{~ns}$ and $0.44 \mathrm{~ns}$ for 4-5Pm-SBF and 2-5Pm-SBF, respectively. It should be 
noted that in other solvents, such as THF, the quantum yields of 4-5Pm-SBF and 2-5Pm-SBF remain very low and the solvent can hence not be responsible of these low values. It must be noted that such a decrease of the fluorescence was not observed for previously reported compounds with pyrimidine units such as TBPSF (Фsol=1 in solution) $)^{35}$ and $\mathbf{F 3}$ ( $\Phi$ sol $=0.85$ in solution) ${ }^{30}$ (see structures in chart 1 ) bearing respectively either a 5 pyrimidine or a 2 pyrimidine unit, both being also substituted with a phenyl ring. The presence of this phenyl ring on the pyrimidine unit appears hence to be very important and we believe that, in our case, the absence of this phenyl ring and hence the presence of the aromatic NCHN fragment in the 5-pyrimidine unit has a strong impact on the deactivation rates of the excited state. Indeed, pyrimidine substituted derivatives 4-5Pm-SBF and 2-5Pm-SBF show a lower radiative rate constant $\mathrm{k}_{\mathrm{r}}$ and a much higher non-radiative rate constant $\mathrm{k}_{\mathrm{nr}}$ compared to phenyl-substituted derivatives 4-Ph-SBF and 2-Ph-SBF, as mentioned in Table 3.

Table 3. Optical properties of the four SBF dyes.

4-5Pm-SBF

4-Ph-SBF

2-5Pm-SBF

2-Ph-SBF

$\lambda$ abs, solution $(\mathrm{nm})$

$\varepsilon\left(10^{4}, \mathrm{~L} \cdot \mathrm{mol}^{-1} \cdot \mathrm{m}^{-2}\right)^{\mathrm{a}}$

$\lambda$ abs, thin-film (nm) ${ }^{b}$

$\lambda$ em, solution $(\mathrm{nm})^{\text {a }}$

$\lambda$ em, thin-film $(\mathrm{nm})^{\mathrm{b}}$

$$
\text { Фsol }{ }^{\mathrm{a}, \mathrm{c}}
$$

$\tau(n s)^{a}$

$\mathrm{k}_{\mathrm{r}}\left(\mathrm{s}^{-1}\right)^{\mathrm{a}}$

$\mathrm{k}_{\mathrm{nr}}\left(\mathrm{s}^{-1}\right)^{\mathrm{a}}$
297 (0.5), 308

(0.6), 318 (sh)

298, 311

365

372

0.04

0.61

$6.6 \times 10^{7}$

$1.6 \times 10^{9}$
297 (0.7), 308 (1.4), 318 (sh)

298, 311

358

363

0.42

4.20

$1.0 \times 10^{8}$

$1.4 \times 10^{8}$
(2.5), 308 (2.5),

$320(1.8)$

$301,312,326$

338,355

355, 366

0.02

0.44

$4.6 \times 10^{7}$

$2.2 \times 10^{9}$
297 (2.4), 308 (2.2),

319 (1.6)

$301,312,329$

335,351

343,359

0.87

1.56

$5.6 \times 10^{8}$

$8.3 \times 10^{7}$

a. in cyclohexane, b. Spin-coated thin film from a solution in THF, [solution] = $10 \mathrm{mg} / \mathrm{mL}$ ), c. Quantum yields in solution (Фsol) were calculated relative to quinine sulfate (Фsol $=0.546$ in $\mathrm{H}_{2} \mathrm{SO}_{4} 1 \mathrm{~N}$ )

From a careful inspection of the dependence of the absorption behaviour of the four dyes on solvent polarity, we note that the absorption maximum is almost insensitive to the dielectric constant of the environment (see Figures in SI). This indicates that the electronic and structural characteristics of the ground and Franck Condon excited states do not differ much with a change in solvent polarity. ${ }^{56}$

While phenyl-substituted SBFs showed minor differences of the PL spectra in various solvents (Figure 6, top), distinct fluorescence solvatochromism was observed in pyrimidine-substituted SBF when the solvent polarity increases from cyclohexane to ethanol (Figure 6, bottom). Indeed, both dyes are highly sensitive to the solvent polarity with fluorescence maxima ranging from 366 and $338 \mathrm{~nm}$ in cyclohexane to 390 and 375 $\mathrm{nm}$ in ethanol for 4-5Pm-SBF and 2-5Pm-SBF respectively. This dependence of the emission wavelength on the solvent polarity is indicative of dipole-dipole interactions between Pm-substituted SBFs and polar solvent molecules and hence of a photoinduced intramolecular charge transfer between the donor (fluorene) and the acceptor part (pyrimidine) of the dye. ${ }^{57}$ 

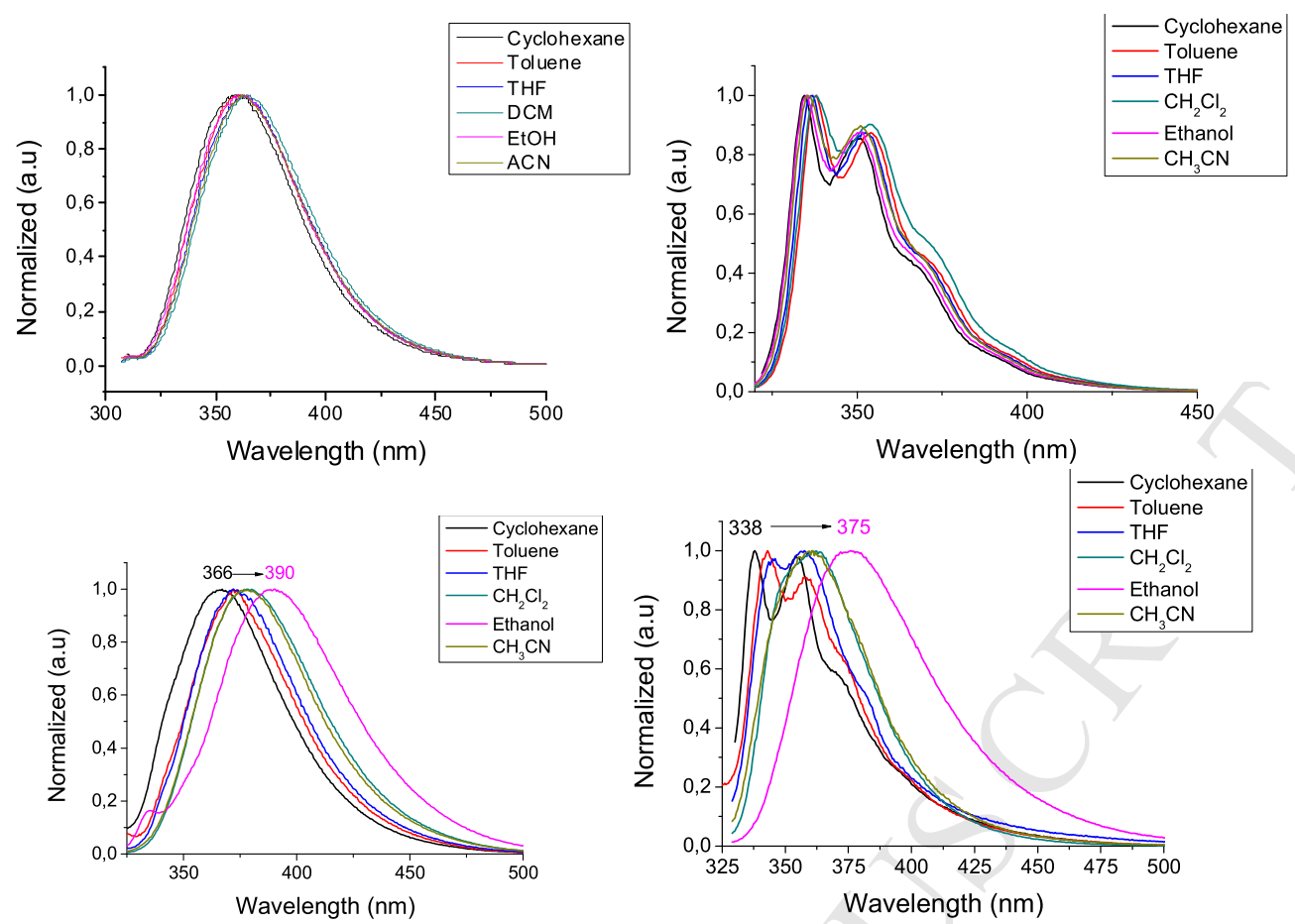

Figure 6. Normalized PL spectra of solutions of 4-Ph-SBF (top left) and 2-Ph-SBF (top right) and of 4-5Pm-SBF (bottom left) and 2-5Pm-SBF (bottom right) in cyclohexane, toluene, THF, $\mathrm{CH}_{2} \mathrm{Cl}_{2}$, ethanol and $\mathrm{CH}_{3} \mathrm{CN}$

The solid state absorption spectra of all dyes (figure 7, left) appear very similar to those in solution (figure 5 left) with only a small red shift of less than $8 \mathrm{~nm}$ detected and a slight increase of the lowest energy band intensity (compared to the band at $310 \mathrm{~nm}$ ) for the 2-substituted-SBFs. Such similarity between absorption spectra in solution and in solid state clearly signs that there are minimal intermolecular interactions in the ground state in thin films.
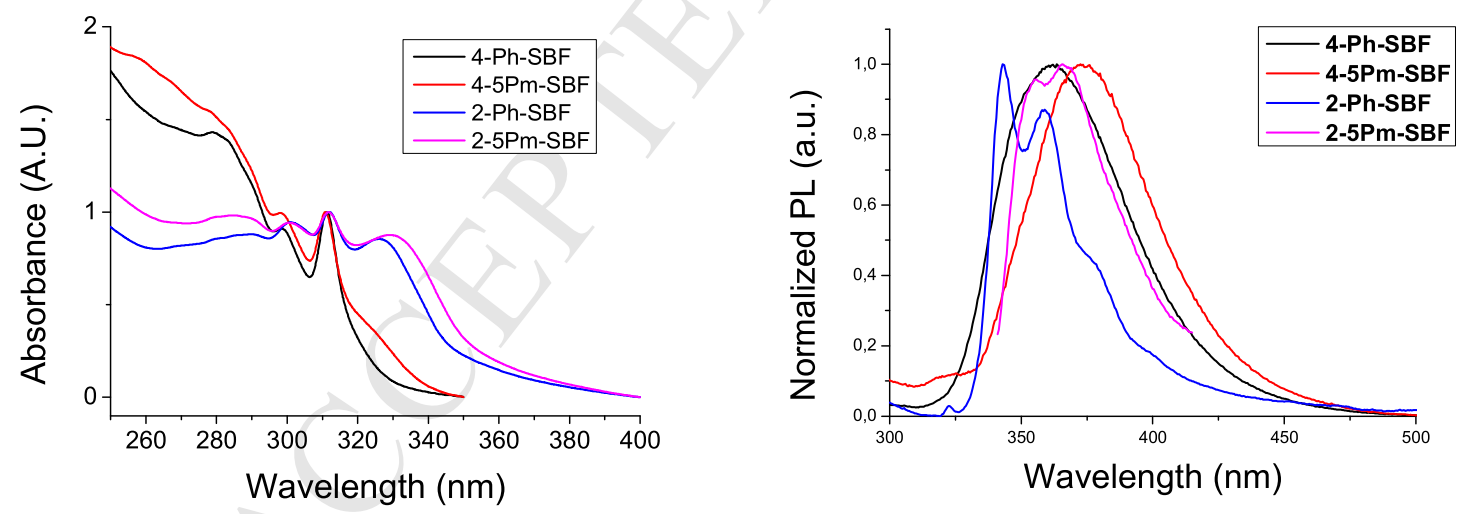

Figure 7. Absorption (left) and Emission (right) spectra of the four dyes recorded in solid state (spin-coated thin film from a solution in THF, [solution] $=10 \mathrm{mg} / \mathrm{mL}$ ).

Regarding the solid-state fluorescent properties (figure 7, right), except for 2-5Pm-SBF, they are almost identical to those recorded in solution (figure 5, right) with only a small red shift ranging from $3 \mathrm{~nm}$ for 4Ph-SBF to $8 \mathrm{~nm}$ for 4-5Pm-SBF and 2-Ph-SBF. Solid-state fluorescent spectrum of 2-5Pm-SBF (figure 7, right, pink line) nevertheless appears poorly resolved with two maxima recorded at 355/366 nm, red shifted by $17 / 11 \mathrm{~nm}$ compared to that in solution. Finally, to examine the suitability of the four dyes as host materials for phosphorescent green and/or blue dopant, the phosphorescence of the molecules was recorded at $77 \mathrm{~K}$ in a methylcyclohexane/2-methylpentane mixture (1:1), Figure 8. From those spectra, $E_{T}$ values of the molecules were calculated from the lowest phosphorescent peak of $2.75 \mathrm{eV}$ for 4-5Pm-SBF and $2.56 \mathrm{eV}$ for 
2-Ph-SBF. Compared to the $\mathrm{E}_{\mathrm{T}}$ value of 4-Ph-SBF $(2.77 \mathrm{eV})$ and of SBF $(2.87 \mathrm{eV})$ reported by our group recently, ${ }^{44}$ we note that the $E_{\mathrm{T}}$ level of 4-5-Pm-SBF is sufficiently high for its use as host material for both green and blue phosphorescent dyes. The $\mathrm{E}_{\mathrm{T}}$ of 2-Ph-SBF $(2.56 \mathrm{eV})$ and that of 2-5-Pm-SBF $(2.58 \mathrm{eV})$ is lower than that of the blue dopant Flrpic $\left(\mathrm{E}_{\mathrm{T}}: 2.62 \mathrm{eV}^{58}\right)$ and these molecules may be used as host material for green dopant Irppy ${ }_{3}\left(E_{T}: 2.42 \mathrm{eV}^{59}\right)$.
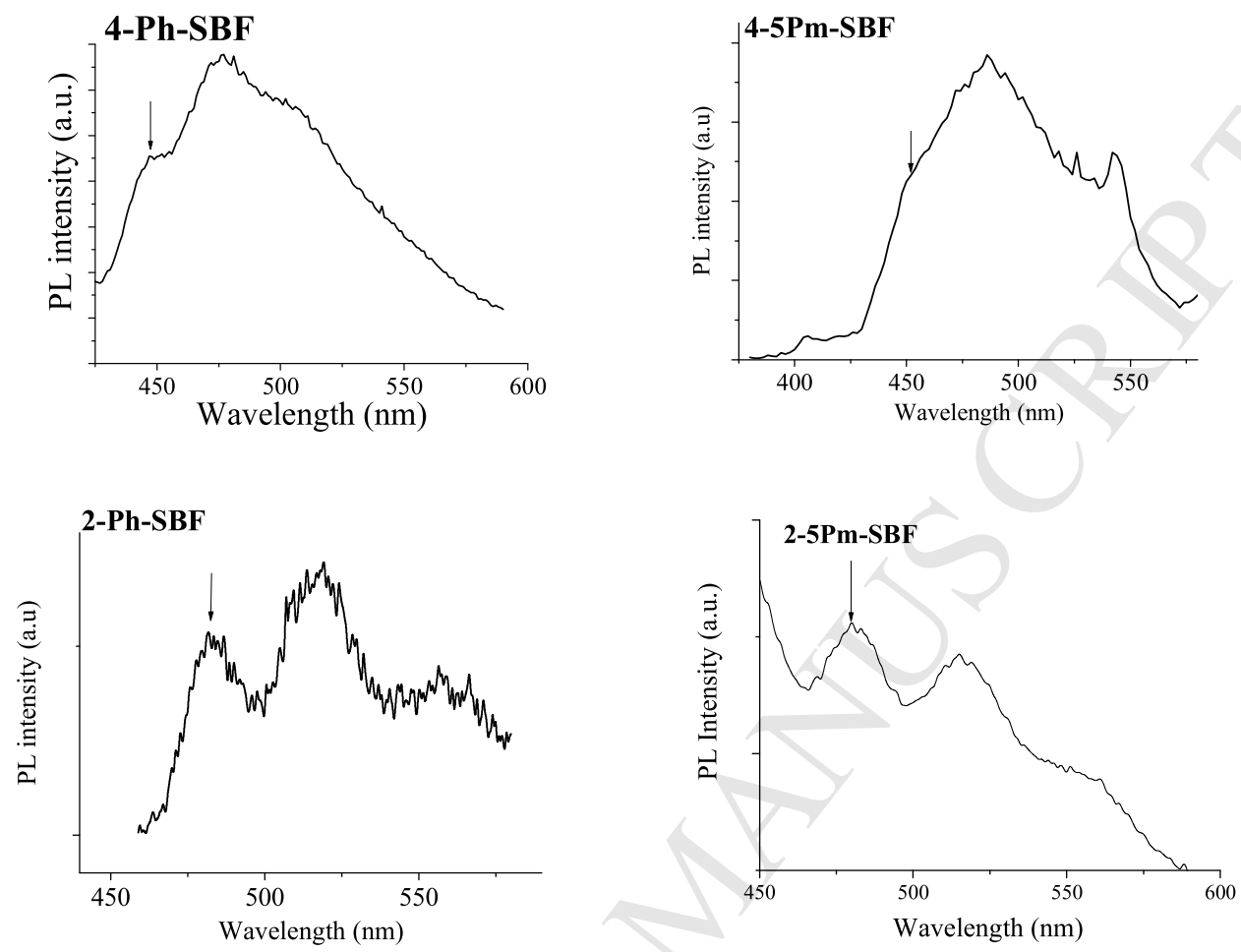

Figure 8. Emission spectra at $77 \mathrm{~K}$ in a methylcyclohexane/2-methylpentane mixture (1:1) of 4-Ph-SBF $\left(\lambda_{\text {exc }}=300 \mathrm{~nm}, 4\right.$ $5 \operatorname{Pm}-\mathrm{SBF}\left(\lambda_{\mathrm{exc}}=300 \mathrm{~nm}\right)$ and 2-Ph-SBF $\left(\lambda_{\text {exc }}=250 \mathrm{~nm}\right)$ and 2-5PmSBF $\left(\lambda_{\text {exc }}=250 \mathrm{~nm}\right)$. The determination of the Et value has been done at from the lowest phosphorescent peak (black arrow)

In conclusion of the above presented photophysical and physico-chemical analysis, the position (C2 vs C4) and the nature of the substituent (phenyl vs pyrimidine) on the SBF core leads to drastic alterations of the resulting properties. Substitution at the $\mathrm{C} 2$ leads to an increase of the conjugation length and therefore to a decrease of the singlet and triplet state energy level, while the substitution at the C4 only has a weak influence on these two key parameters, keeping them almost identical to those of their constituting building block SBF. This has been assigned to $\pi$-conjugation breaking induced by the large torsion angle made by the substituents in C4. This chemical design allows hence obtaining organic semiconductors based on a C4-substituted SBF with high singlet and triplet state energy level with excellent thermal/morphological properties. On the other hand, the substitution by the pyrimidine group leads to a decrease of the LUMO level due to the pyrimidine electron affinity, which should lead in principle to a decrease of the threshold voltage of the resulting devices. Thus, the four dyes possess the prerequisites for their uses as host in PhOLEDs that is, a high $\mathrm{T}_{\mathrm{g}}$ and $\mathrm{Td}$, HOMO/LUMO levels adapted for hole and electron injection/transport in the devices and $\mathrm{E}_{\mathrm{T}}$ higher that of the green phosphorescent emitter $\operatorname{Ir}(\mathrm{ppy})_{3}(2.42$ $\left.\mathrm{eV}^{59}\right)$ and in the case of 4-Ph-SBF and 4-5Pm-SBF for the blue phosphorescent emitter FIrpic $\left(2.62 \mathrm{eV}^{58}\right)$. 


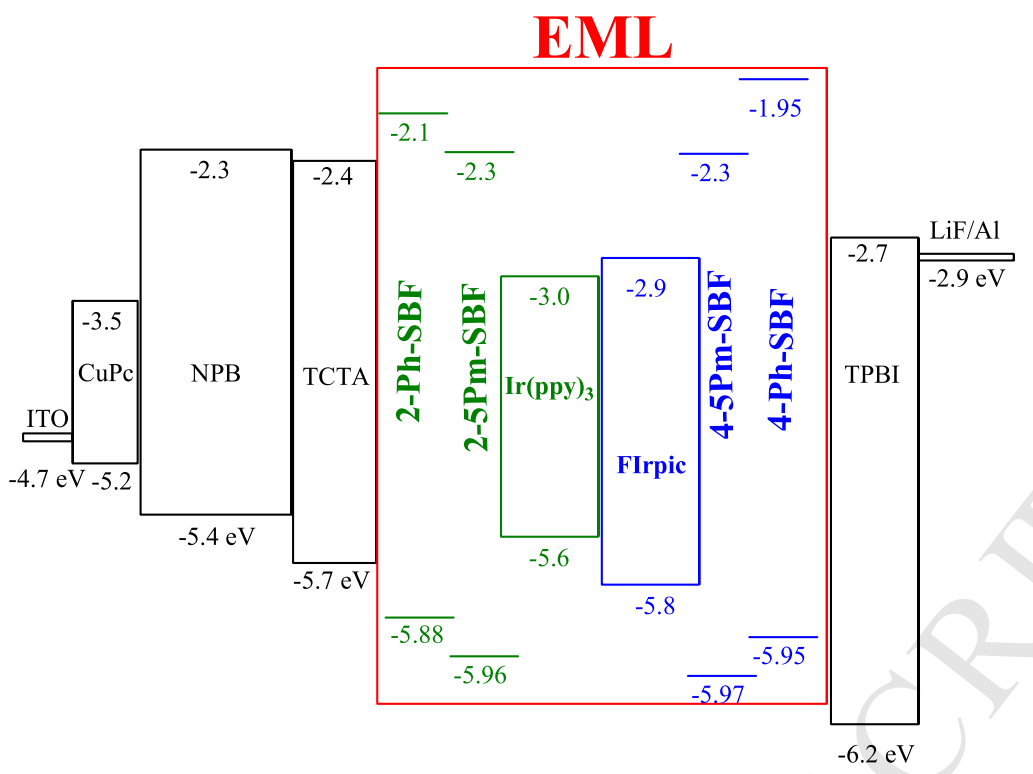

Scheme 2. Energy level diagram of the devices.

In order to explore the potential of the present semi-conductors as host for triplet emitters, green $\left(\operatorname{Ir}(\mathrm{ppy})_{3}\right)$ and blue (Flrpic) PhOLEDs were fabricated. The device configuration was ITO/CuPc(10 nm)/NPB (40 $\mathrm{nm}) /$ TCTA $(10 \mathrm{~nm}) /$ EML:dopant $(20 \mathrm{~nm}) /$ TPBi $(40 \mathrm{~nm}) / \mathrm{LiF}(1.2 \mathrm{~nm}) / \mathrm{Al}(100 \mathrm{~nm})$. ITO is used as the anode, CuPc (copper phtalocyanine) is the hole injecting layer, NPB (N, $\mathrm{N}^{\prime}$-di(1-naphtyl)-N,N'-diphenyl-[1,1'-biphenyl]-4,4'-diamine) is the hole-transporting layer, TCTA $\left(4,4^{\prime}, 4^{\prime \prime}\right.$-Tris(carbazol-9-yl)-triphenylamine) is the electron/exciton blocking layer, TPBI (1,3,5-Tris(1-phenyl-1H-benzimidazol-2-yl)benzene) is both the electron transporting layer and the hole blocking layer and a thin film of lithium fluoride covered with aluminum is the cathode. $\operatorname{Ir}(\mathrm{PPy})_{3}$ and FIrpic are used as dopant for green and blue OLEDs respectively. The relative energy levels of the successive layers of the devices are reported in scheme 2. Table 4 gathers selected data obtained from the average of two experiments.

Due to their $E_{T}$ values higher than that of $\operatorname{Ir}(p p y)_{3}$, the four substituted-SBFs were used as host for $\operatorname{Ir}(\mathrm{ppy})_{3}$ green dopant. Performance of the best green PhOLEDs is presented in figure 9 (left) and average parameters are gathered in table 4. The best green PhOLED performance was obtained with 2-5Pm-SBF and 4-5Pm-SBF host materials doped with $10 \% \operatorname{Ir}(\mathrm{ppy})_{3}$. As shown in figure 9 (left), maximum current and power efficiencies of $58 \mathrm{~cd} / \mathrm{A}$ and $35 \mathrm{~lm} / \mathrm{W}$ are obtained respectively for the pyrimidine substituted SBF. Maximum luminance as high as $30000 \mathrm{~cd} / \mathrm{m}^{2}$ is reached for these devices as shown in table 4. Phenyl substituted dyes, 4-Ph-SBF and 2-Ph-SBF presents lower performance with EQE of $10.4 \%$ and $11.3 \%$, highlighting the great interest of the incorporation of the pyrimidine unit in SBF scaffold. The threshold voltage for all devices appears to be low and as low as $2.5 \mathrm{eV}$ for 2-5Pm-SBF.

The EL spectra of the four devices based on the different host materials are identical, exclusively showing the emission of the green dopant at 516/540 nm (figure 9 right) close to the PL emission of pure $\operatorname{Ir}(\mathrm{ppy})_{3}$ film $(509 / 540 \mathrm{~nm})^{57}$ with no parasite emission in the range of the undoped device. This result demonstrates an efficient energy transfer from the four SBF-derivatives to $\operatorname{Ir}(\mathrm{ppy})_{3}$, due to their high triplet energy levels.

The device performance obtained with small pure hydrocarbon host molecules 4-Ph-SBF and 2-Ph-SBF are comparable to those obtained with more complicated pure-hydrocarbon-based host materials recently reported, ${ }^{38,37,58}$ Performances obtained with pyrimidine-substituted SBF are even more interesting with lowest turn-on voltages and highest EQE (close to 14\%) and clearly demonstrate the interest of the pyrimidine substitution in notably favouring the injection of electron. 
Table 4. Selected EL data of green and bue devices (average values calculated from two experiments).

\begin{tabular}{|c|c|c|c|c|c|c|}
\hline & & \multicolumn{3}{|c|}{ at $\mathrm{J}=10 \mathrm{~mA} / \mathrm{cm}^{2}$} & \\
\hline $\begin{array}{c}\text { Host } \\
\text { /Guest (\%) }\end{array}$ & $V_{\text {on }}(V)$ & EQE (\%) & $\begin{array}{l}\text { Current } \\
\text { efficiency } \\
\left(c d . A^{-1}\right) \\
\end{array}$ & $\begin{array}{l}\text { Power } \\
\text { efficiency } \\
(\mathrm{Im} / \mathrm{W})\end{array}$ & $\begin{array}{l}\mathrm{L}^{\max }\left(\mathrm{cd} \cdot \mathrm{m}^{-2}\right) \text { at } \\
\text { current density } \\
\quad\left(\mathrm{mA} \cdot \mathrm{cm}^{-2}\right)\end{array}$ & $\begin{array}{l}\text { CIE }(x ; y) \text { at } \\
10 \mathrm{~mA} \cdot \mathrm{cm}^{-2}\end{array}$ \\
\hline \multicolumn{7}{|c|}{ Green Phosphorescent OLEDs } \\
\hline $\begin{array}{c}\text { 2-Ph-SBF } \\
/ \operatorname{Ir}(\mathrm{ppy})_{3}(10)\end{array}$ & 2.6 & 11.3 & 42.7 & 17.8 & $27990(210)$ & $0.33 ; 0.62$ \\
\hline $\begin{array}{l}\text { 2-5Pm-SBF } \\
/ \operatorname{Ir}(\mathrm{ppy})_{3}(9)\end{array}$ & 2.5 & 13.3 & 49.2 & 21.5 & $30000(160)$ & $0.33 ; 0.61$ \\
\hline $\begin{array}{c}\text { 4-Ph-SBF } \\
/ \operatorname{lr}(\text { ppy })_{3}(10)\end{array}$ & 3.5 & 10.4 & 40.3 & 16.7 & $25700(230)$ & $0.32 ; 0.62$ \\
\hline $\begin{array}{l}\text { 4-5Pm-SBF } \\
/ \operatorname{Ir}(\mathrm{ppy})_{3}(10)\end{array}$ & 3.3 & 13.7 & 49.9 & 17.6 & $28000(150)$ & $0.34 ; 0.61$ \\
\hline \multicolumn{7}{|c|}{ Blue Phosphorescent OLEDs } \\
\hline $\begin{array}{l}\text { 4-Ph-SBF } \\
\text { /FIrPic (19) }\end{array}$ & 4.0 & 5.7 & 16.2 & 6.0 & $3800(70)$ & $0.20 ; 0.44$ \\
\hline $\begin{array}{l}\text { 4-5Pm-SBF } \\
\text { /FIrPic (19) }\end{array}$ & 3.3 & 4.8 & 14.1 & 5.5 & $2030(50)$ & $0.20 ; 0.45$ \\
\hline
\end{tabular}
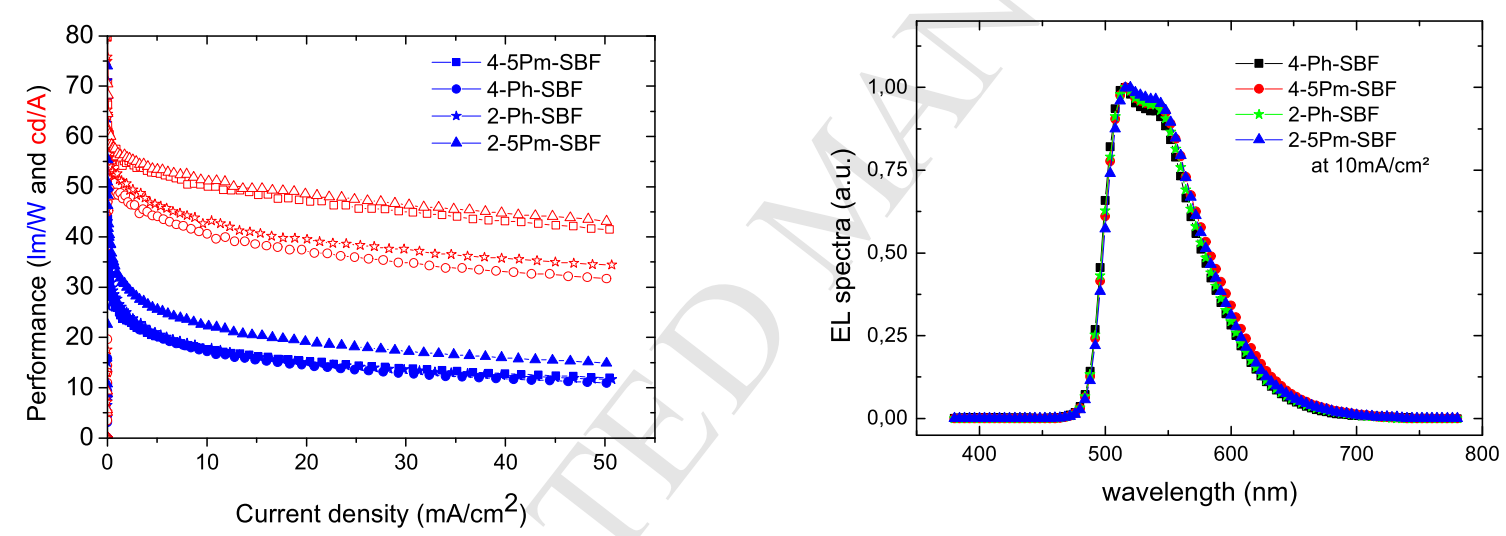

Figure 9. Current (empty symbol) and power efficiencies (filled symbol) versus current density of the green devices using 4-Ph-SBF, 4-5Pm-SBF, 2-Ph-SBF and 2-5Pm-SBF doped with $\operatorname{Ir}(\mathrm{ppy})_{3}$ (10\% in mass) as emitting layer (left). Corresponding EL spectra recorded at $10 \mathrm{~mA} / \mathrm{cm}^{2}$ (right).

Due to their high $E_{T}$ values (2.77 eV for 4-Ph-SBF and $2.75 \mathrm{eV}$ for 4-5Pm-SBF), higher than that of FIrpic ( $E_{T}$ : $2.62 \mathrm{eV})$, the two 4-substituted-SBFs were used as host for this blue dopant. Characteristics of the two blue devices are presented in figure 10 . The best performance is obtained with 4-Ph-SBF with an EQE of $5.7 \%$, a LE of $16.2 \mathrm{~cd} / \mathrm{A}$ and a threshold voltage of $4 \mathrm{~V}$ while blue PhOLEDs with 4-5Pm-SBF as host reach an EQE of $4.8 \%$, a LE of $14.1 \mathrm{~cd} / \mathrm{A}$ and a threshold voltage of $3.3 \mathrm{~V}$ reported at a current density value of $10 \mathrm{~mA} / \mathrm{cm}^{2}$ (Figure 10 left and Table 4). The threshold voltage of 4-5Pm-SBF is hence decreased by ca $0.7 \mathrm{~V}$ compared to that of 4-Ph-SBF due to the incorporation of the pyrimidinium group in the former (which leads to a decrease of the LUMO level and hence an easier injection of the electron in the device). This highlights the efficiency of the chemical design investigated in this work. Both devices, reach brightness of $3800 / 2030$ $\mathrm{cd} / \mathrm{m}^{2}$ for 4-Ph-SBF / 4-5Pm-SBF based devices respectively.

EL spectra of the devices (Figure 10 right) point a main emission of the blue dopant with maxima at 473 and $500 \mathrm{~nm}$ close to the PL emission of pure FIrpic film $(475 / 500 \mathrm{~nm})^{59}$ but also, in the case of 4-PhSBF of an additional tiny emission in the range of the undoped device $(360 / 440 \mathrm{~nm})$. This emission may be due to a small amount of recombination in the other organic layers and especially in TCTA. CIE coordinates of 4-PhSBF-based device $(0.20 ; 0.44)$ and of 4-5Pm-SBF-based device $(0.20 ; 0.45)$ appear nevertheless almost identical as shown in Table 4. 

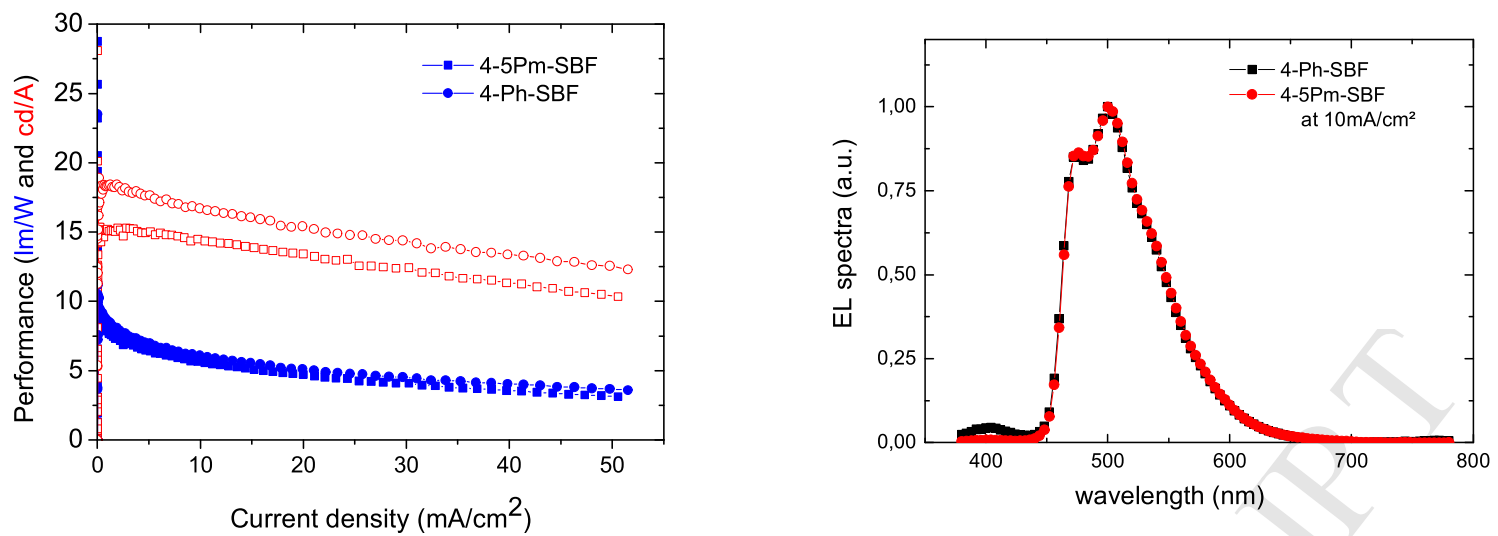

Figure 10. Current (empty symbol) and power efficiencies (filled symbol) versus current density of the blue devices using 4-Ph-SBF and 4-5Pm-SBF doped with FIrPic (19\% in mass) as emitting layer (left). Corresponding EL spectra recorded at a current density of $10 \mathrm{~mA} / \mathrm{cm}^{2}$ (right).

\section{Conclusion}

In summary, four substituted SBF dyes have been synthesized and their thermal, electrochemical and photophysical properties have been scrutinized and compared to the properties of their constituting SBF unit. From these studies it has been demonstrated that, compare to SBF, the substitution by a phenyl unit at the C4 position of SBF leads to weaker modification of the HOMO and LUMO levels compared to the phenyl substitution at the $\mathrm{C} 2$ position, which leads to a conjugation extension and hence a decrease of the HOMO-LUMO gap. On the other hand, the substitution by the electro-deficient pyrimidine unit compared to the substitution by the phenyl unit leads to a significant lowering of the LUMO level. Overall, the combination of the two effects (lowering of the HOMO through the extension of conjugation, lowering of the LUMO through pyrimidine electro deficient effect) in 2-5Pm-SBF leads to the highest modification of the optical energy gap (from $4.05 \mathrm{eV}$ in SBF to $3.66 \mathrm{eV}$ in 2-5Pm-SBF). Thus, the optical energy gap of the four compounds is finely tuned from $4 \mathrm{eV}$ for $4-\mathrm{Ph}-\mathrm{SBF}$ to $3.66 \mathrm{eV}$ for 2-5Pm-SBF. In addition, the substitution in $\mathrm{C} 2$ or in $\mathrm{C} 4$ has an impressive influence on the $E_{T}$. Indeed, the C2-substituted dyes have $E_{T}$ values at ca $2.42 \mathrm{eV}$, whereas the $\mathrm{C} 4$ substituted dyes have an $\mathrm{E}_{\mathrm{T}}$ as high as $2.7 \mathrm{eV}$ due to the $\pi$-conjugation disruption. This structure properties relationship study clearly highlights how a different substitution may lead to very different properties keeping others intact. As all compounds possess a triplet energy level higher than $2.42 \mathrm{eV}$, they have been used as host for green dopant in PhOLEDs. Remarkable performance has been obtained with 2-5Pm-SBF as host (CE > $58 \mathrm{~cd} / \mathrm{A}, \mathrm{PE}>35 \mathrm{Im} / \mathrm{W}$, EQE $>14 \%$ and threshold voltage of $2.5 \mathrm{~V}$ ). Furthermore, the two 4-substituted SBF with triplet energy levels as high as $2.8 \mathrm{eV}$ have also been successfully used as host materials for blue PhOLEDs with high performance. The effect of the pyrimidine substituent leads to a lowering of the threshold working voltage of the device from $4 \mathrm{~V}$ for 4-Ph-SBF based blue device to $3.3 \mathrm{~V}$ for 4-5Pm-SBF based blue device.

\section{Acknowledgements}

S.T. and G. S. thank ANR (HOME-OLED Project $n^{\circ}$ ANR-11-BS07-020-01) for a studentship. C. D thanks ANR (HOME-OLED Project $n^{\circ}$ ANR-11-BS07-020-01) for a financial support as postdoctoral position. We wish to thank the C.R.M.P.O (Centre Régional de Mesures Physiques de l'Ouest, Rennes) for high resolution mass measurements, Service de Microanalyse-CNRS (Gif sur Yvette) for CHN analyses, CINES (Montpellier) for computing time, the CDIFX (Rennes) for X-Ray data collection, the "Institut des Sciences Analytiques" (UMR CNRS 5280, Villeurbanne) for TGA. Arnaud Brosseau (Cachan) is thanked for his precious assistance in photophysical measurements. Dr Franck Camerel (Rennes) is warmly acknowledged for his help and advice 
in the understanding of thermal properties. Prof. Abdou Boucekkine is also warmly thanked for his help in DFT and TD-DFT calculations.

\section{Experimental Section}

\section{Synthesis:}

All manipulations of oxygen- and moisture-sensitive materials were conducted with a standard Schlenk technique. Commercially available reagents and solvents were used without further purification other than those detailed below. THF was distilled from sodium/benzophenone prior to use. Light petroleum refers to the fraction with $b p 40-60^{\circ} \mathrm{C}$. $2.5 \mathrm{M}$ solutions of $\mathrm{n}-\mathrm{BuLi}$ in hexanes or THF were purchased from Sigma Aldrich. 2,2'-dibromobiphenyl was purchased from Fluorochem. Reactions were stirred magnetically, unless otherwise indicated. Analytical thin layer chromatography was carried out using aluminum backed plates coated with Merck Kieselgel 60 GF254 and visualized under UV light (at 254 and $360 \mathrm{~nm}$ ). Chromatography was carried out using Teledyne Isco CombiFlash ${ }^{\circledR}$ Rf 400 (UV detection 200-360nm), over standard silica cartridges (Redisep ${ }^{\circledR}$ Isco, GraceResolv ${ }^{\mathrm{TM}}$ Grace or Puriflash ${ }^{\circledR}$ columns Interchim). ${ }^{1} \mathrm{H}$ and ${ }^{13} \mathrm{C}$ NMR spectra were recorded using Bruker $300 \mathrm{MHz}$ instruments $\left({ }^{1} \mathrm{H}\right.$ frequency, corresponding ${ }^{13} \mathrm{C}$ frequency: $75 \mathrm{MHz}$ ); chemical shifts were recorded in ppm and $\mathrm{J}$ values in $\mathrm{Hz}$. In the ${ }^{13} \mathrm{C}$ NMR spectra, signals corresponding to $\mathrm{C}, \mathrm{CH}, \mathrm{CH}_{2}$ or Me groups, assigned from DEPT, are noted. The residual signals for the NMR solvents are: $\mathrm{CDCl}_{3} ; 7.26 \mathrm{ppm}$ for the proton and $77.00 \mathrm{ppm}$ for the carbon, $\mathrm{CD}_{2} \mathrm{Cl}_{2} ; 5.32 \mathrm{ppm}$ for the proton and $53.80 \mathrm{ppm}$ for the carbon. The following abbreviations have been used for the NMR assignment: $s$ for singlet, $d$ for doublet, $t$ for triplet and $m$ for multiplet. High resolution mass spectra were recorded at the Centre Régional de Mesures Physiques de l'Ouest (Rennes) on (i) Bruker MicrO-Tof-Q II (Source: Atmospheric Pressure Chemical Ionization (APCI - direct introduction) (ASAPAtmospheric Solids Analysis Probe) at a temperature of $30^{\circ} \mathrm{C}$ - positive mode) or on (ii) Waters Q-Tof II. The synthesis of 4-bromo-9,9'-spirobi[fluorene] (1) and of 4-Ph-SBF have been previously described ${ }^{44}$

2-bromo-9,9'-spirobi[fluorene] (2) ${ }^{63}$ 2-bromo-1,1'-biphenyl (2.16 g, $\left.9.27 \mathrm{mmol}, 1.15 \mathrm{eq}\right)$ was dissolved in dry THF $(40 \mathrm{~mL})$ under argon atmosphere, cooled at $-78^{\circ} \mathrm{C}$, and stirred during 10 minutes at this temperature. A $2.5 \mathrm{M} \mathrm{n}$-BuLi solution in THF $(4.31 \mathrm{~mL}, 10.78 \mathrm{mmol}, 1.34 \mathrm{eq})$ was then slowly injected via a seringue, at $-78^{\circ} \mathrm{C}$. The resulting yellow mixture was stirred at the same temperature for $30 \mathrm{~min}$. 2-bromo$9 \mathrm{H}$-fluoren-9-one $(2.08 \mathrm{~g}, 8.03 \mathrm{mmol})$ in dry THF $(35 \mathrm{~mL})$ was then added dropwise, and the mixture was stirred for another $30 \mathrm{~min}$ at $-78^{\circ} \mathrm{C}$, and allows warming up to room temperature gradually and stirred overnight. Saturated brine solution $(10 \mathrm{~mL})$ was added, and the mixture was extracted twice with ethyl acetate $(2 \times 30 \mathrm{~mL})$. The combined organic extracts were dried over anhydrous magnesium sulfate, filtered, and concentrated under reduced pressure. Without other purification, the crude was dissolved into a mixture of acetic acid/hydrochloric acid $(50 \mathrm{~mL} / 5 \mathrm{~mL})$ and warmed at $70^{\circ} \mathrm{C}$ during $2 \mathrm{~h}$ under stirring. Then, the mixture was poured into water/ice $(200 \mathrm{~mL})$, and the solution was neutralized with solid sodium hydroxide until $\mathrm{pH} 7$. Then the organic layer was extracted three times with dichloromethane $(3 \times 50 \mathrm{~mL})$. The combined organic extracts were dried over magnesium sulfate, filtered, and concentrated under reduced pressure. The residue was purified by flash chromatography on silica gel (light petroleum/dichloromethane $95 / 5)$ to afford a colorless solid $(2.14 \mathrm{~g})$. [column conditions: Silica cartridge $40 \mathrm{~g}$ (Serlabo); solid deposit on Celite ${ }^{\circledR}$; $\lambda_{\text {detection }}$ ( $254 \mathrm{~nm}, 280 \mathrm{~nm}$ ); light petroleum/dichloromethane $(95 / 5)$ at $25 \mathrm{~mL} / \mathrm{min}$; collected fraction: $18-42 \mathrm{~min}$ ]. Yield: $67 \% \mathrm{mp}: 168-170^{\circ} \mathrm{C}$ (lit. $160{ }^{\circ} \mathrm{C}$ ) $;^{64}{ }^{1} \mathrm{H} \mathrm{NMR}(300 \mathrm{MHz}$, $\left.\mathrm{CD}_{2} \mathrm{Cl}_{2}\right): \delta 7.89(\mathrm{~m}, 3 \mathrm{H}, \mathrm{ArH}), 7.76(\mathrm{~d}, \mathrm{~J}=8.1 \mathrm{~Hz}, 1 \mathrm{H}, \mathrm{ArH}), 7.52(\mathrm{dd}, \mathrm{J}=8.1,1.8 \mathrm{~Hz} ; 1 \mathrm{H}, \operatorname{ArH}), 7.42(\mathrm{~m}, 3 \mathrm{H}$, $\mathrm{ArH}), 7.15(\mathrm{~m}, 3 \mathrm{H}, \mathrm{ArH}), 6.87(\mathrm{~m}, 1 \mathrm{H}, \mathrm{ArH}), 6.71(\mathrm{~m}, 3 \mathrm{H}, \mathrm{ArH}) ;{ }^{13} \mathrm{C} \mathrm{NMR}\left(75 \mathrm{MHz}, \mathrm{CD}_{2} \mathrm{Cl}_{2}\right): \delta 151.5(\mathrm{C}), 149.1$ (C), $148.5(\mathrm{C}), 142.4(\mathrm{C}), 141.4(\mathrm{C}), 141.3(\mathrm{C}), 131.4(\mathrm{CH}), 128.8(\mathrm{CH}), 128.6(\mathrm{CH}), 128.54(\mathrm{CH}), 128.48(\mathrm{CH})$, 127.6 (CH), $124.37(\mathrm{CH}), 124.35(\mathrm{CH}), 122.1(\mathrm{CH}), 121.8(\mathrm{C}), 120.8$ (2xCH seen from HSQC), 66.4 (Spiro C).

\section{General procedure for Suzuki coupling}

9,9'-spirobi[fluorene] brominated compound, boronic acid compound, $\mathrm{K}_{2} \mathrm{CO}_{3}$ and $\mathrm{Pd}(\mathrm{dppf}) \mathrm{Cl}_{2}{ }^{*}$ were dissolved in dry DMF or xylenes. The mixture was warmed to $150^{\circ} \mathrm{C}$ (DMF) and $135^{\circ} \mathrm{C}$ (xylenes) stirred overnight. After cooling to room temperature, saturated solution of ammonium chloride $(50 \mathrm{~mL})$ was ad-

\footnotetext{
${ }^{*} \mathrm{Pd}(\mathrm{dppf}) \mathrm{Cl}_{2}:$ : [1,1'-Bis(diphenylphosphino)ferrocene]palladium(II) dichloride complex with dichloromethane
} 
ded, and organic layer was extracted three times with dichloromethane $(3 \times 30 \mathrm{~mL})$ and washed with brine $(3 \times 30 \mathrm{~mL})$. The combined organic extracts were dried over magnesium sulfate, filtered, and concentrated under reduced pressure. The residue was purified by flash chromatography on silica gel using Teledyne Isco CombiFlash ${ }^{\circledR}$ Rf 400 . Column conditions can be found in each compounds description below.

5-(9,9'-spirobi[fluoren]-4-yl)pyrimidine (4-5Pm-SBF). 5-(9,9'-spirobi[fluoren]-4-yl)pyrimidine was synthesized according to the general coupling procedure between 4-bromo-9,9'-spirobi[fluorene] $(\mathbf{1})^{44}(0.808 \mathrm{~g}$, $2.045 \mathrm{mmol})$, pyrimidin-5-yl-boronic acid $(0.333 \mathrm{~g}, 2.688 \mathrm{mmol}, 1.31 \mathrm{eq}), \mathrm{K}_{2} \mathrm{CO}_{3}(2.800 \mathrm{~g}, 20.260 \mathrm{mmol}, 9.91$ eq) and $\mathrm{Pd}(\mathrm{dppf}) \mathrm{Cl}_{2}(0.088 \mathrm{~g}, 0.108 \mathrm{mmol}, 0.05 \mathrm{eq})$ in dry DMF $(30 \mathrm{~mL})$. The residue was purified by flash chromatography on silica gel (light petroleum/ethyl acetate $85 / 15)$ to afford a colorless solid $(0.759 \mathrm{mg}$, $1.924 \mathrm{mmol}$ ) [column conditions: Silica cartridge $12 \mathrm{~g}$ (Serlabo); solid deposit on Celite ${ }^{\circledR}$; $\lambda_{\text {detection }}$ : $(254 \mathrm{~nm}$, $280 \mathrm{~nm}$ ); ethyl acetate in ligth petroleum (85/15) at $20 \mathrm{~mL} / \mathrm{min}$; collected fraction: 8-17 min]. Yield: $94 \%$. $\mathrm{mp}: 167^{\circ} \mathrm{C}$; IR $\left(\mathrm{ATR}, \mathrm{cm}^{-1}\right) \mathrm{v}=593,646,723,752,908,1030,1157,12821405,1444,1545,3020,3072 ;{ }^{1} \mathrm{H}$ $\operatorname{NMR}\left(300 \mathrm{Mhz}, \mathrm{CD}_{2} \mathrm{Cl}_{2}\right): \delta 9.36(\mathrm{~s}, 1 \mathrm{H}, \mathrm{ArH}), 9.04(\mathrm{~s}, 2 \mathrm{H}, \mathrm{ArH}), 7.89(\mathrm{~m}, 2 \mathrm{H}, \mathrm{ArH}), 7.41(\mathrm{td}, \mathrm{J}=7.5,1.2 \mathrm{~Hz}, 2 \mathrm{H}$, $\mathrm{ArH}), 7.22-7.01(\mathrm{~m}, 7 \mathrm{H}, \mathrm{ArH}), 6.76(\mathrm{~m}, 3 \mathrm{H}, \mathrm{ArH}), 6.68(\mathrm{~s}, 1 \mathrm{H}, \mathrm{ArH}) ;{ }^{13} \mathrm{C} \mathrm{NMR}\left(75 \mathrm{MHz}, \mathrm{CD}_{2} \mathrm{Cl}_{2}\right): \delta 158.6(\mathrm{CH})$, $157.4(\mathrm{CH}), 150.7$ (C), 149.9 (C), 149.0 (C), 142.5 (C), 141.3 (C), 139.7 (C), 135.1 (C), 130.8 (C), $130.7(\mathrm{CH})$, $128.7(\mathrm{CH}), 128.53(\mathrm{CH}), 128.48(\mathrm{CH}), 128.3(\mathrm{CH}), 128.2(\mathrm{CH}), 124.9(\mathrm{CH}), 124.7(\mathrm{CH}), 124.3(\mathrm{CH}), 123.0(\mathrm{CH})$, 120.8 (CH), 66.24 (Spiro C) ; HRMS calculated for $\mathrm{C}_{29} \mathrm{H}_{19} \mathrm{~N}_{2} 395.1542$, found $395.1542[\mathrm{M}+\mathrm{H}]^{+}$; Elemental analysis calculated for $\mathrm{C}_{29} \mathrm{H}_{18} \mathrm{~N}_{2}: \mathrm{C}, 88.30 \% ; \mathrm{H}, 4.60 \% ; \mathrm{N}, 7.10 \%$. Found: $\mathrm{C}, 87.81 \% ; \mathrm{H}, 4.81 \% ; \mathrm{N}, 6.81 \%$; $\lambda_{\text {abs }}[\mathrm{nm}]\left(\varepsilon\left[10^{4}\right.\right.$. L. $\left.\left.\mathrm{mol}^{-1} . \mathrm{cm}^{-1}\right]\right)=297(0.5), 308(0.6)$.

2-phenyl-9,9'-spirobi[fluorene] (2-Ph-SBF). 2-phenyl-9,9'-spirobi[fluorene] was synthesized according to the general procedure between 2-bromo-9,9'-spirobiffluorene] (2) $(0.751 \mathrm{~g}, 1.901 \mathrm{mmol})$, phenylboronic acid $(0.304 \mathrm{~g}, 2.488 \mathrm{mmol}, 1.31 \mathrm{eq}), \mathrm{K}_{2} \mathrm{CO}_{3}(1.227 \mathrm{~g}, 8.883 \mathrm{mmol}, 4.67 \mathrm{eq})$ and $\mathrm{Pd}(\mathrm{dppf}) \mathrm{Cl}_{2}(0.061 \mathrm{~g}, 0.076$ $\mathrm{mmol}, 0.04 \mathrm{eq})$ in xylenes $(20 \mathrm{~mL}$ ). The residue was purified by flash chromatography on silica gel (light petroleum/dichloromethane 9/1) to afford a colorless solid $(0.581 \mathrm{~g}, 1.482 \mathrm{mmol})$, [column conditions: Silica cartridge $24 \mathrm{~g}$ (Serlabo); solid deposit on Celite ${ }^{\oplus} \lambda_{\text {detection: }}(254 \mathrm{~nm}, 280 \mathrm{~nm})$; dichloromethane in light petroleum (9/1) at $20 \mathrm{~mL} / \mathrm{min}$; collected fraction: 35-45 min]. Yield: $78 \% \cdot \mathrm{mp}: 100-108^{*}$ IR $\left(\right.$ ATR, $\left.\mathrm{cm}^{-1}\right) \mathrm{v}=$ $476,494,617,634,650,692,727,748,829,1020,1155,1280,1444,1597,3014,3059 ;{ }^{1} \mathrm{H}$ NMR (300 MHz, $\left.\mathrm{CD}_{2} \mathrm{Cl}_{2}\right): \delta 7.96(\mathrm{dd}, J=8.0,0.6 \mathrm{~Hz}, 1 \mathrm{H}, \mathrm{ArH}), 7.93-7.88(\mathrm{~m}, 3 \mathrm{H}, \mathrm{ArH}), 7.66(\mathrm{dd}, J=8.0,1.7 \mathrm{~Hz}, 1 \mathrm{H}, \mathrm{ArH}), 7.45$ $-7.36(\mathrm{~m}, 5 \mathrm{H}, \mathrm{ArH}), 7.35-7.20(\mathrm{~m}, 3 \mathrm{H}, \mathrm{ArH}), 7.13(\mathrm{td}, J=7.5,1.1 \mathrm{~Hz}, 3 \mathrm{H}, \mathrm{ArH}), 6.94(\mathrm{dd}, J=1.7,0.6 \mathrm{~Hz}, 1 \mathrm{H}$, ArH), $6.78-6.72(\mathrm{~m}, 2 \mathrm{H}, \mathrm{ArH}), 6.72-6.67(\mathrm{~m}, 1 \mathrm{H}, \mathrm{ArH}) ;{ }^{13} \mathrm{C} \mathrm{NMR}\left(75 \mathrm{MHz}, \mathrm{CD}_{2} \mathrm{Cl}_{2}\right): \delta 150.1(\mathrm{C}), 149.7(\mathrm{C})$, 149.2 (C), 142.4 (C), 142.0 (C), 141.7 (C), 141.4 (C), 141.3 (C), $129.1(\mathrm{CH}), 128.40\left(2 \times \mathrm{CH}^{+}\right), 128.38(\mathrm{CH})$, $128.37(\mathrm{CH}), 127.8(\mathrm{CH}), 127.43(\mathrm{CH}), 127.38(\mathrm{CH}), 124.4(\mathrm{CH}), 124.3(\mathrm{CH}), 123.0(\mathrm{CH}), 121.0(\mathrm{CH}), 120.8$ (CH), $120.7(\mathrm{CH}), 66.6$ (Spiro C); HRMS calculated for $\mathrm{C}_{31} \mathrm{H}_{21} 393.1643$, found $393.1646[\mathrm{M}+\mathrm{H}]^{+}$; Elemental analysis calculated for $\mathrm{C}_{31} \mathrm{H}_{20}$ : C, $94.86 \% ; \mathrm{H}, 5.14 \%$. Found: C, $94.93 \% ; \mathrm{H}, 5.24 \% ; \lambda_{\text {abs }}[\mathrm{nm}]\left(\varepsilon\left[10^{4}\right.\right.$.L.mol ${ }^{-}$ $\left.\left.{ }^{1} . \mathrm{cm}^{-1}\right]\right)=297(2.4), 308(2.2), 319(1.6)$.

5-(9,9'-spirobi[fluoren]-2-yl)pyrimidine (2-5Pm-SBF). 5-(9,9'-spirobi[fluoren]-2-yl)pyrimidine was synthesized according to the general procedure between 2-bromo-9,9'-spirobi[fluorene] (2) (0.749 g, $1.897 \mathrm{mmol})$, pyrimidin-5-yl-boronic acid (0.312 g, $2.519 \mathrm{mmol}, 1.33 \mathrm{eq}), \mathrm{K}_{2} \mathrm{CO}_{3}(1.226 \mathrm{~g}, 8.872 \mathrm{mmol}, 4.68 \mathrm{eq})$ and $\mathrm{Pd}(\mathrm{dppf}) \mathrm{Cl}_{2}(0.059 \mathrm{~g}, 0.073 \mathrm{mmol}, 0.04 \mathrm{eq})$ in dry DMF $(20 \mathrm{~mL})$. The residue was purified by flash chromatography on silica gel (light petroleum/ethyl acetate $8 / 2)$ to afford a colorless solid $(0.5743 \mathrm{~g}, 1.456$ mmol) [column conditions: Silica cartridge $24 \mathrm{~g}$ (Serlabo); solid deposit on Celite ${ }^{\circledR} ; \lambda_{\text {detection }}$ : $(254 \mathrm{~nm}, 280$ $\mathrm{nm})$; ethyl acetate in light petroleum (8/2) at $20 \mathrm{~mL} / \mathrm{min}$; collected fraction: $34-50 \mathrm{~min}$. Yield (77 \%). $\mathrm{mp}$ : 197-198 ${ }^{\circ} \mathrm{C}$; IR (ATR, $\mathrm{cm}^{-1}$ ) $v=491,604,619,636,721,731,750,833,862,1018,1105,1153,1186,1267$, 1400, 1414, 1446, 1554, 3016, 3039, 3053; ${ }^{1} \mathrm{H}$ NMR (300 MHz, $\left.\mathrm{CD}_{2} \mathrm{Cl}_{2}\right): \delta 8.94(\mathrm{~s}, 1 \mathrm{H}, \mathrm{ArH}), 8.67$ (s, 2H, ArH), $7.93(\mathrm{dd}, J=7.9,0.6 \mathrm{~Hz}, 1 \mathrm{H}, \mathrm{ArH}), 7.87-7.83(\mathrm{~m}, 1 \mathrm{H}, \mathrm{ArH}), 7.83-7.79(\mathrm{~m}, 2 \mathrm{H}, \mathrm{ArH}), 7.56$ (dd, $J=7.9,1.7$ $\mathrm{Hz}, 1 \mathrm{H}, \mathrm{ArH}), 7.37-7.26(\mathrm{~m}, 3 \mathrm{H}, \mathrm{ArH}), 7.06(\mathrm{dtd}, J=10.2,7.5,1.1 \mathrm{~Hz}, 3 \mathrm{H}, \mathrm{ArH}), 6.86(\mathrm{dd}, J=1.7,0.6 \mathrm{~Hz}, 1 \mathrm{H}$,

\footnotetext{
${ }^{*}$ This transition appears to be not very clear, occurring on a large range.

${ }^{+}$In the light of the protons assignment of 2-5Pm-SBF, we believe that 2 carbons are present at $128.40 \mathrm{ppm}$.
} 
ArH), $6.68-6.60(\mathrm{~m}, 3 \mathrm{H}, \mathrm{ArH}) ;{ }^{13} \mathrm{C}$ NMR $\left(75 \mathrm{MHz}, \mathrm{CD}_{2} \mathrm{Cl}_{2}\right): \delta 157.8(\mathrm{CH}), 155.2(\mathrm{CH}), 150.7(\mathrm{C}), 149.7(\mathrm{C})$, 148.8 (C), 143.2 (C), 142.4 (C), $141.4(\mathrm{C}), 134.53$ (C), 134.45 (C), $129.0(\mathrm{CH}), 128.6(\mathrm{CH}), 128.5(2 \times \mathrm{CH}$ seen from HSQC), $127.3(\mathrm{CH}), 124.42(\mathrm{CH}), 124.35(\mathrm{CH}), 122.9(\mathrm{CH}), 121.6(\mathrm{CH}), 121.1(\mathrm{CH}), 120.8(\mathrm{CH}), 66.6$ (Spiro C); HRMS calculated for $\mathrm{C}_{29} \mathrm{H}_{19} \mathrm{~N}_{2} 395.1548$, found $395.1548[\mathrm{M}+\mathrm{H}]^{+} ; \lambda_{\text {abs }}[\mathrm{nm}]\left(\varepsilon\left[10^{4} . \mathrm{L} \cdot \mathrm{mol}^{-1} . \mathrm{cm}^{-1}\right]\right)=$ 296 (2.5), 308 (2.5), 320 (1.8).

X-Ray:

Crystal was picked up with a cryoloop and then frozen at $150 \mathrm{~K}$ under a stream of dry $\mathrm{N}_{2}$ on a APEX II Brucker AXS diffractometer for X-ray data collection (Mo K $\alpha$ radiation, $\lambda=0.71073 \AA$ ). 4-Ph-SBF structure was published previously. ${ }^{44}$

2-Ph-SBF $\left.\left(\mathrm{C}_{62} \mathrm{H}_{40}\right)\right) ; M=784.94$. APEXII, Bruker-AXS diffractometer, Mo-K $\alpha$ radiation $(\lambda=0.71073$ $\AA ̊ 丿), T=150(2) \mathrm{K}$; triclinic $P$-1 (I.T.2), $a=10.9027(4), b=13.7902(6), c=15.7771(5) \AA, \alpha=102.1400(10), \beta=$ $97.4710(10), \gamma=111.5900(10)^{\circ}, V=2099.47(14) \AA^{3} . Z=2, d=1.242 \mathrm{~g}^{\circ} \mathrm{cm}^{-3}, \mu=0.07 \mathrm{~mm}^{-1}$. The structure was solved by direct methods using the SIR97 program, ${ }^{65}$ and then refined with full-matrix least-square methods based on $F^{2}$ (SHELXL-97) ${ }^{66}$ with the aid of the WINGX ${ }^{67}$ program. All non-hydrogen atoms were refined with anisotropic atomic displacement parameters. $\mathrm{H}$ atoms were finally included in their calculated positions. A final refinement on $F^{2}$ with 9543 unique intensities and 559 parameters converged at $\omega R\left(F^{2}\right)=$ $0.1128(R(F)=0.0447)$ for 7649 observed reflections with $I>2 \sigma(I)$.

2-5Pm-SBF $\left(\mathrm{C}_{29} \mathrm{H}_{18} \mathrm{~N}_{2}, \mathrm{CH}_{4} \mathrm{O}\right) ; M=426.5$. APEXII, Bruker-AXS diffractometer, Mo-Ka radiation $(\lambda=$ $0.71073 \AA), T=150(2) \mathrm{K}$; orthorhombic $P$ c a b (I.T.\#61), $a=8.4342(3), b=13.6588(5), c=38.5506(13) \AA, V=$ $4441.1(3) \AA^{3} . Z=8, d=1.276 \mathrm{~g} . \mathrm{cm}^{-3}, \mu=0.078 \mathrm{~mm}^{-1}$. The structure was solved by direct methods using the SIR97 program [1], and then refined with full-matrix least-square methods based on $F^{2}$ (SHELXL-97) [2] with the aid of the WINGX [3] program. All non-hydrogen atoms were refined with anisotropic atomic displacement parameters. $\mathrm{H}$ atoms were finally included in their calculated positions. A final refinement on $F^{2}$ with 5055 unique intensities and 300 parameters converged at $\omega R\left(F^{2}\right)=0.1246(R(F)=0.0461)$ for 3820 observed reflections with $I>2 \sigma(I)$. The figures were generated with Mercury software 3.3

\section{Spectroscopic studies:}

Cyclohexane (analytical grade, VWR) was used without further purification. Standard $1 \mathrm{~N}$ solution of sulfuric acid was purcharsed from Alfa Aesar. UV-visible spectra were recorded using an UV-Visible spectrophotometer SHIMADZU UV-1605. The energy gap was calculated from the absorption edge of the UV-vis absorption spectra in solution in cyclohexane, using the formula $\Delta \mathrm{E}^{\mathrm{opt}}(\mathrm{eV})=\mathrm{hc} / \lambda, \lambda$ being the absorption edge (in meter). With $\mathrm{h}=6.6 \times 10^{-34} \mathrm{~J} . \mathrm{s}\left(1 \mathrm{eV}=1.6 \times 10^{-19} \mathrm{~J}\right)$ and $\mathrm{c}=3.0 \times 10^{8} \mathrm{~m} \cdot \mathrm{s}^{-1}$, this equation may be simplified as: $\Delta \mathrm{E}^{\mathrm{opt}}(\mathrm{eV})=1237.5 / \lambda$ (in $\mathrm{nm}$ ). Triplet energy level $\mathrm{E}_{\mathrm{T}}$ was calculated from the maximum of the first phosphorescence emission peak, and conversion in electron-volt was obtained with the previous formula. Emission spectra were recorded with a PTI spectrofluorimeter (PTI-814 PDS, MD 5020, LPS 220B) using a Xenon lamp. Quantum yields in solution $\left(\varnothing_{\text {sol }}\right)$ were calculated relative to quinine sulfate $\left(\phi_{\text {sol }}=0.546\right.$ in $\mathrm{H}_{2} \mathrm{SO}_{4} 1 \mathrm{~N}$ ). $\emptyset_{\text {sol }}$ was determined according to the following equation,

$$
\text { øsol }=\varnothing \text { ref } \times 100 \times \frac{\left(T_{s} \times A_{\mathrm{r}}\right)}{\left(T_{\mathrm{r}} \times A_{S}\right)} \times\left(\frac{n_{s}}{n_{\mathrm{r}}}\right)^{2}
$$

where, subscripts $s$ and $r$ refer respectively to the sample and reference. The integrated area of the emission peak in arbitrary units is given as $T, n$ is the refracting index of the solvent $\left(n_{s}=1.426\right.$ for cyclohexane) and $A$ is the absorbance. Three solutions of different concentration of the substrate $(A<0.1)$ and three solutions of the reference (quinine sulfate) were prepared. The quinine sulfate concentration was chosen so as the absorption of the reference and the substrate were the same at the excitation wavelength. Three quantum yields were then calculated at this wavelength and the average value is reported. IR spectra were recorded on a Bruker Vertex 70 using a diamond crystal MIRacle ATR (Pike). Thin films were prepared by spin-coating $300 \mu \mathrm{L}$ of solution of THF $(10 \mathrm{~g} / \mathrm{L})$ on a sapphire plate $(10 \mathrm{~mm} \times 10 \mathrm{~mm})$ at $2500 \mathrm{tr} / \mathrm{min}$ on a Süss MicroTech Labspin 6.

Fluorescence intensity decays were obtained by the time-correlated single-photon counting (TCSPC) method with femtosecond laser excitation using a Spectra-Physics set-up composed of a Titanium Sapphire Tsunami laser pumped by a doubled YAG laser Millennia. Light pulses at $990 \mathrm{~nm}$ (resp. $900 \mathrm{~nm}$ ) were selected by optoacoustic crystals at a repetition rate of $4 \mathrm{MHz}$, and the third harmonics at $330 \mathrm{~nm}$ 
(resp. $300 \mathrm{~nm}$ ) was obtained through non-linear crystals. Fluorescence photons were detected through a monochromator by means of a Hamamatsu MCP R3809U photomultiplier. The time-to-amplitude converter was purchased from Tennelec. The fluorescence data were analyzed by a nonlinear least-squares global method using the Globals software package developed at the Laboratory for Fluorescence Dynamics at the University of Illinois, Urbana-Champaign.

Electrochemical studies. Electrochemical experiments were performed under argon atmosphere using a Pt disk electrode (diameter $1 \mathrm{~mm}$ ), the counter electrode was a vitreous carbon rod and the reference electrode was a silver wire in a $0.1 \mathrm{M} \mathrm{AgNO}$ solution in $\mathrm{CH}_{3} \mathrm{CN}$. Ferrocene was added to the solution at the end of a series of experiments. The ferrocene/ferrocenium ( $\left.\mathrm{Fc} / \mathrm{Fc}^{+}\right)$couple served as internal standard. The three electrodes cell was connected to a PAR Model 273 potentiostat/galvanostat (PAR, EG\&G, USA) monitored with the ECHEM Software. Activated $\mathrm{Al}_{2} \mathrm{O}_{3}$ was added in the electrolytic solution to remove excess moisture. For a further comparison of the electrochemical and optical properties, all potentials are referred to the SCE electrode that was calibrated at $-0.405 \mathrm{~V}$ vs. $\mathrm{Fc} / \mathrm{Fc}^{+}$system. Following the work of Jenekhe, ${ }^{48}$ we estimated the electron affinity (EA) or lowest unoccupied molecular orbital (LUMO) and the ionisation potential (IP) or highest occupied molecular orbital (HOMO) from the redox data (tangent to the oxidation or reduction wave). The LUMO level was calculated from: LUMO (eV) $=-\left[\mathrm{E}_{\text {onset }}\right.$ (ved $\left.(\mathrm{VS} S \mathrm{SE})+4.4\right]$ and the HOMO level from: HOMO $(\mathrm{eV})=-\left[\mathrm{E}_{\text {onset }}{ }^{\mathrm{ox}}\right.$ (VS SCE) + 4.4], based on an SCE energy level of $4.4 \mathrm{eV}$ relative to the vacuum. The electrochemical gap was calculated from: $\Delta \mathrm{E}^{\mathrm{el}}=|\mathrm{HOMO}-\mathrm{LUMO}|$ (in eV).

Theoretical modeling. Full geometry optimization with Density Functional Theory (DFT) ${ }^{68} 69$ and TimeDependent Density Functional Theory (TD-DFT) calculations were performed with the hybrid Becke-3 parameter exchange ${ }^{70-72}$ functional and the Lee-Yang-Parr non-local correlation functional ${ }^{73}$ (B3LYP) implemented in the Gaussian 09 (Revision B.01) program suite ${ }^{74}$ using the $6-311 \mathrm{G}+(\mathrm{d}, \mathrm{p})$ basis set and the default convergence criterion implemented in the program. The figures were generated with GaussView 5.0. The computed triplet adiabatic $S_{0}$ to $T_{1}$ excitation energies were calculated from the difference between the total energy of the molecule in their respective singlet and triplet states.

\section{Thermal analysis:}

Thermal Gravimetric Analysis (TGA) was carried out by using TA SDT Q600 instrument, at the "Ecole Nationale Supérieure de Chimie de Rennes" or at the "Institut des Sciences Analytiques" (UMR CNRS 5280) of Villeurbanne. TGA curves were measured at $10^{\circ} \mathrm{C} / \mathrm{min}$ from 0 to $600^{\circ} \mathrm{C}$ under an azote atmosphere. Differential Scanning Calorimetry (DSC) was carried out by using NETZSCH DSC 200 F3 instrument equipped with an intracooler. DSC traces were measured at $10^{\circ} \mathrm{C} / \mathrm{min}$. Two heating/cooling cycles were succesively carried out and the glass transition Tg was determined from the $2^{\text {nd }}$ heating cycle. Temperatures of the different transitions given are obtained with the tangent to the transition peak.

\section{Device fabrication and characterisation:}

OLEDs based on a multilayer structure have been fabricated onto patterned ITO coated glass substrates from XinYan Tech (thickness: $100 \mathrm{~nm}$ and sheet resistance: less of $20 \mathrm{~W} / \mathrm{m}$ ). The organic materials (from Aldrich and Lumtec) are deposited onto the ITO anode by sublimation under high vacuum $\left(<10^{-6} \mathrm{Torr}\right)$ at a rate of $0.2-0.3 \mathrm{~nm} / \mathrm{s}$. The structure of the device is the following: ITO/CuPc(10 nm)/NPB $(40 \mathrm{~nm}) / \mathrm{TCTA}(10$ $\mathrm{nm}) /$ Hosts:dopant $(20 \mathrm{~nm}) / \mathrm{TPBi}(40 \mathrm{~nm}) / \mathrm{LiF}(1.2 \mathrm{~nm}) / \mathrm{Al}(100 \mathrm{~nm})$. In this device, ITO is used as the anode, CuPc (copper phtalocyanine) is the hole injecting layer, NPB (N, $\mathrm{N}^{\prime}$-di(1-naphtyl)-N, $\mathrm{N}^{\prime}$-diphenyl-[1,1'-biphenyl]-4,4'-diamine) is the hole-transporting layer, TCTA $\left(4,4^{\prime}, 4^{\prime \prime}\right.$-Tris(carbazol-9-yl)-triphenylamine) is the electron/exciton blocking layer, TPBI (1,3,5-Tris(1-phenyl-1H-benzimidazol-2-yl)benzene) is both the electron transporting layer and the hole blocking layer and a thin film of lithium fluoride over aluminum is the cathode. The entire device is fabricated in the same run without breaking the vacuum. In this study, the thicknesses of the different organic layers were kept constant for all the devices. The active area of the devices defined by the overlap of the ITO anode and the metallic cathode was $0.3 \mathrm{~cm}^{2}$. The current-voltage-luminance (I-V-L) characteristics of the devices were measured with a regulated power supply (Laboratory Power Supply EA-PS 3032-10B) combined with a multimeter and a $1 \mathrm{~cm}^{2}$ area silicon calibrated photodiode (Hamamatsu). The spectral emission was recorded with a SpectraScan PR650 spectrophotometer. All the measurements were performed at room temperature and at ambient atmosphere with no further encapsulation of devices. 


\section{REFERENCES}

(1) Meng, Q.; Hu, W. Phys. Chem. Chem. Phys. 2012, 14, 14152-14164.

(2) Müllen, K.; Scherf, U. Organic Light-Emitting Devices: Synthesis, Properties and Applications; Wiley-VCH Verlag GMbH \& Co.

KGaA: Weinheim, 2006.

(3) Tang, C. W.; VanSlyke, S. A. Appl. Phys. Lett. 1987, 51, 913-915.

(4) Mishra, A.; Bäuerle, P. Angew. Chem. Int. Ed. 2012, 51, 2020-2067.

(5) Shaheen, S. E.; Ginley, D. S.; Jabbour, G. E. Mat. Res. Soc. Bull. 2005, 30, 10-19.

(6) Forrest, S. R.; Thompson, M. E. Chem. Rev. 2007, 107, 923-925.

(7) Grimsdale, A. C.; Müllen, K. Macromol. Rapid Commun. 2007, 28, 1676-1702.

(8) Special issue: $\pi$-Functional Materials; Bredas, J.-L.; Marder, S. R.; Reichmanis, E. Chem. Mater. 2011, 23.

(9) Shih, P.-I.; Chien, C.-H.; Chuang, C.-Y.; Shu, C.-F.; Yang, C.-H.; Chen, J.-H.; Chi, Y. J. Mater. Chem. 2007, 17, $1692-1698$.

(10) Yeh, S.-J.; Wu, M.-F.; Chen, C.-T.; Song, Y.-H.; Chi, Y.; Ho, M.-H.; Hsu, S.-F.; Chen, C. H. Adv. Mater. 2005, 17, $285-289$.

(11) Yook, K. S.; Lee, J. Y. L. Adv. Mater. 2012, 24, 3169-3190.

(12) Xie, J.-H.; Zhou, Q.-L. Acc. Chem. Res. 2008, 41, 581-594.

(13) Poriel, C.; Ferrand, Y.; Le Maux, P.; Rault-Berthelot, J.; Simonneaux, G. Synth. Met. 2008, 158, 796-801.

(14) Poriel, C.; Ferrand, Y.; Le Maux, P.; Rault-Berthelot, J.; Simonneaux, G. Chem. Commun. 2003, 1104-1105.

(15) Poriel, C.; Ferrand, Y.; Le Maux, P.; Rault-Berthelot, J.; Simonneaux, G. Inorg. Chem. 2004, 43, 5086-5095.

(16) Ferrand, Y.; Poriel, C.; Le Maux, P.; Rault-Berthelot, J.; Simonneaux, G. Tet. Asym. 2005, 16, 1463-1472.

(17) Poriel, C.; Ferrand, Y.; Le Maux, P.; Paul-Roth, C.; Simonneaux, G.; Rault-Berthelot, J. J. Electroanal. Chem. 2005, 583, 92-103.

(18) Schneider, D.; Rabe, T.; Riedl, T.; Dobbertin, T.; Kröger, M.; Becker, E.; H.-H., J.; Kowalski, W.; Weimann, T.; Wang, J.; Hinze, P.; Gerhard, A.; Stössel, P.; Vestweber, H. Adv. Mater. 2005, 17, 31-34.

(19) Kim, Y. S.; Lee, M.; Boo, B. H. J. Chem. Phys. 1998, 109, 2593.

(20) Moreau, F.; Audebrand, N.; Poriel, C.; Moizan-Baslé, V.; Ouvry, J. J. Mater. Chem. 2011, 21, 18715-18722.

(21) Saragi, T. P. I.; Spehr, T.; Siebert, A.; Fuhrmann-Lieker, T.; Salbeck, J. Chem. Rev. 2007, 107, 1011-1065.

(22) Romain, M.; Tondelier, D.; Vanel, J.-C.; Geffroy, B.; Jeannin, O.; Rault-Berthelot, J.; Métivier, R.; Poriel, C. Angew. Chem. Int. Ed. 2013, 52, 14147-14151.

(23) Thirion, D.; Romain, M.; Rault-Berthelot, J.; Poriel, C. J. Mater. Chem. 2012, 22, 7149-7157.

(24) Tao, Y.; Ao, L.; Wang, Q.; Zhong, C.; Yang, C.; Qin, J.; Ma, D. Chem. Asian J. 2010, 5, 278-284.

(25) Jeon, S. O.; Yook, K. S.; Lee, J. Y. Thin Solid Films 2010, 519, 890-893.

(26) Jahng, Y.; Rahman, A. F. M. M. Bull. Chem. Soc. Jpn. 2010, 83, 672-677.

(27) Ying, L.; Zou, J.; Yang, W.; Zhang, A.; Wu, Z.; Zhao, W.; Cao, Y. Dyes and Pigments 2009, 82, 251-257.

(28) Wu, P.-T.; Kim, F. S.; Champion, R. D.; Jenekhe, S. A. Macromol. 2008, 41, 7021 - 7028.

(29) Hughes, G.; Bryce, M. R. J. Mater. Chem. 2005, 15, 94-107.

(30) Hughes, G.; Wang, C.; Batsanov, A. S.; Fern, M.; Frank, S.; Bryce, M. R.; Perepichka, I. F.; Monkman, A. P.; Lyons, B. P. Org. Biomol. Chem. 2003, 1, 3069-3077.

(31) Montilla, F.; Mallavia, R. Adv. Funct. Mater. 2007, 17, 71-78.

(32) Poriel, C.; Rault-Berthelot, J.; Thirion, D.; Barrière, F.; Vignau, L. Chem. -Eur. J. 2011, 17, 14031-14046.

(33) Grimsdale, A. C. Curr. Org. Chem. 2010, 14, 2196-2217.

(34) Farrar, S. R.; Contoret, A. E. A.; O'Neill, M.; Nicholls, J. E.; Eastwood, A. J.; Richards, G. J.; Vlachos, P.; Kelly, S. M. Appl. Surf. Sc. 2002, 186, 435-440.

(35) Wu, C.-C.; Lin, Y.-T.; Chiang, H.-H.; Cho, T. Y.; Chen, C. W.; Wong, K.-T.; Liao, Y.-L.; Lee, G. H.; Peng, S. M. App. Phys. Lett. 2002, 81, 577-579.

(36) Lee, R.-H.; Huang, Y.-W.; Wang, Y.-Y.; Chang, H.-Y. Thin Solid Films 2008, 516, 5062-5068.

(37) Jiang, Z.; Yao, H.; Zhang, Z.; Yang, C.; Liu, Z.; Tao, Y.; Qin, J.; Ma, D. Org. Lett. 2009, 11, 2607-2610.

(38) Fan, C.; Chen, Y.; Gan, P.; Yang, C.; Zhong, C.; Qin, J.; Ma, D. Org. Lett. 2010, 12, 5648-5651.

(39) Jang, S. E.; Joo, C. W.; Ok, J. S.; Soo, Y. K.; Lee, J. Y. Org. Elec. 2010, 11, 1059-1065.

(40) Lee, K. H.; Kim, S. O.; Yook, K. S.; Jeon, S. O.; Lee, J. Y.; Yoon, S. S. Synt. Met. 2011, 161, 2024-2030.

(41) Dong, S.-C.; Gao, C.-H.; Zhang, Z.-H.; Jiang, Z.-Q.; Lee, S.-T.; Liao, L.-S. Phys. Chem. Chem. Phys. 2012, 14, $14224-14228$.

(42) Dong, S.-C.; Gao, C.-H.; Yuan, X.-D.; Cui, L.-S.; Jiang, Z.-Q.; Lee, S.-T.; Liao, L.-S. Org. Elec. 2013, 14, 902-908.

(43) Poriel, C.; Métivier, R.; Rault-Berthelot, J.; Thirion, D.; Barrière, F.; Jeannin, O. Chem. Commun. 2011, 47, 11703-11705.

(44) Thiery, S.; Tondelier, D.; Declairieux, C.; Seo, G.; Geffroy, B.; Jeannin, O.; Rault-Berthelot, J.; Métivier, R.; Poriel, C. J. Mater.

Chem. C 2014, 2014, 2, 4156-4166

(45) Pei, J.; Ni, J.; Zhou, X.-H.; Cao, X.-Y.; Lai, Y.-H. J. Org. Chem. 2002, 67, 4924-4936.

(46) Demers, E.; Maris, T.; Wiest, J. D. W. Cryst. Growth Des. 2005, 5, 1227-1235.

(47) Wong, K.-T.; Liao, Y.-L.; Peng, Y.-C.; Wang, C.-C.; Lin, S.-Y.; Yang, C.-H.; Tseng, S.-M.; Lee, G.-H.; Peng, S.-M. Cryst. Growth Des. 2005, 5, 667-671.

(48) Kulkarni, A. P.; Tonzola, C. J.; Babel, A.; Jenekhe, S. A. Chem. Mater. 2004, 16, 4556-4573.

(49) Poriel, C.; Liang, J.-J.; Rault-Berthelot, J.; Barrière, F.; Cocherel, N.; Slawin, A. M. Z.; Horhant, D.; Virboul, M.; Alcaraz, G.;

Audebrand, N.; Vignau, L.; Huby, N.; Wantz, G.; Hirsch, L. Chem. -Eur. J. 2007, 13, 10055-10069.

(50) Aizawa, N.; Pu, Y.-J.; Sasabe, H.; Kido, J. Org. Electron. 2012, 13, 2235-2242. 
(51) Tsai, M.-H.; Hong, Y.-H.; Chang, C.-H.; Su, H.-C.; Wu, C.-C.; Matoliukstyte, A.; Simokaitiene, J.; Grigalevicius, S.; Grazulevicius, J. V.; Hsu, C.-P. Adv. Mater. 2007, 19, 862-866.

(52) Belletête, M.; Ranger, M.; Beaupré, S.; Leclerc, M.; Durocher, G. Chem. Phys. Lett. 2000, 316, 101-107.

(53) Wang, J.-F.; Feng, J.-K.; Ren, A.-M.; Yang, L. Chin. J. Chem. 2005, 23, 1618-1624.

(54) Thirion, D.; Poriel, C.; Métivier, R.; Rault-Berthelot, J.; Barrière, F.; Jeannin, O. Chem. -Eur. J. 2011, 17, 10272-10287.

(55) Thirion, D.; Poriel, C.; Barrière, F.; Métivier, R.; Jeannin, O.; Rault-Berthelot, J. Org. Lett. 2009, 11, 4794-4797.

(56) Ooyama, Y.; Ito, G.; Kushimoto, K.; Komaguchi, K.; Imae, I.; Harima, Y. Org. Biomol. Chem. 2010, 8, 2756-2770.

(57) Chi, C.-C.; Chiang, C.-L.; Liu, S.-W.; Yueh, H.; Chen, C.-T.; Chen, C.-T. J. Mater. Chem. 2009, 19, 5561-5571.

(58) Adachi, C.; Kwong, R. C.; Djurovich, P.; Adamovich, V.; Baldo, M. A.; Thompson, M. E.; Forrest, S. R. Appl. Phys. Lett. 2001, 79, 2082.

(59) Wong, K.-T.; Chen, Y.-M.; Lin, Y.-T.; Su, H.-C.; Wu, C.-C. Org.Lett. 2005, 7, 5361-5364.

(60) Seo, J. H.; Han, N. S.; Shim, H. S.; Kwon, J. H.; Song, J. K. Bull. Korean Chem. Soc. 2011, 32, 1415.

(61) Chi, L.-C.; Hung, W.-Y.; Chiu, H.-C.; Wong, K.-T. Chem. Commun. 2009, 3892-3894.

(62) Han, N. S.; Sohn, S. H.; Park, S. M.; Song, J. K. Bull. Korean Chem. Soc. 2013, 34, 1547-1550.

(63) Winter-Werner, B.; Diederich, F.; Gramlich, V. Helv. Chim. Acta 1996, 79, 1338-1360.

(64) Jeon, S. O.; Yook, K. S.; Joo, C. W.; Son, H. S.; Lee, J. Y. Thin Solid Films 2010, 518, 3716-3720.

(65) Altomare, A.; Burla, M. C.; Camalli, M.; Cascarano, C.; Giacovazzo, A.; Guagliardi, A.; Moliterni, A. G. G.; Polidori, G.; Spagna, R. J. Appl. Cryst. 1999, 32, 115-119.

(66) Sheldrick, G. M. Acta Crystallogr. 2008, A64, 112-122.

(67) Farrugia, L. J. J. Appl. Cryst. 2012, 45, 849-854.

(68) Hohenberg, P.; Kohn, W. Phys. Rev. 1964, 136, B864-B871.

(69) Calais, J.-L. Int. J. Quantum Chem. 1993, 47, 101.

(70) Becke, A. D. Phys. Rev. A 1988, 38, 3098-3100.

(71) Becke, A. D. J. Chem. Phys. 1993, 98, $5648-5652$.

(72) Becke, A. D. J. Chem. Phys. 1993, 98, 1372-1377.

(73) Lee, C.; Yang, W.; Parr, R. G. Phys. Rev. B 1988, 37, 785-789.

(74) Frisch, M. J.; Trucks, G. W.; Schlegel, H. B.; Scuseria, G. E.; Robb, M. A.; Cheeseman, J. R.; Scalmani, G.; Barone, V.; Mennucci, B.; Petersson, G. A.; Nakatsuji, H.; Caricato, M.; Li, X.; Hratchian, H. P.; Izmaylov, A. F.; Bloino, J.; Zheng, G.; Sonnenberg, J. L.; Hada, M.; Ehara, M.; Toyota, K.; Fukuda, R.; Hasegawa, J.; Ishida, M.; Nakajima, T.; Honda, Y.; Kitao, O.; Nakai, H.; Vreven, T.;

Montgomery, J. A. J.; Peralta, J. E.; Ogliaro, F.; Bearpark, M.; Heyd, J. J.; Brothers, E.; Kudin, K. N.; Staroverov, V. N.; Keith, T.; Kobayashi, R.; Normand, J.; Raghavachari, K.; Rendell, A.; Burant, J. C.; Iyengar, S. S.; Tomasi, J.; Cossi, M.; Rega, N.; Millam, J. M.; Klene, M.; Knox, J. E.; Cross, J. B.; Bakken, V.; Adamo, C.; Jaramillo, J.; Gomperts, R.; Stratmann, R. E.; Yazyev, O.; Austin, A. J.; Cammi, R.; Pomelli, C.; Ochterski, J. W.; Martin, R. L.; Morokuma, K.; Zakrzewski, V. G.; Voth, G. A.; Salvador, P.; Dannenberg, J. J.; Dapprich, S.; Daniels, A. D.; Farkas, O.; Foresman, J. B.; Ortiz, J. V.; Cioslowski, J.; Fox, D. J., Gaussian 09, Revision B.01, Gaussian, Inc., Wallingford CT, 2010. 


\section{Supplementary Materials for}

\section{2-substituted vs 4-substituted-9,9'-spirobifluorene host materials} for green and blue phosphorescent OLEDs: A Structure-Property Relationship Study

Sébastien Thiery, ${ }^{a}$ Céline Declairieux, ${ }^{c}$ Denis Tondelier, ${ }^{c}$ Gijun Seo, ${ }^{c}$ Bernard Geffroy, ${ }^{c, d}$ Olivier Jeannin, ${ }^{a}$ Rémi Métivier, ${ }^{b}$ Joëlle Rault-Berthelot, ${ }^{*}{ }^{a}$ Cyril Poriel ${ }^{* a}$

a. Université de Rennes 1-UMR CNRS 6226, "Institut des Sciences Chimiques de Rennes" MaCSE group. Bat 10C, Campus de Beaulieu, 35042 Rennes, France

b. PPSM, Institut d'Alembert, ENS Cachan, UMR CNRS 8531, 61 Avenue du Président Wilson, 94235 Cachan, France

c. LPICM, Ecole Polytechnique, UMR CNRS 7647, Route de Saclay, 91128, Palaiseau

d. LICSEN, CEA Saclay, IRAMIS/NIMBE, 91191 Gif sur Yvette

\section{Summary}

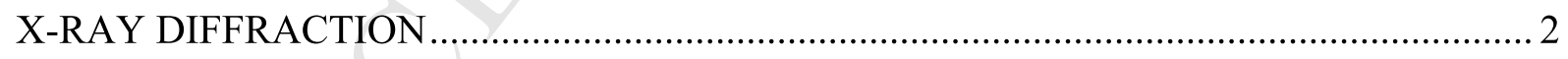

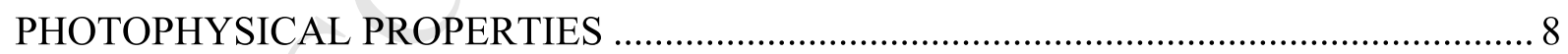

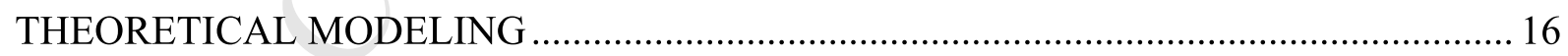

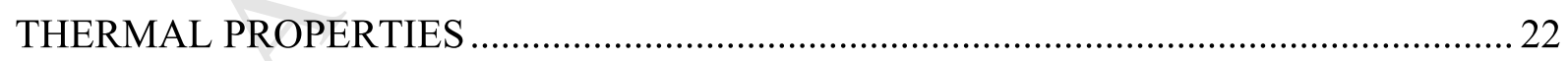

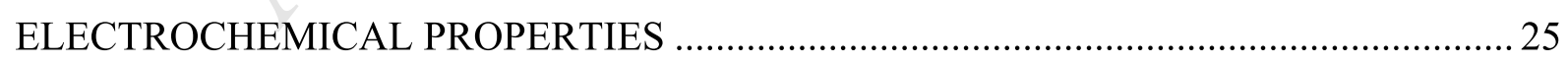

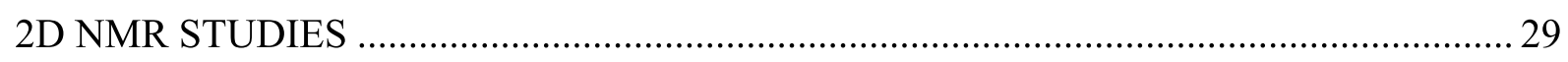

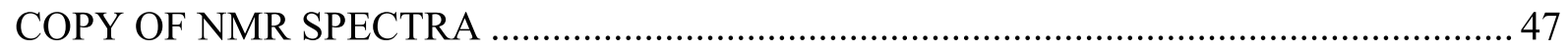

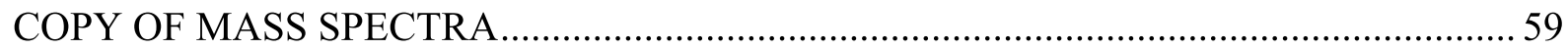




\section{X-RAY DIFFRACTION}

Table 1 Crystal data and structure refinement for 2-Ph-SBF

\begin{tabular}{|c|c|}
\hline Identification code & 2-Ph-SBF \\
\hline Empirical formula & $\mathrm{C}_{62} \mathrm{H}_{40}$ \\
\hline Formula weight & 784.94 \\
\hline Temperature & $150(2) \mathrm{K}$ \\
\hline Wavelength & $0.71073 \AA$ \\
\hline Crystal system & Triclinic \\
\hline Space group & $\mathrm{P}-1$ \\
\hline \multirow[t]{3}{*}{ Unit cell dimensions } & $a=10.9027(4) \AA \alpha=102.1400(10)^{\circ}$ \\
\hline & $\mathrm{b}=13.7902(6) \AA \beta=97.4710(10)^{\circ}$. \\
\hline & $\mathrm{c}=15.7771(5) \AA \gamma=111.5900(10)^{\circ}$ \\
\hline Volume & $2099.47(14) \AA^{3}$ \\
\hline $\mathrm{Z}$ & 2 \\
\hline Density (calculated) & $1.242 \mathrm{~g} / \mathrm{cm}^{3}$ \\
\hline Absorption coefficient & $0.070 \mathrm{~mm}^{-1}$ \\
\hline $\mathrm{F}(000)$ & $824 \sim$ \\
\hline Crystal size & $0.26 \times 0.24 \times 0.09 \mathrm{~mm}^{3}$ \\
\hline Theta range for data collection & 1.36 to $27.50^{\circ}$. \\
\hline Index ranges & $-14<=\mathrm{h}<=13,-17<=\mathrm{k}<=17,-20<=\mathrm{l}<=20$ \\
\hline Reflections collected & 20625 \\
\hline Independent reflections & $9543[\mathrm{R}(\mathrm{int})=0.0307]$ \\
\hline Completeness to theta $=27.50^{\circ}$ & $98.9 \%$ \\
\hline Absorption correction & Semi-empirical from equivalents \\
\hline Max. and min. transmission & 0.994 and 0.982 \\
\hline Refinement method & Full-matrix least-squares on $\mathrm{F}^{2}$ \\
\hline Data / restraints / parameters & $9543 / 0 / 559$ \\
\hline Goodness-of-fit on $\mathrm{F}^{2}$ & 1.074 \\
\hline Final $R$ indices $[\mathrm{I}>2 \operatorname{sigma}(\mathrm{I})]$ & $\mathrm{R} 1=0.0447, \mathrm{wR} 2=0.1128$ \\
\hline $\mathrm{R}$ indices (all data) & $\mathrm{R} 1=0.0583, \mathrm{wR} 2=0.1272$ \\
\hline Largest diff. peak and hole & 0.261 and -0.269 e. $\AA^{-3}$ \\
\hline
\end{tabular}


Table 2 Crystal data and structure refinement for 2-5Pm-SBF

\begin{tabular}{|c|c|}
\hline Identification code & 2-5Pm-SBF \\
\hline Empirical formula & $\mathrm{C}_{30} \mathrm{H}_{22} \mathrm{~N}_{2} \mathrm{O}$ \\
\hline Formula weight & 426.5 \\
\hline Temperature & $150(2) K$ \\
\hline Wavelength & $0.71073 \AA$ \\
\hline Crystal system & orthorhombic \\
\hline space group & $P c a b$ \\
\hline Unit cell dimensions & $\begin{array}{c}\mathrm{a}=8.4342(3) \AA, \alpha=90^{\circ} \\
\mathrm{b}=13.6588(5) \AA, \beta=90^{\circ} \\
\mathrm{c}=38.5506(13) \AA, \gamma=90^{\circ}\end{array}$ \\
\hline Volume & $4441.1(3) \AA^{3}$ \\
\hline$Z$ & 8 \\
\hline Calculated density & $1.276\left(\mathrm{~g} \cdot \mathrm{cm}^{-3}\right)$ \\
\hline Absorption coefficient & $0.078 \mathrm{~mm}^{-1}$ \\
\hline$F(000)$ & 1792 \\
\hline Crystal size & $0.36 \times 0.31 \times 0.05 \mathrm{~mm}$ \\
\hline Theta range for data collection & 1.06 to $27.46^{\circ}$ \\
\hline h_min, h_max & $-10,9$ \\
\hline $\mathrm{k} \_\min , \mathrm{k} \_\max$ & $-17,16$ \\
\hline 1_min, $1 \_\max$ & $-45,50$ \\
\hline Reflections collected / unique & $21000 / 5055\left[\mathrm{R}(\mathrm{int})^{\mathrm{a}}=0.0327\right]$ \\
\hline Reflections $[I>2 \sigma]$ & 3820 \\
\hline Completeness to theta_max & 0.994 \\
\hline Absorption correction type & multi-scan \\
\hline Refinement method & Full-matrix least-squares on $F^{2}$ \\
\hline Data / restraints / parameters & $5055 / 0 / 300$ \\
\hline Goodness-of-fit & 1.124 \\
\hline Final $R$ indices $[\mathrm{I}>2 \sigma]$ & $R 1^{c}=0.0461, w R 2^{d}=0.1246$ \\
\hline$R$ indices (all data) & $R 1^{c}=0.0711, w R 2^{d}=0.1511$ \\
\hline Largest diff. peak and hole & 0.36 and $-0.315 \mathrm{e}^{-} \cdot \AA^{-3}$ \\
\hline
\end{tabular}




\section{2-Ph-SBF}

\section{2-Ph-SBF MOLECULE 1}
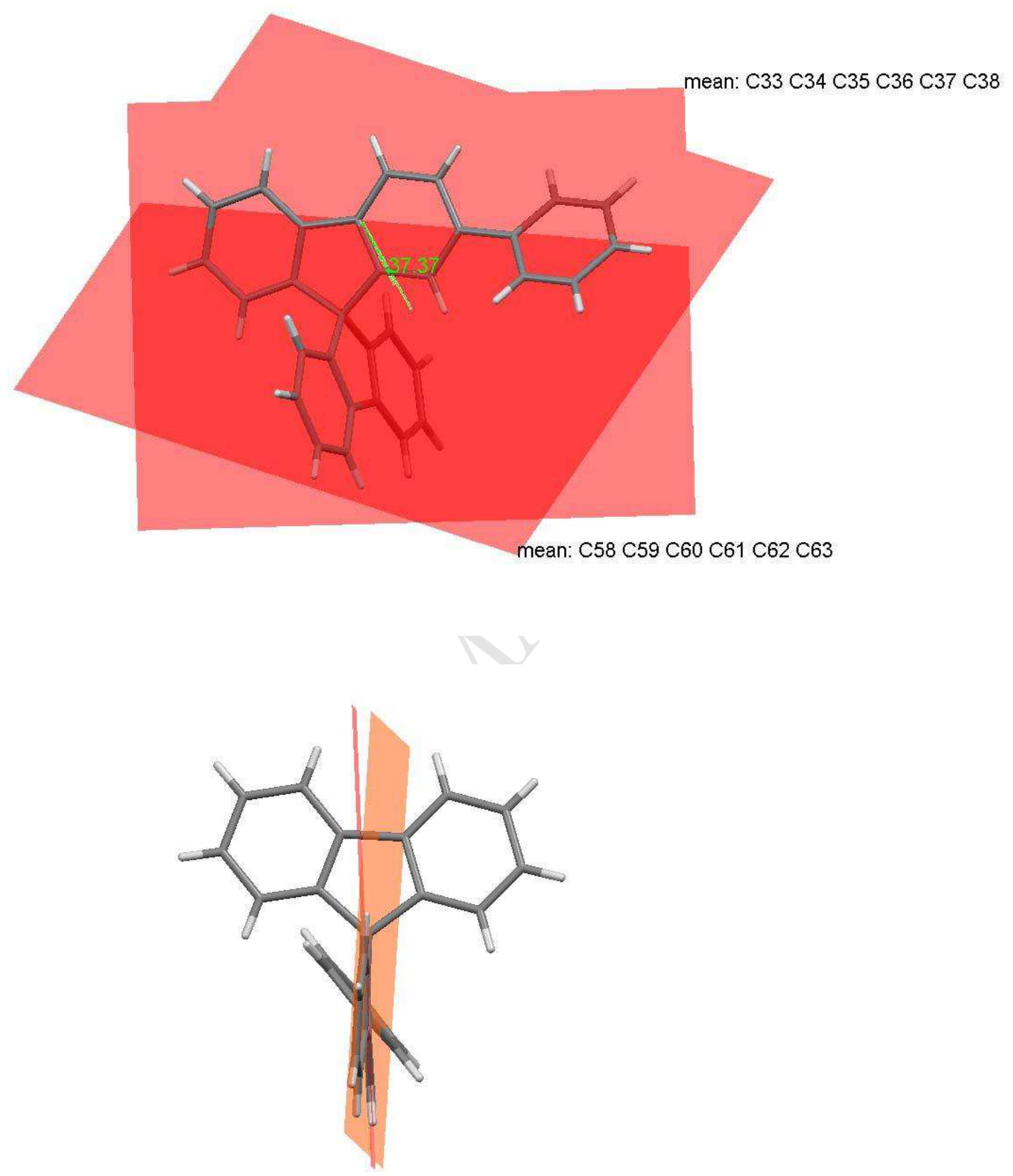

S 1 Top: Angle between the mean plane of the pendant phenyl ring and that of its attached phenyl ring of the fluorene : $37.37^{\circ}$; Bottom: Angle between the two mean planes of each fluorene: $7.08^{\circ}$ 


\section{2-Ph-SBF MOLECULE 2}

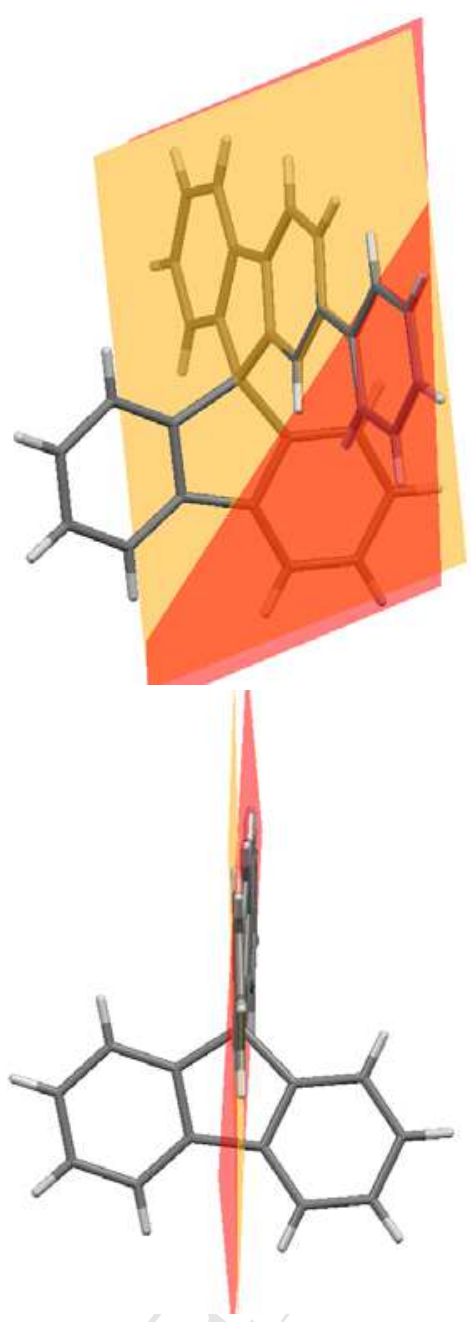

$\underline{\mathbf{S} 2}$ Angle between the mean plane of the pendant phenyl ring and that of its attached phenyl ring of the fluorene: $4.58^{\circ}$ 


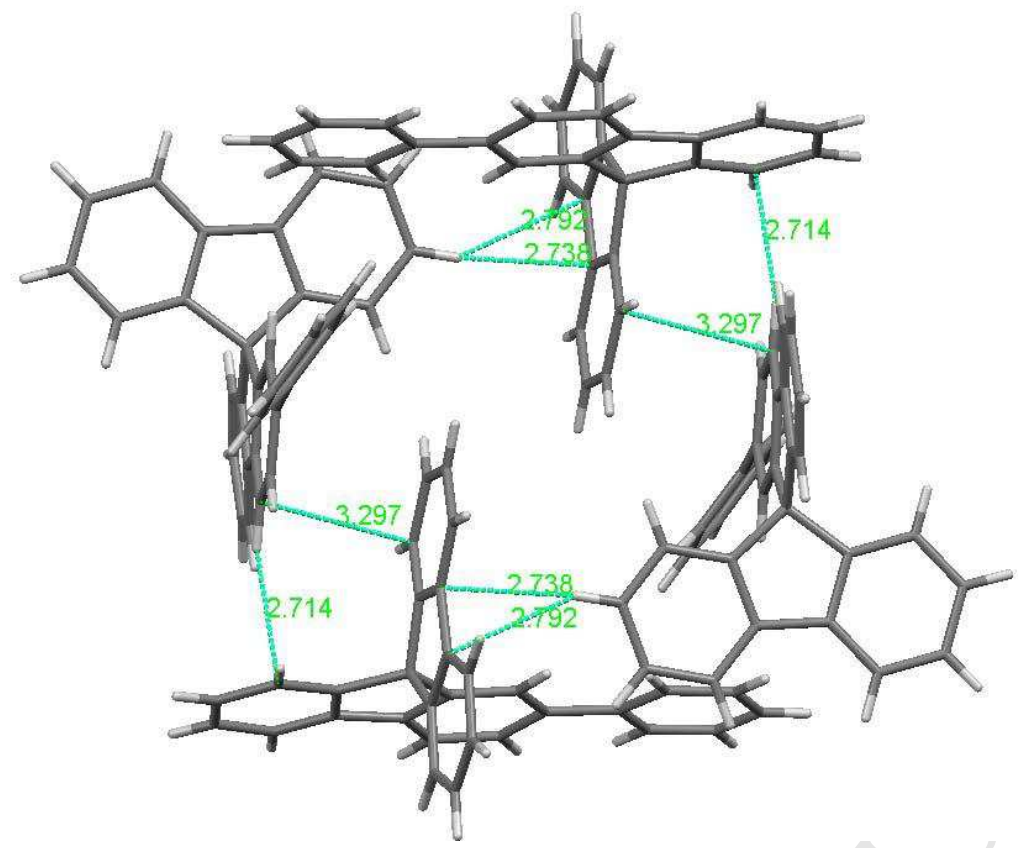

S 3 Short contacts ( $\mathrm{CH}$ and $\mathrm{C}-\mathrm{C}$, distance $<$ (sum of $\mathrm{r}_{\mathrm{vdw}}-0.1$ ) detected in crystal packing of 2-PhSBF.

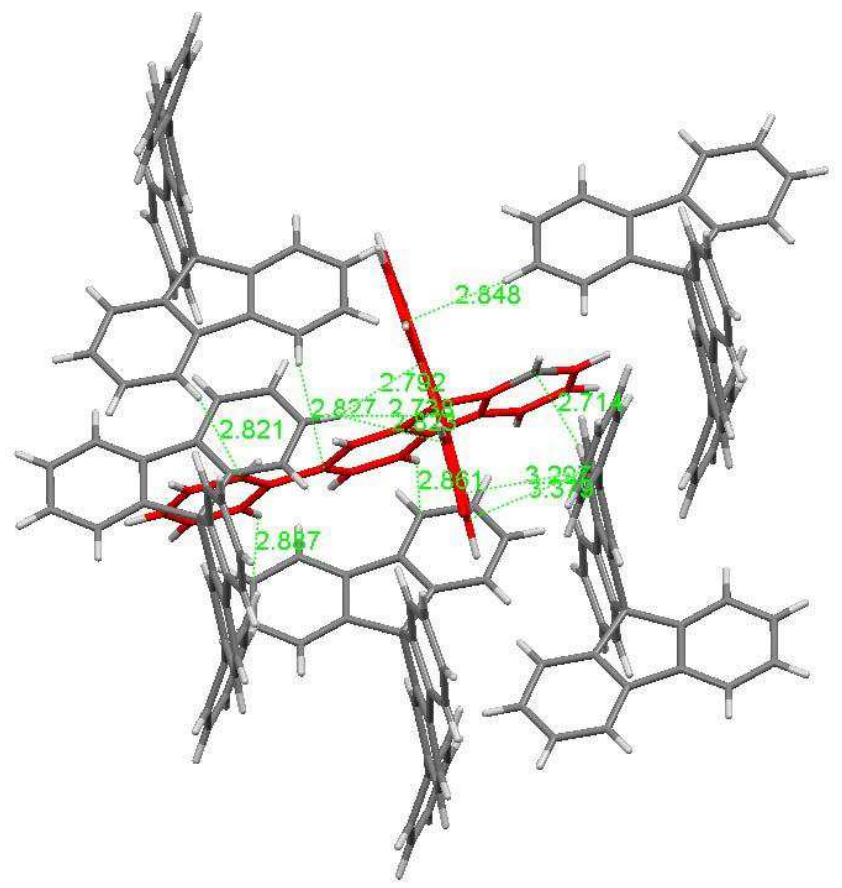

S4 Short contacts ( $\mathrm{CH}$ and $\mathrm{C}-\mathrm{C}$, distance $<$ (sum of $\mathrm{r}_{\mathrm{vdw}}$ ) detected for the 2-Ph-SBF molecule 2 (in red above) 


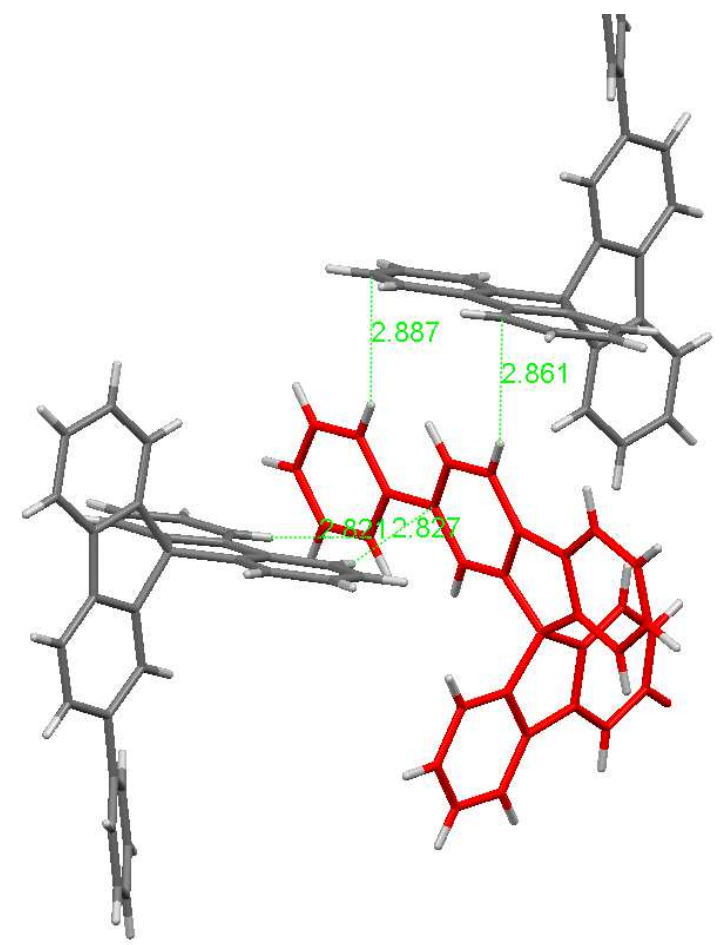

S 5 Short contacts $\left(\mathrm{CH}\right.$ and $\mathrm{C}-\mathrm{C}$, distance $<$ (sum of $\left.\mathrm{r}_{\mathrm{vdw}}\right)$ detected for the pendant phenyl unit of 2Ph-SBFmolecule 2 (in red above)

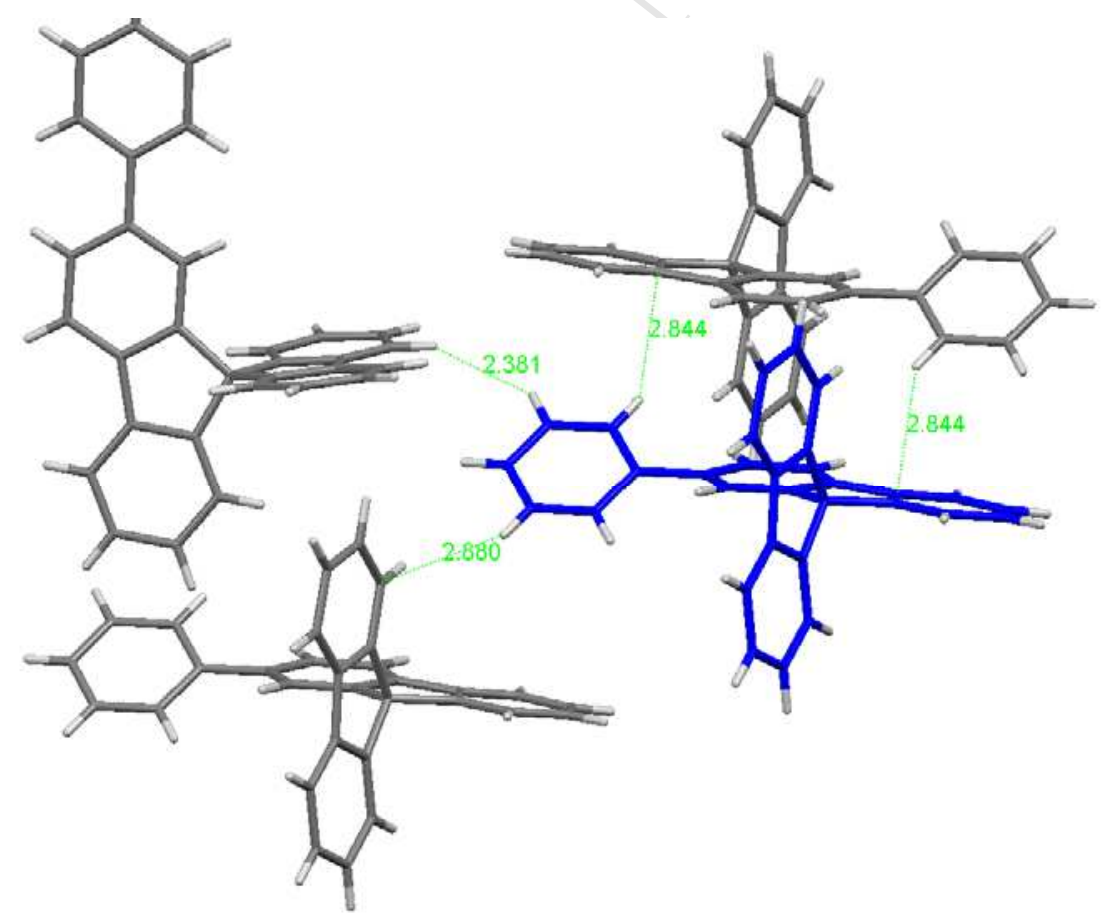

S6 Short contacts ( $\mathrm{CH}$ and $\mathrm{C}-\mathrm{C}$, distance $<$ (sum of $\mathrm{r}_{\mathrm{vdw}}$ ) detected for the pendant phenyl unit of 2Ph-SBF molecule 1 (in blue above) 


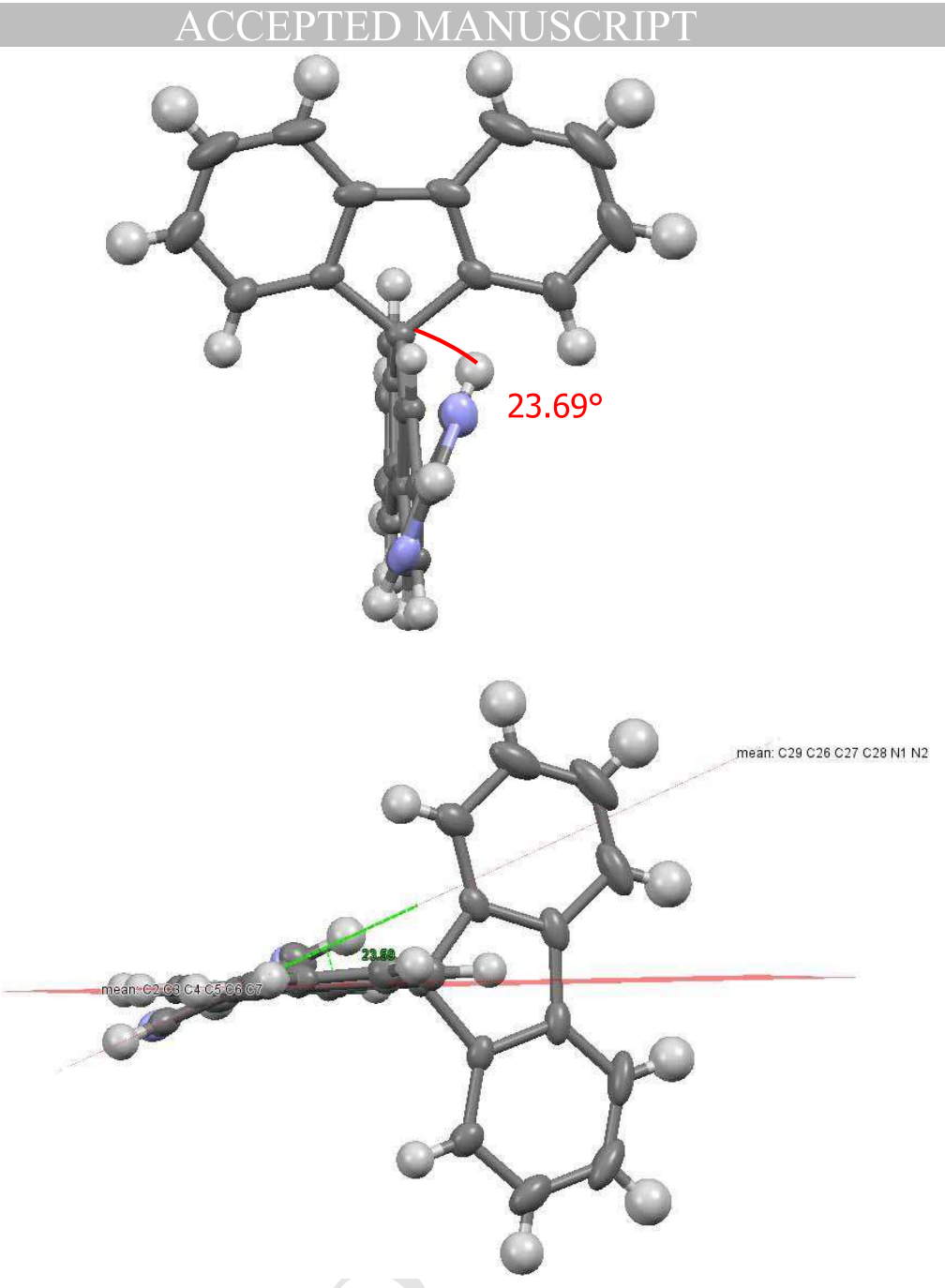

S 7 2-5Pm-SBF :Angle between the mean plane of the pyrimidine plane and that of its attached phenyl ring: $23.69^{\circ}$

\section{Photophysical properties}

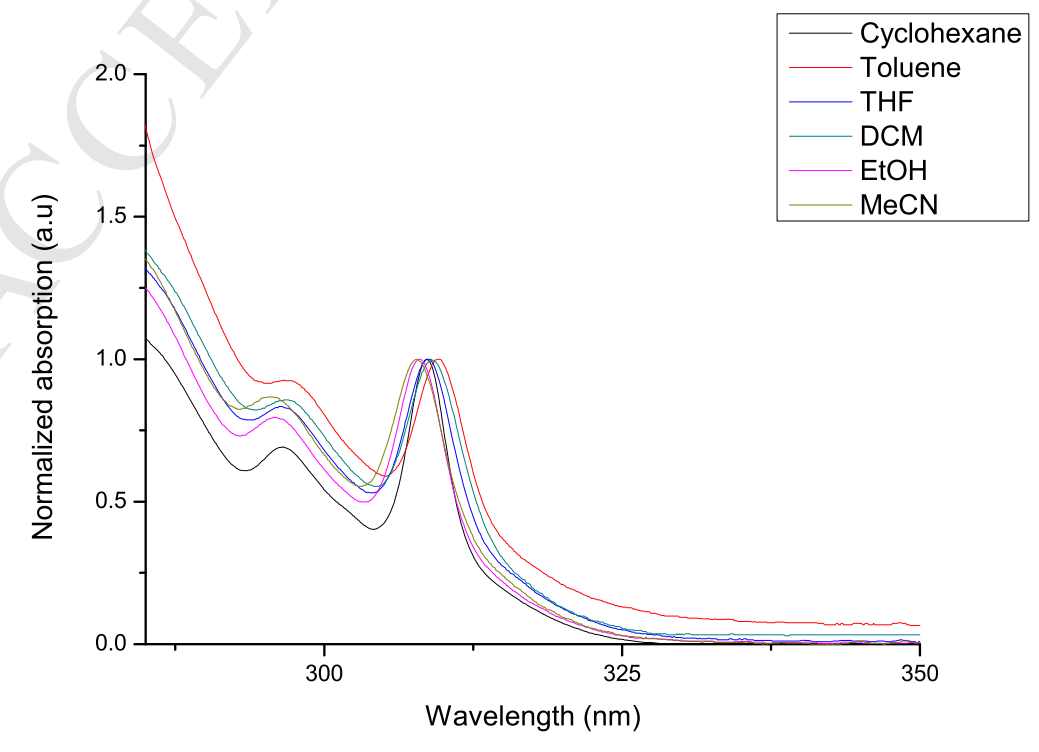


$\underline{\mathbf{S} 8}$ UV-Vis absorption spectrum of 4-Ph-SBF in various solvents

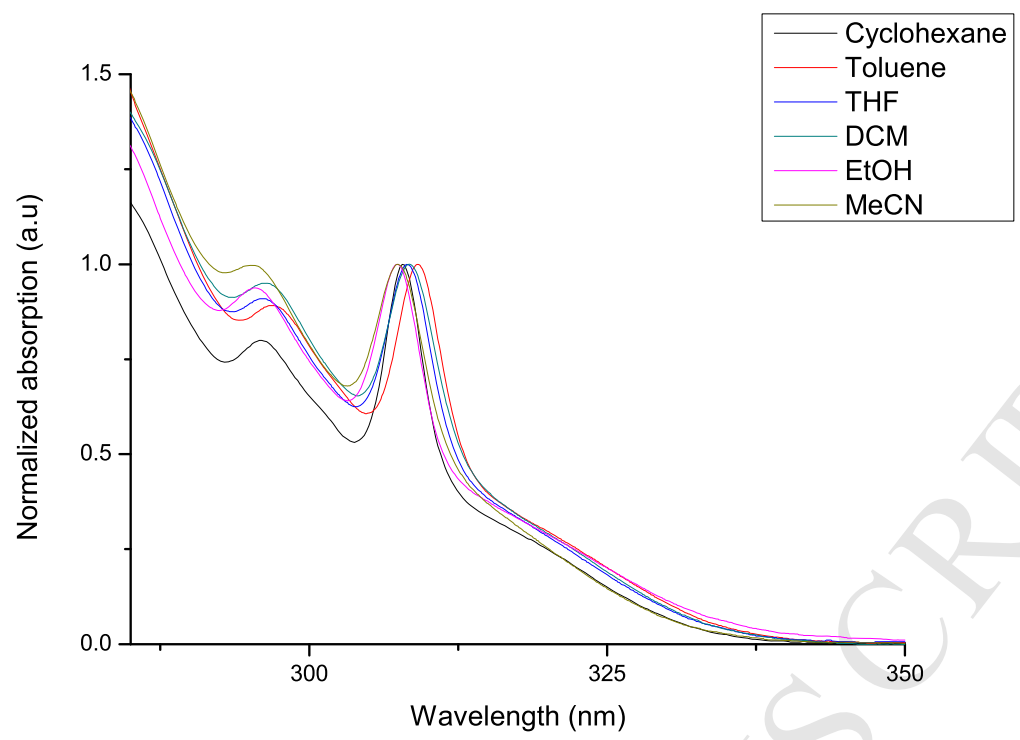

$\underline{\mathbf{S} 9}$ UV-Vis absorption spectrum of 4-5Pm-SBF in various solvents

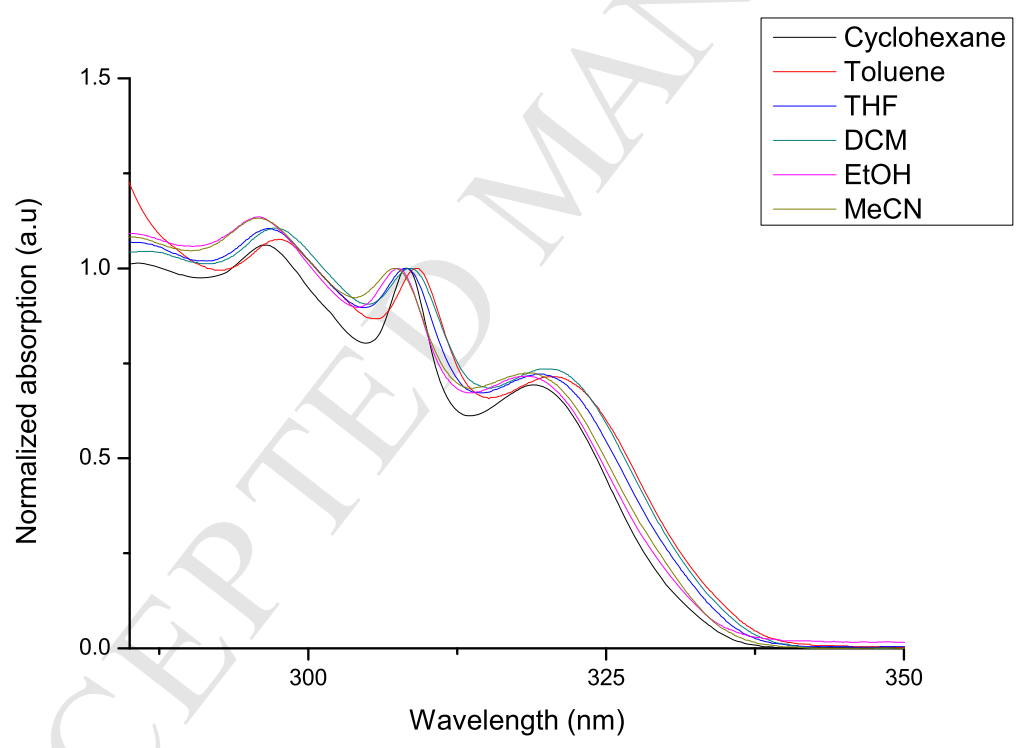

S 10 UV-Vis absorption spectrum of 2-Ph-SBF in various solvents 


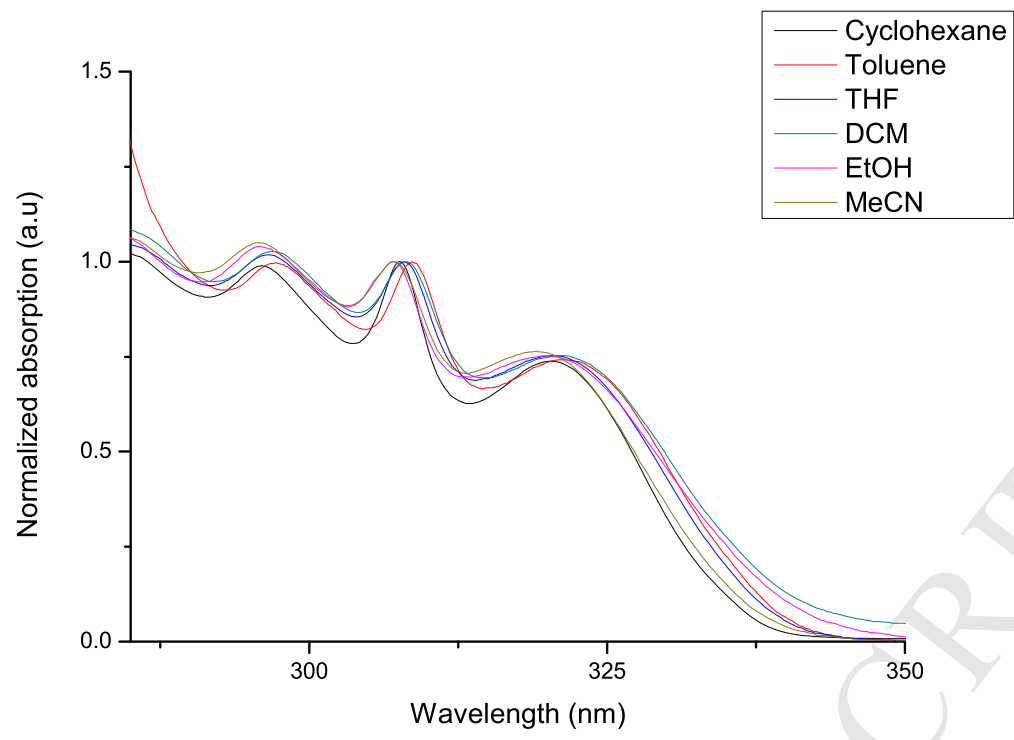

S11 UV-Vis absorption spectrum of 2-5Pm-SBF in various solvents

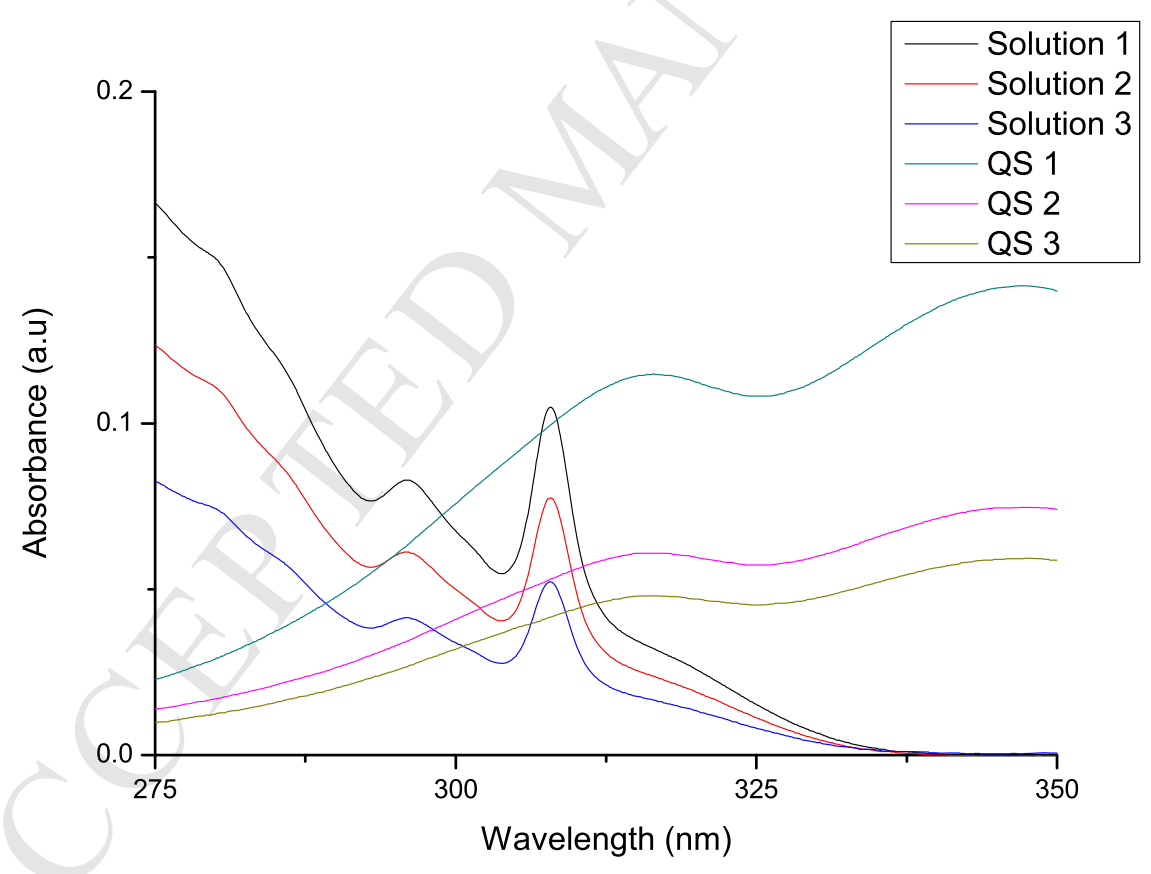

S12 Quantum yield measurements: Absorption of solutions of 4-5Pm-SBF in cyclohexane and quinine sulfate (QS) in $\mathrm{H}_{2} \mathrm{SO}_{4} 1 \mathrm{~N}$ 
Table 2 Quantum yield calculation of 4-5Pm-SBF

\begin{tabular}{|c|c|c|c|c|c|c|c|}
\hline Solution & $\lambda(\mathrm{nm})$ & $\mathrm{A}$ & $\mathrm{T}_{\mathrm{S}}$ & $\mathrm{T}_{\mathrm{QS}}$ & $n_{D}{ }^{25}$ (cyclohexane) & $n_{D}{ }^{25}\left(\mathrm{H}_{2} \mathrm{SO}_{4} 1 \mathrm{~N}\right)$ & $\varphi$ \\
\hline \multirow{2}{*}{1} & 308.5 & 0.1011 & 14134.4 & 238032 & 1.42662 & 1.3325 & $4 \%$ \\
\cline { 2 - 9 } & 299 & 0.0721 & 7610.04 & 120670 & 1.42662 & 1.3325 & $4 \%$ \\
\hline \multirow{2}{*}{2} & 309.5 & 0.0569 & 10314.6 & 150249 & 1.42662 & 1.3325 & $4 \%$ \\
\cline { 2 - 8 } & 302 & 0.0442 & 6316.68 & 89861.1 & 1.42662 & 1.3325 & $4 \%$ \\
\hline \multirow{2}{*}{3} & 309 & 0.0435 & 8040.89 & 122287 & 1.42662 & 1.3325 & $4 \%$ \\
\cline { 2 - 8 } & 300.5 & 0.0328 & 4539.62 & 67376.1 & 1.42662 & 1.3325 & $4 \%$ \\
\hline
\end{tabular}

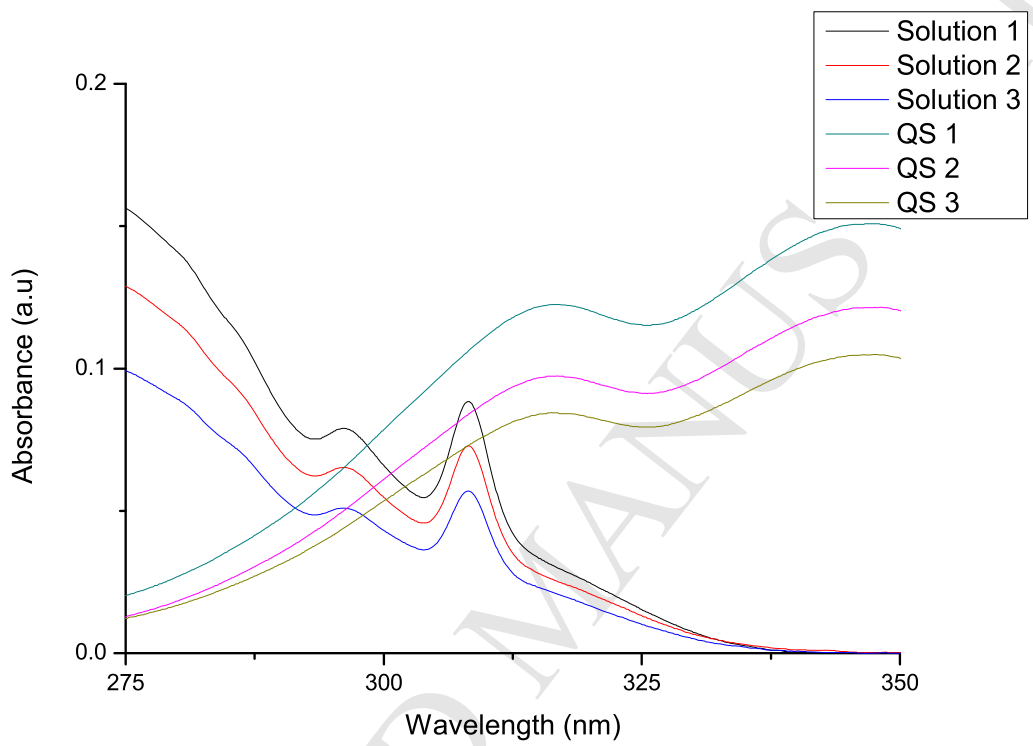

S13 Quantum yield measurements: Absorption of solutions of 4-5Pm-SBF in tetrahydrofurane and quinine sulfate (QS) in $\mathrm{H}_{2} \mathrm{SO}_{4} 1 \mathrm{~N}$

Table 3 Quantum yield calculation of 4-5Pm-SBF

\begin{tabular}{|c|c|c|c|c|c|c|c|}
\hline Solution & $\lambda(\mathrm{nm})$ & $\mathrm{A}$ & $\mathrm{T}_{\mathrm{S}}$ & $\mathrm{T}_{\mathrm{QS}}$ & $n_{D}{ }^{25}$ (cyclohexane) & $n_{D}{ }^{25}\left(\mathrm{H}_{2} \mathrm{SO}_{4} 1 \mathrm{~N}\right)$ & $\varphi$ \\
\hline 1 & 299 & 0,073 & 5032,56 & 60164,3 & 1,42662 & 1,3325 & $5 \%$ \\
\hline 2 & 299 & 0,058 & 4262,56 & 52110,2 & 1,42662 & 1,3325 & $5 \%$ \\
\hline 3 & 298 & 0,049 & 5132,74 & 43404,5 & 1,42662 & 1,3325 & $7 \%$ \\
\hline
\end{tabular}




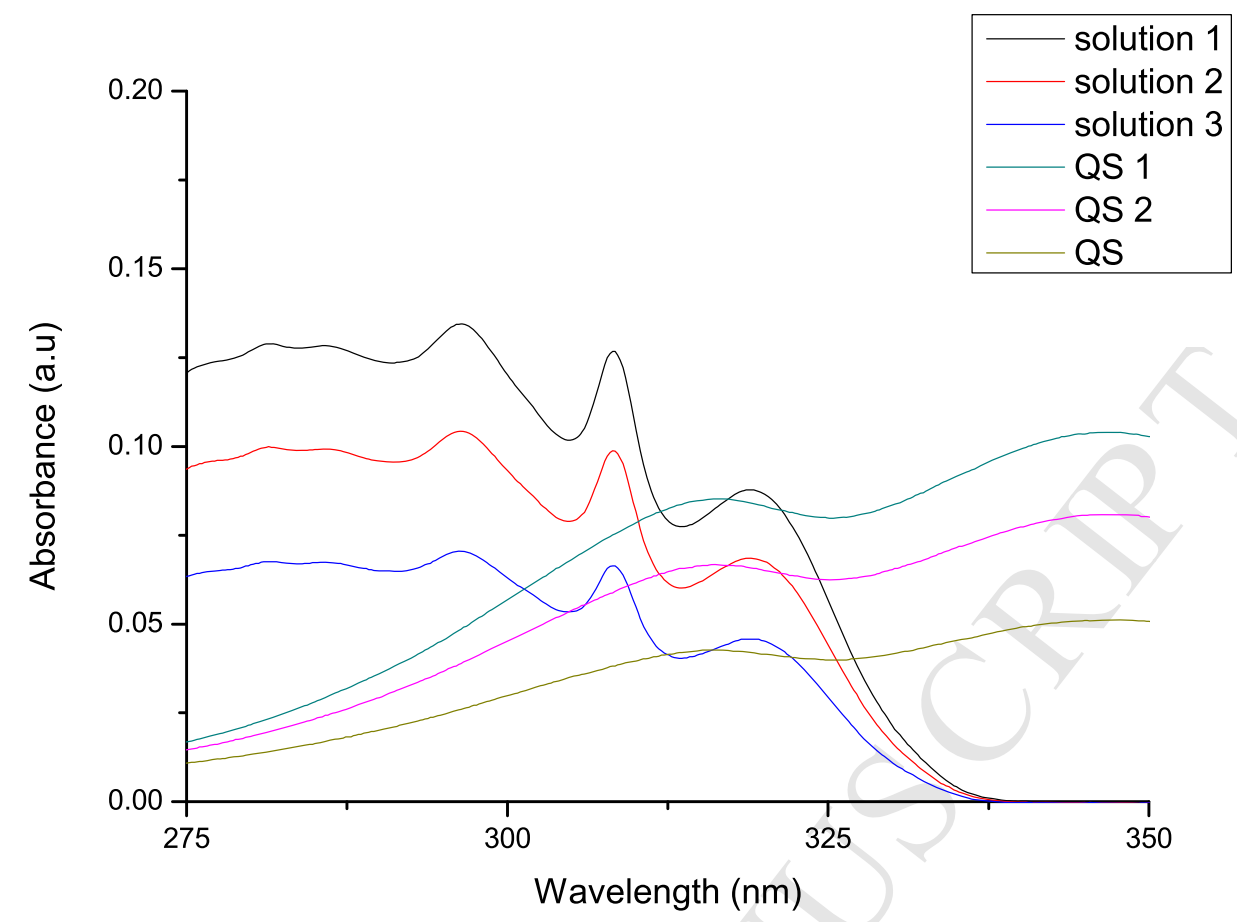

S14 Quantum yield measurements: Absorption of solutions of 2-Ph-SBF in cyclohexane and quinine sulfate (QS) in $\mathrm{H}_{2} \mathrm{SO}_{4} 1 \mathrm{~N}$

Table 4 Quantum yield calculation of 2-Ph-SBF

\begin{tabular}{|c|c|c|c|c|c|c|c|}
\hline Solution & $\lambda(\mathrm{nm})$ & $\mathrm{A}$ & $\mathrm{T}_{\mathrm{S}}$ & $\mathrm{T}_{\mathrm{QS}}$ & $n_{D}{ }^{25}$ (cyclohexane) & $n_{D}{ }^{25}\left(\mathrm{H}_{2} \mathrm{SO}_{4} 1 \mathrm{~N}\right)$ & $\varphi$ \\
\hline 1 & 312 & 0.0815 & 65759.6 & 48449.5 & 1.42662 & 1.3325 & $85 \%$ \\
\hline 2 & 312 & 0.064 & 51316.1 & 37356.8 & 1.42662 & 1.3325 & $86 \%$ \\
\hline 3 & 312.5 & 0.0413 & 36521.4 & 25376.8 & 1.42662 & 1.3325 & $90 \%$ \\
\hline
\end{tabular}




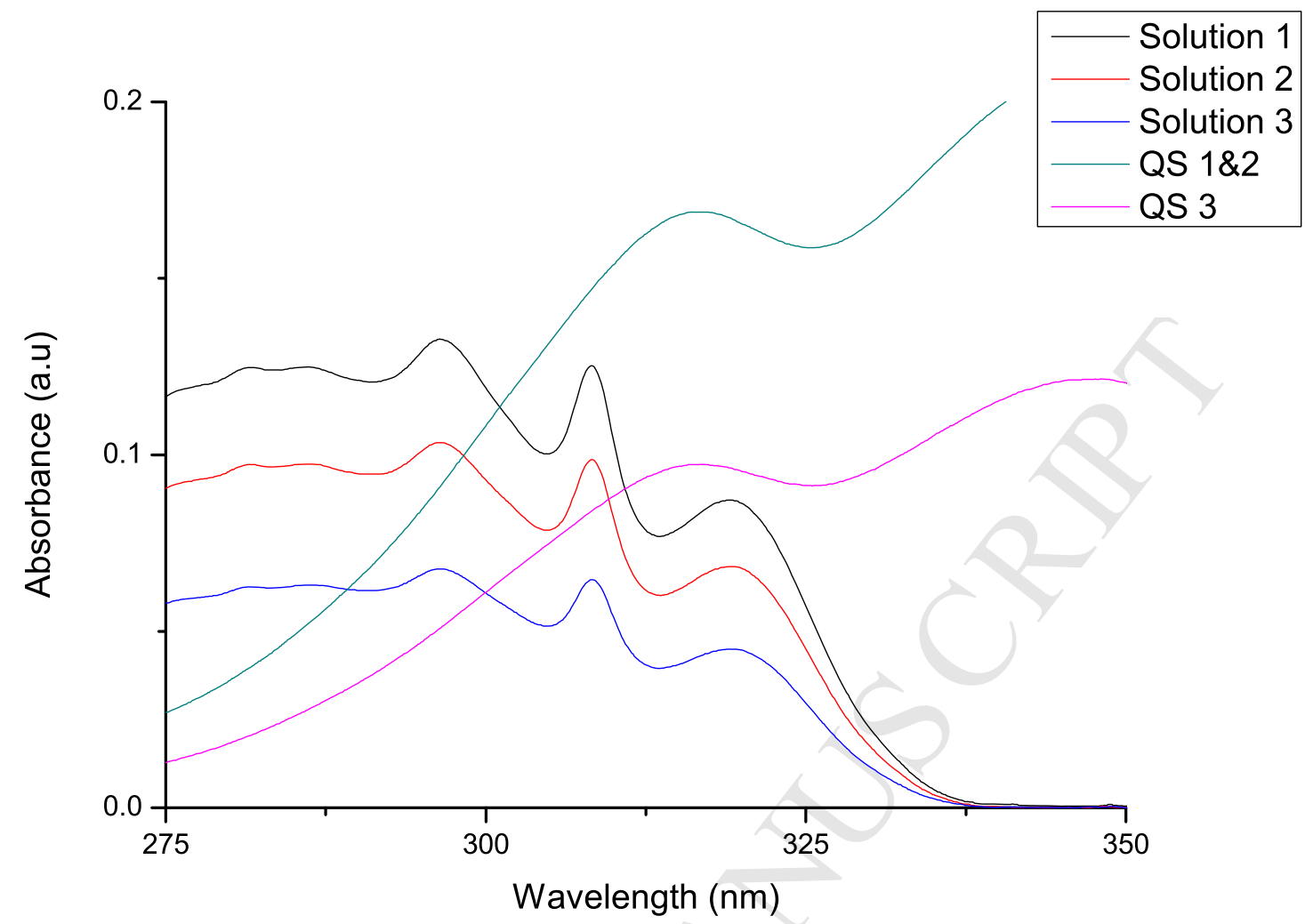

S15 Quantum yield measurements: Absorption of solutions of 2-Ph-SBF in cyclohexane and quinine sulfate (QS) in $\mathrm{H}_{2} \mathrm{SO}_{4} 1 \mathrm{~N}$

Table 5: Quantum yield calculation of 2-Ph-SBF

\begin{tabular}{|c|c|c|c|c|c|c|c|}
\hline Solution & $\begin{array}{c}\lambda \\
(\mathrm{nm})\end{array}$ & $\mathrm{A}$ & $\mathrm{T}_{\mathrm{S}}$ & $\mathrm{T}_{\mathrm{QS}}$ & $n_{D}{ }^{25}$ (cyclohexane) & $n_{D}{ }^{25}\left(\mathrm{H}_{2} \mathrm{SO}_{4} 1 \mathrm{~N}\right)$ & $\varphi$ \\
\hline 1 & 301 & 0.113 & 119399 & 95186.3 & 1.42662 & 1.3325 & $79 \%$ \\
\hline 2 & 299 & 0.100 & 96821.3 & 77070.8 & 1.42662 & 1.3325 & $79 \%$ \\
\hline 3 & 300 & 0.061 & 73910.6 & 57692.5 & 1.42662 & 1.3325 & $80 \%$ \\
\hline
\end{tabular}




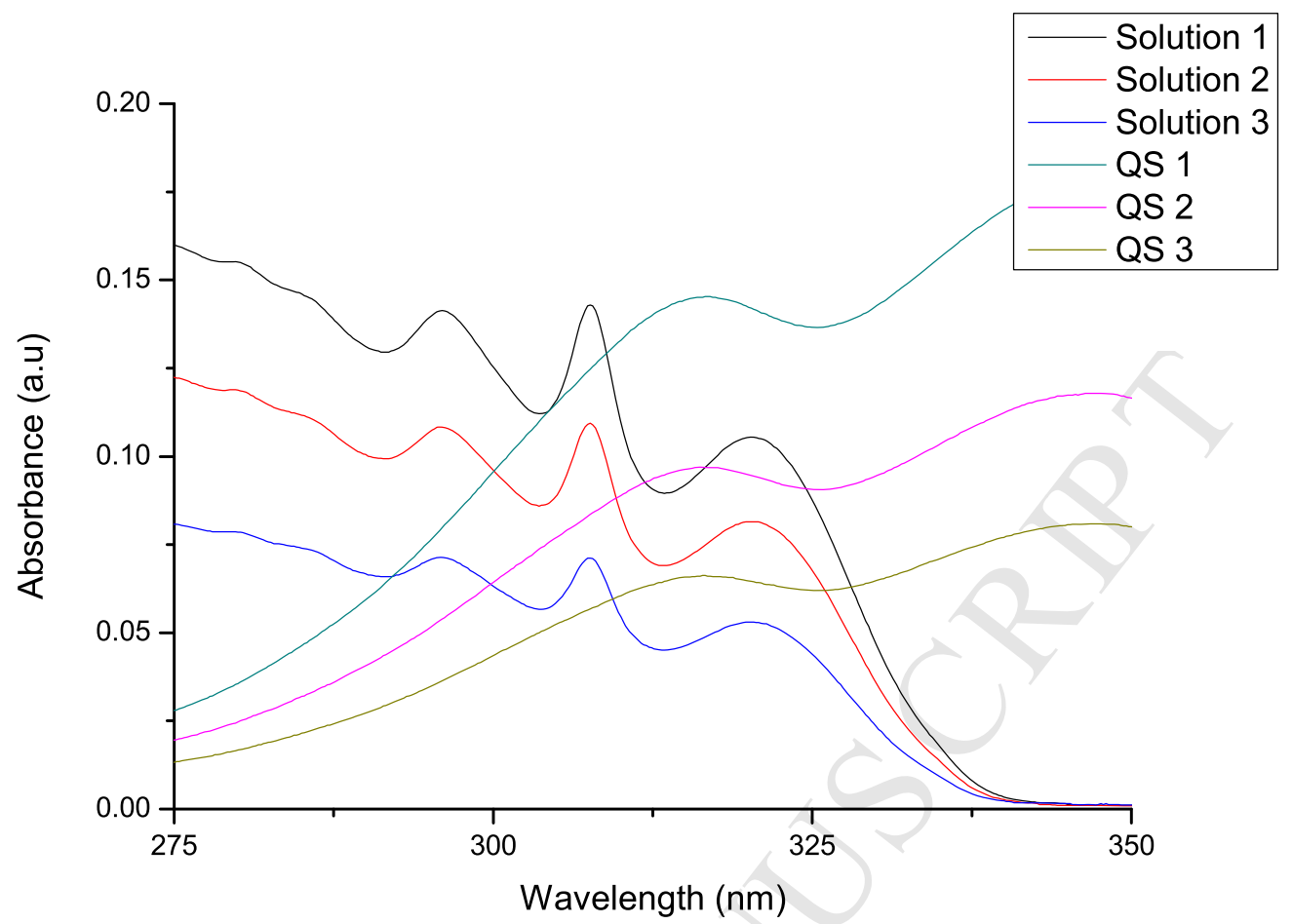

S16 Quantum yield measurements: Absorption of solutions of 2-5Pm-SBF in cyclohexane and quinine sulfate (QS) in $\mathrm{H}_{2} \mathrm{SO}_{4} 1 \mathrm{~N}$

Table 6 Quantum yield calculation of 2-5Pm-SBF

\begin{tabular}{|c|c|c|c|c|c|c|c|}
\hline Solution & $\lambda(\mathrm{nm})$ & $\mathrm{A}$ & $\mathrm{T}_{\mathrm{S}}$ & $\mathrm{T}_{\mathrm{QS}}$ & $n_{D}^{25}$ (cyclohexane) & $n_{D}^{25}\left(\mathrm{H}_{2} \mathrm{SO}_{4} 1 \mathrm{~N}\right)$ & $\varphi$ \\
\hline 1 & 309 & 0.129 & 10082.1 & 240980 & 1.42662 & 1.3325 & $3 \%$ \\
\hline 2 & 309.5 & 0.0881 & 6580.11 & 176643 & 1.42662 & 1.3325 & $2 \%$ \\
\hline 3 & 309.5 & 0.0593 & 5162.04 & 134942 & 1.42662 & 1.3325 & $2 \%$ \\
\hline
\end{tabular}




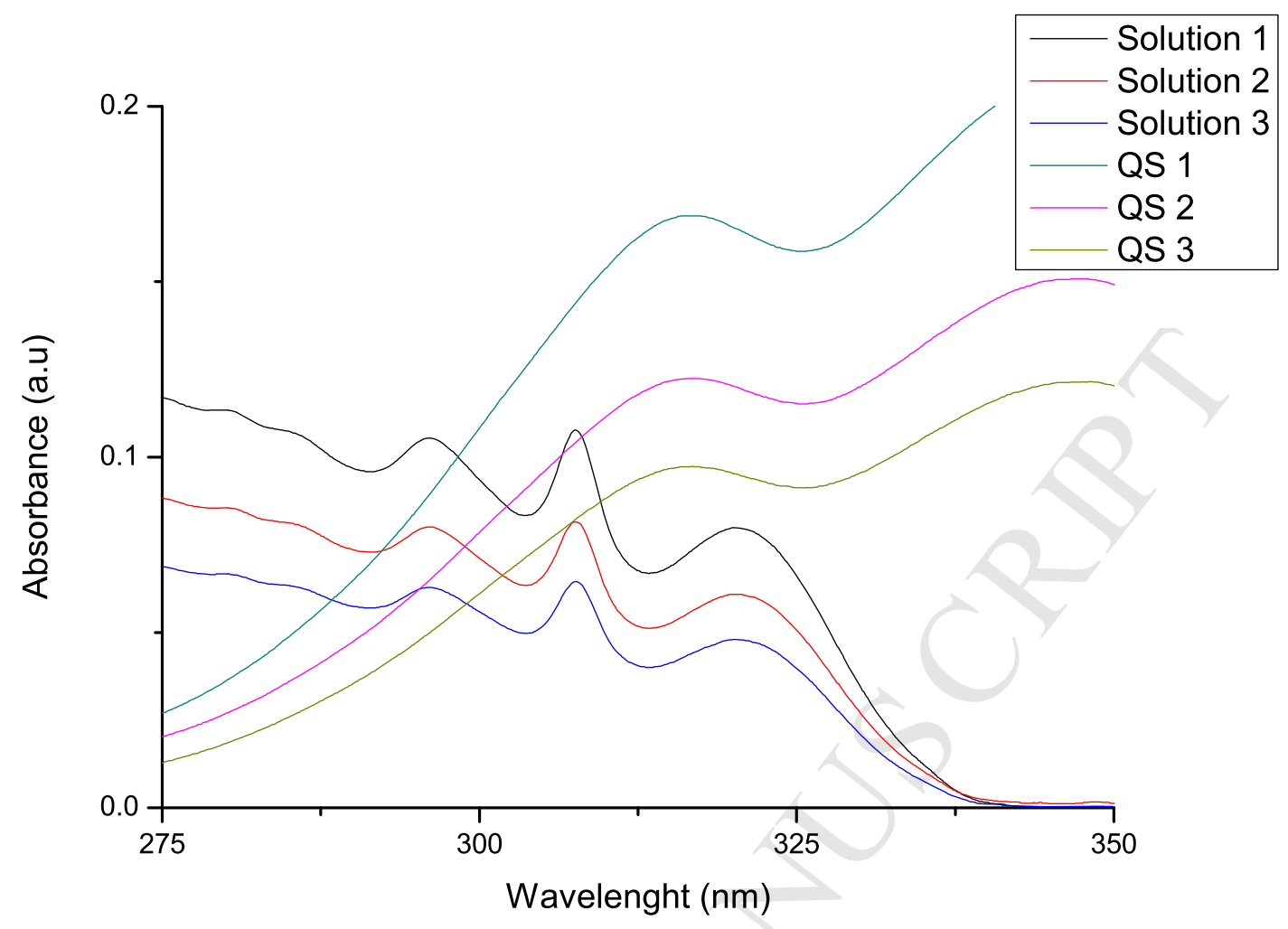

S1 Quantum yield measurements: Absorption of solutions of 2-5Pm-SBF in cyclohexane and quinine sulfate (QS) in $\mathrm{H}_{2} \mathrm{SO}_{4} 1 \mathrm{~N}$

Table 7 Quantum yield calculation of 2-5Pm-SBF

\begin{tabular}{|c|c|c|c|c|c|c|c|}
\hline Solution & $\lambda(\mathrm{nm})$ & $\mathrm{A}$ & $\mathrm{T}_{\mathrm{S}}$ & $\mathrm{T}_{\mathrm{QS}}$ & $n_{D}{ }^{25}$ (cyclohexane) & $n_{D}{ }^{25}\left(\mathrm{H}_{2} \mathrm{SO}_{4} 1 \mathrm{~N}\right)$ & $\varphi$ \\
\hline 1 & 299 & 0.100 & 2965.74 & 77070.8 & 1.42662 & 1.3325 & $2 \%$ \\
\hline 2 & 299 & 0.074 & 2565.15 & 63262.2 & 1.42662 & 1.3325 & $3 \%$ \\
\hline 3 & 299 & 0.058 & 2084.54 & 52110.2 & 1.42662 & 1.3325 & $3 \%$ \\
\hline
\end{tabular}


THEORETICAL MODELING

Predicted UV-vis Spectra from TD-DFT energy calculations

SBF

\section{4-Ph-SBF}

\section{4-5Pm-SBF}
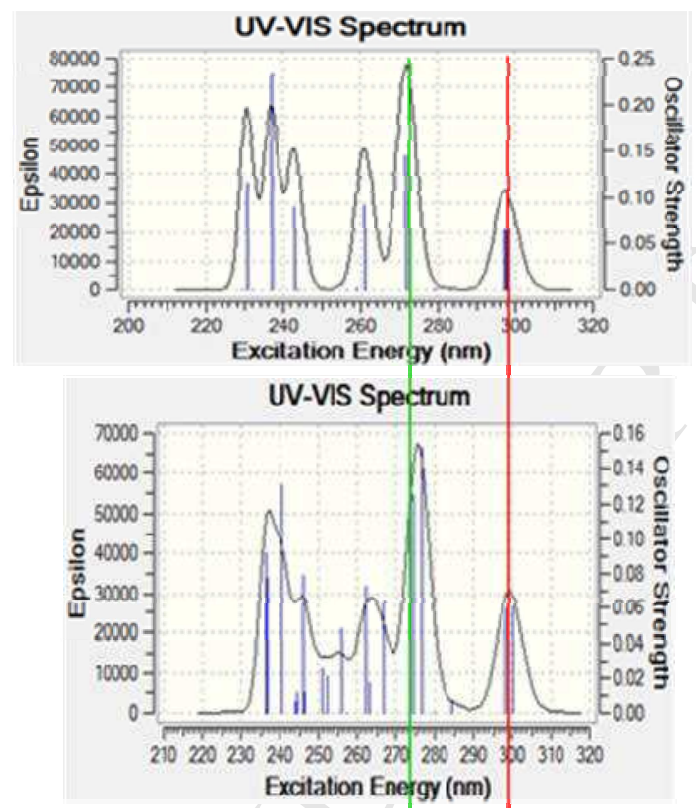

UV-VIS Spectrum
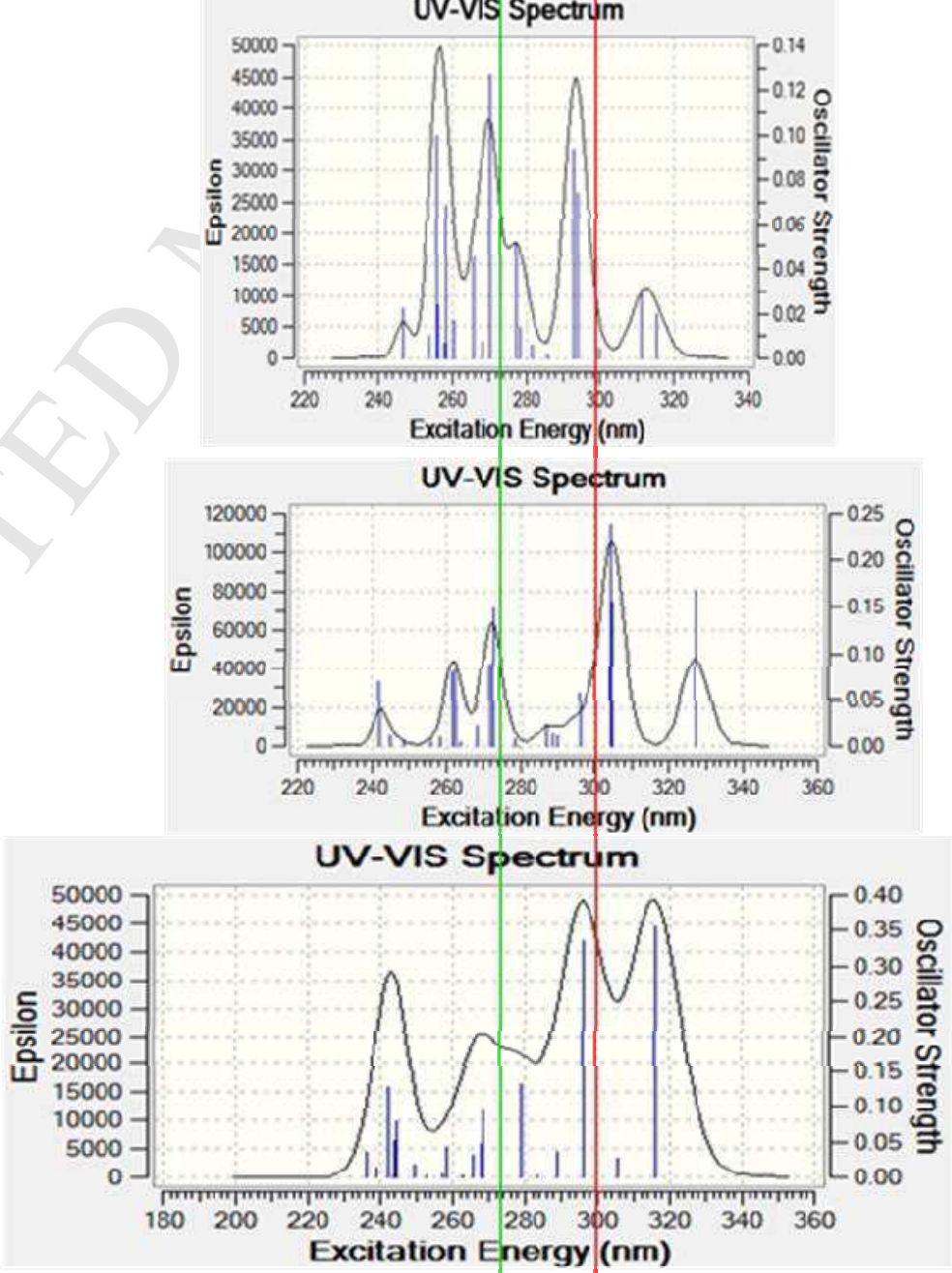

2-5Pm-SBF

2-Ph-SBF 


\section{SBF}
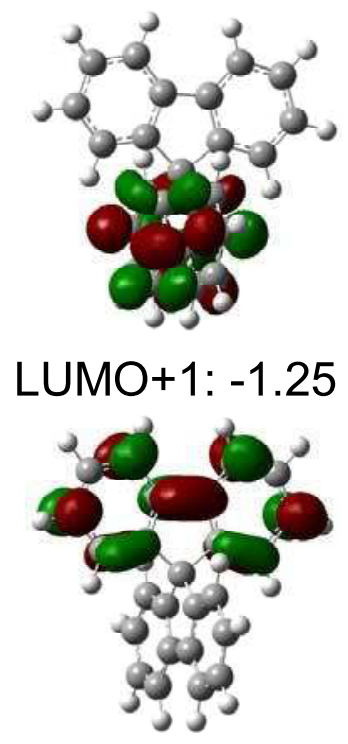

LUMO: $-1.25 \mathrm{eV}$

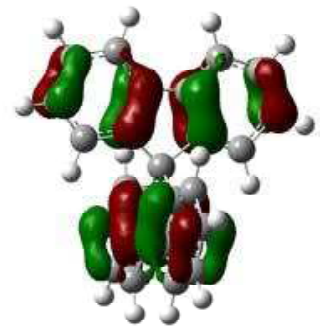

HOMO: $-5.99 \mathrm{eV}$

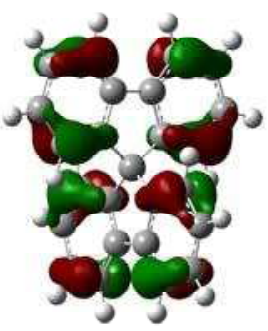

HOMO-2: -6.79 eV

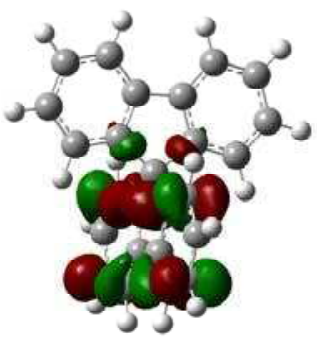

LUMO+2: -0.84 eV

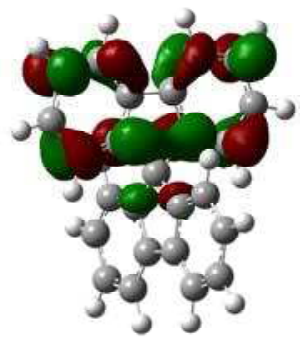

LUMO+3: -0.84 eV
Excited state 1

$\lambda: 297.6 \mathrm{~nm}$

f: 0.064

Excited state 2

$\lambda: 297.59 \mathrm{~nm}$

f: 0.064

Excited states 3 and 4

f: 0

Excited state 5

$\lambda: 271.95 \mathrm{~nm}$

f: 0.1449

Excited state 6

$\lambda: 271.95 \mathrm{~nm}$

f: 0.1449

Excited state 7

$\lambda: 261.09 \mathrm{~nm}$

f: 0.0905

Excited state 8

$\lambda: 261.09 \mathrm{~nm}$

f: 0.0906

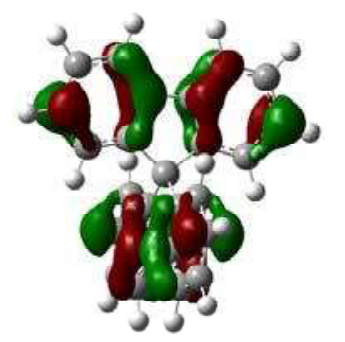

HOMO-1: $-6.26 \mathrm{eV}$

S 3 Calculated frontier molecular orbitals by DFT and the 6th first calculated electronic transitions by TD-DFT of SBF, after geometry optimization with DFT B3LYP/6-311G+(d,p), show with an isovalue of 0.04 


\section{4-Ph-SBF}

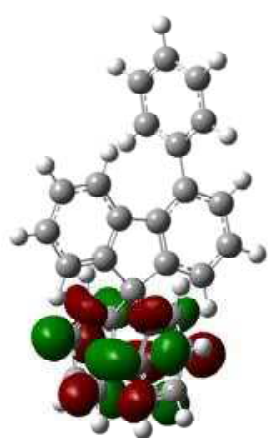

LUMO+1: -1.24 eV

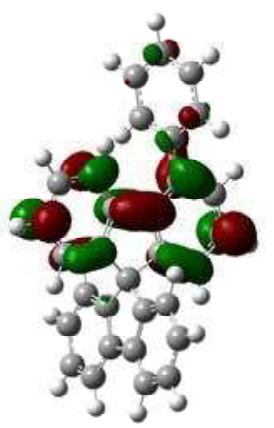

LUMO: $-1.27 \mathrm{eV}$

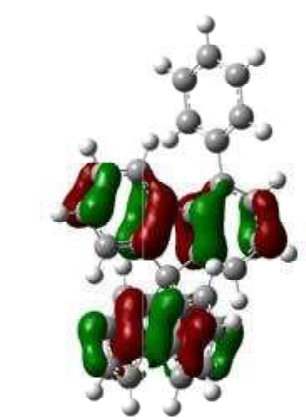

HOMO: $-5.97 \mathrm{eV}$

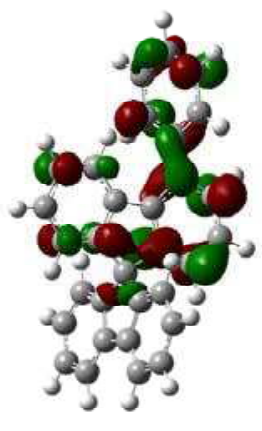

LUMO+2: -0.94 eV

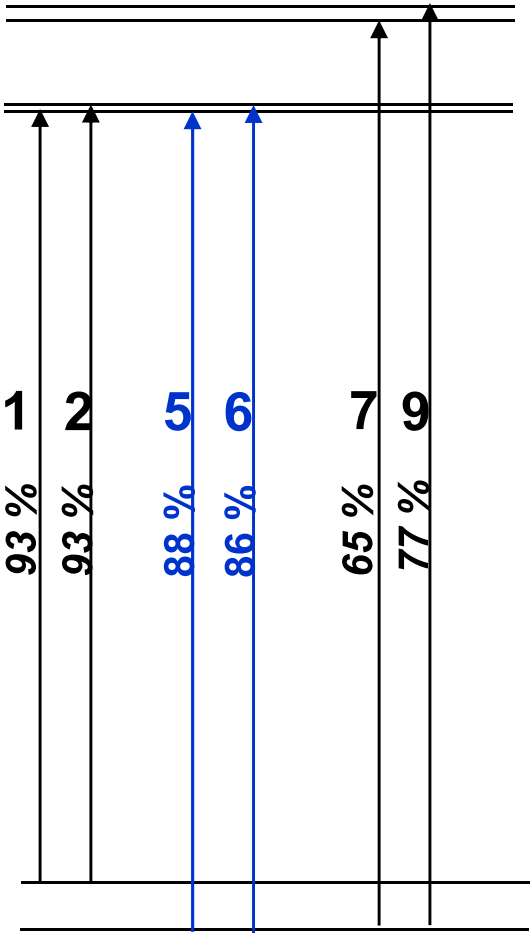

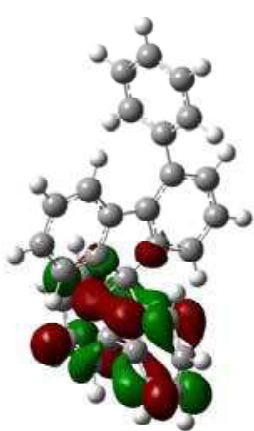

LUMO+3: $-0.84 \mathrm{eV}$

Excited state 1

$\lambda: 300.25 \mathrm{~nm}$

f: 0.06

Excited state 2

$\lambda: 298.49 \mathrm{~nm}$

f: 0.059

Excited states 3 and 4

f: 0

Excited state 5

$\lambda: 276.78 \mathrm{~nm}$

f: 0.1519

Excited state 6

$\lambda: 274.41 \mathrm{~nm}$

f: 0.1249

Excited state 7

$\lambda: 266.68 \mathrm{~nm}$

f: 0.06

Excited state 8

f: 0

Excited state 9

$\lambda: 263.08 \mathrm{~nm}$

f: 0.01

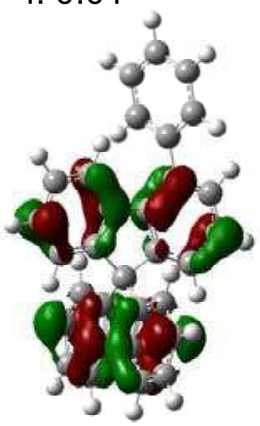

HOMO-1: -6.25 eV

S 4 Calculated frontier molecular orbitals by DFT and the 6 th first calculated electronic transitions by TD-DFT of 4-Ph-SBF, after geometry optimization with DFT B3LYP/6-311G+(d,p), show with an isovalue of 0.04 


\section{4-5Pm-SBF}

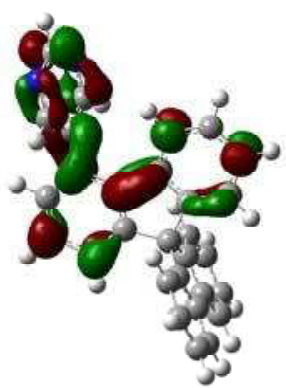

LUMO+1: -1.645 eV

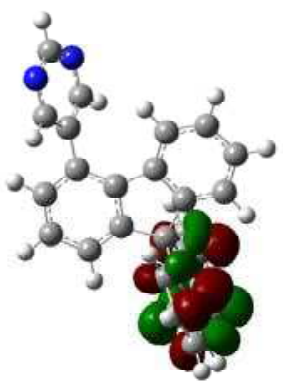

LUMO+2: -1.38 eV

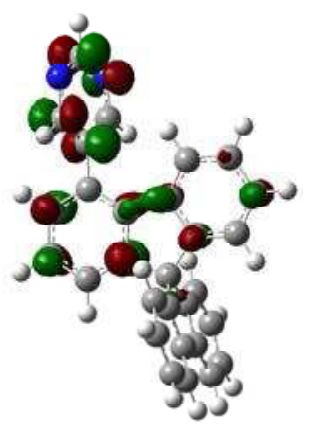

LUMO+3: -1.18 eV

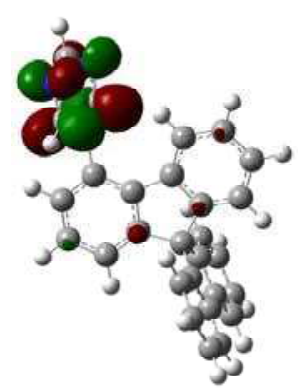

LUMO: $-1.65 \mathrm{eV}$

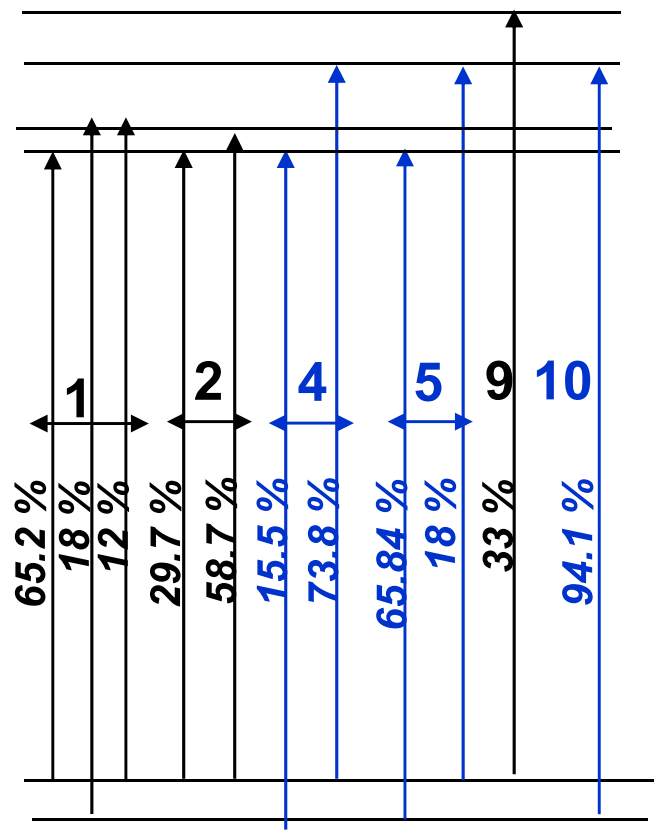

Excited state 1 $\lambda: 315.225 \mathrm{~nm}$

f: 0.0198

Excited state 2 $\lambda: 311.07 \mathrm{~nm}$ f: 0.0303

Excited state 4 $\lambda: 293.96 \mathrm{~nm}$ f: 0.0744

Excited state 5

$\lambda: 292.97 \mathrm{~nm}$

f: 0.0937

Excited state 9

$\lambda: 277.29 \mathrm{~nm}$

f: 0.0513

Excited state 10

$\lambda: 270.34 \mathrm{~nm}$

f: 0.1271

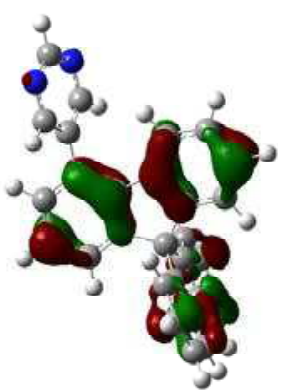

HOMO-1: -6.25 eV

S 5 Calculated frontier molecular orbitals by DFT and the 6th first calculated electronic transitions by TD-DFT of 4-5Pm-SBF, after geometry optimization with DFT B3LYP/6-311G+(d,p), show with an isovalue of 0.04 


\section{2-Ph-SBF}
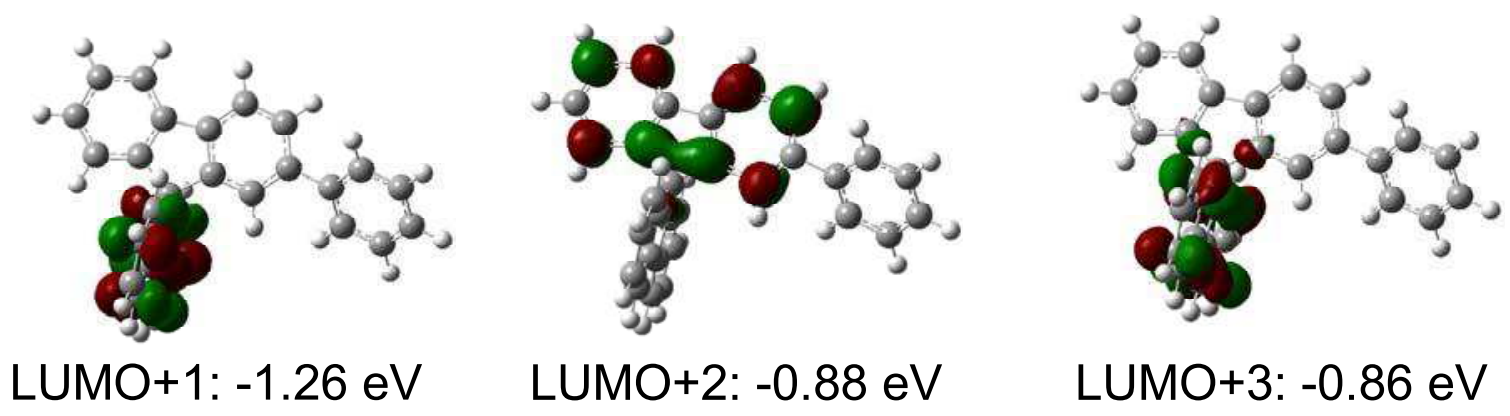

LUMO+2: -0.88 eV

LUMO+3: -0.86 eV

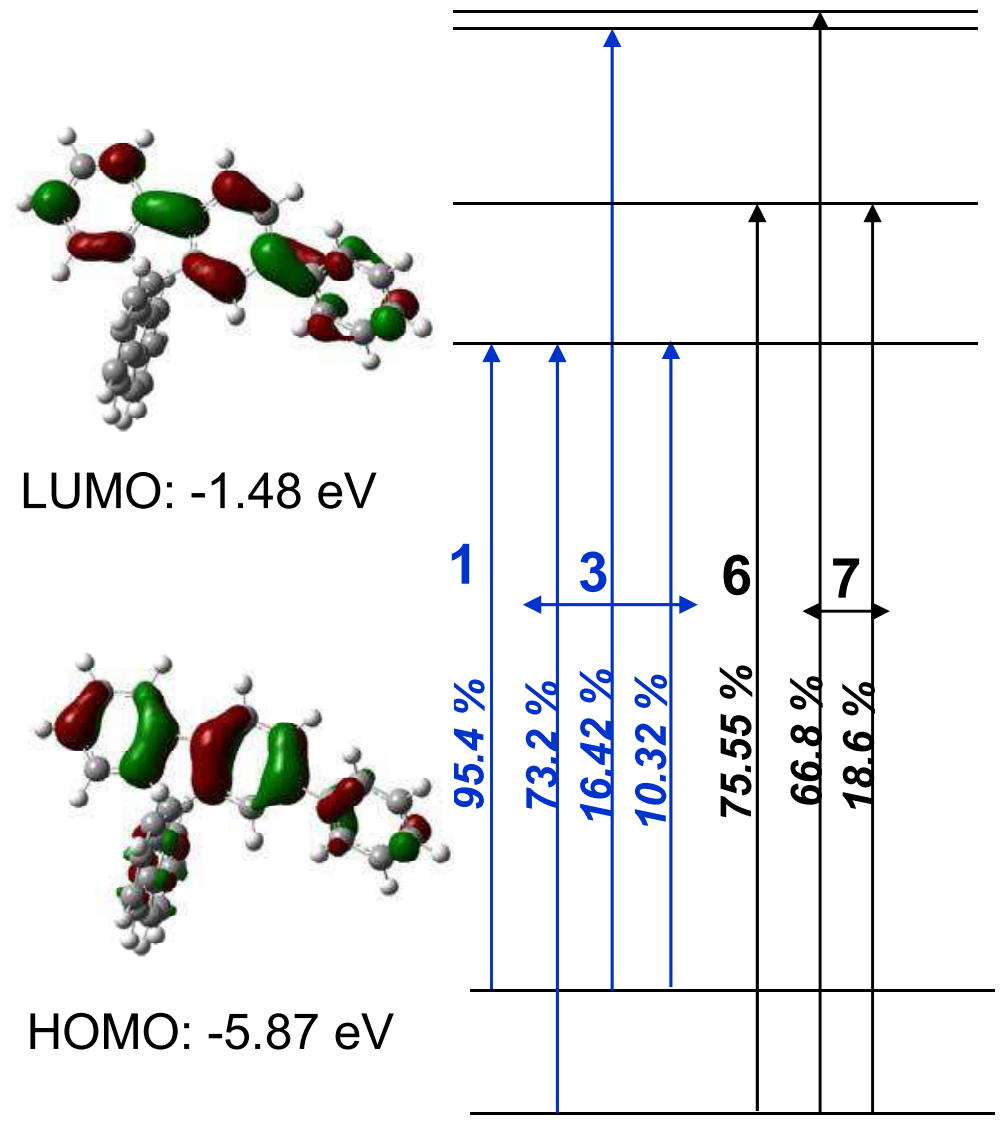

\section{Excited state 1}

$\lambda: 315.93 \mathrm{~nm}$

f: 0.3552

Excited state 3

$\lambda: 295.96 \mathrm{~nm}$

f: 0.3346

Excited state 6

$\lambda: 278.70 \mathrm{~nm}$

f: 0.1324

Excited state 7

$\lambda: 268.32 \mathrm{~nm}$

f: 0.0941

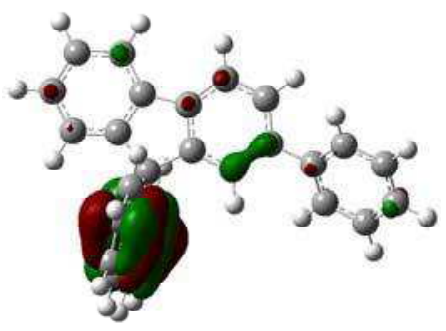

HOMO-1: -6.17 eV

$\underline{\mathbf{S} 22}$ Calculated frontier molecular orbitals by DFT and the 6th first calculated electronic transitions by TD-DFT of 2-Ph-SBF, after geometry optimization with DFT B3LYP/6-311G+(d,p), show with an isovalue of 0.04 


\section{2-5Pm-SBF}
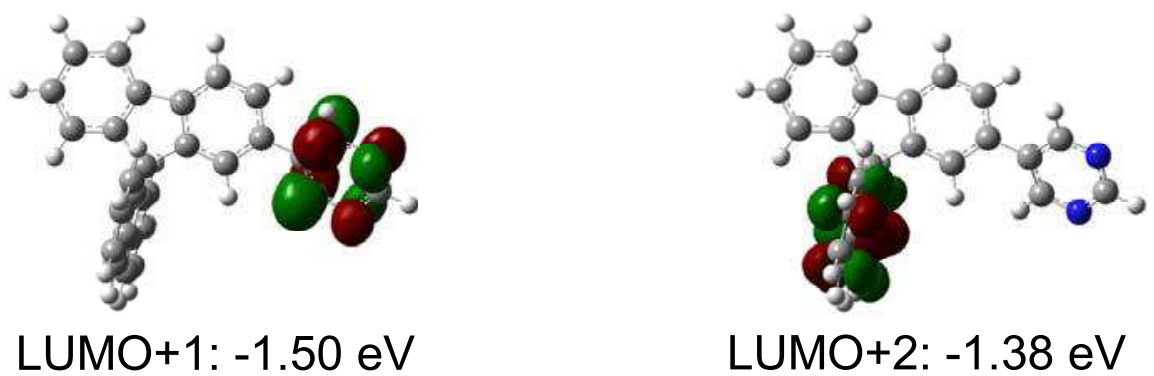

LUMO+2: $-1.38 \mathrm{eV}$
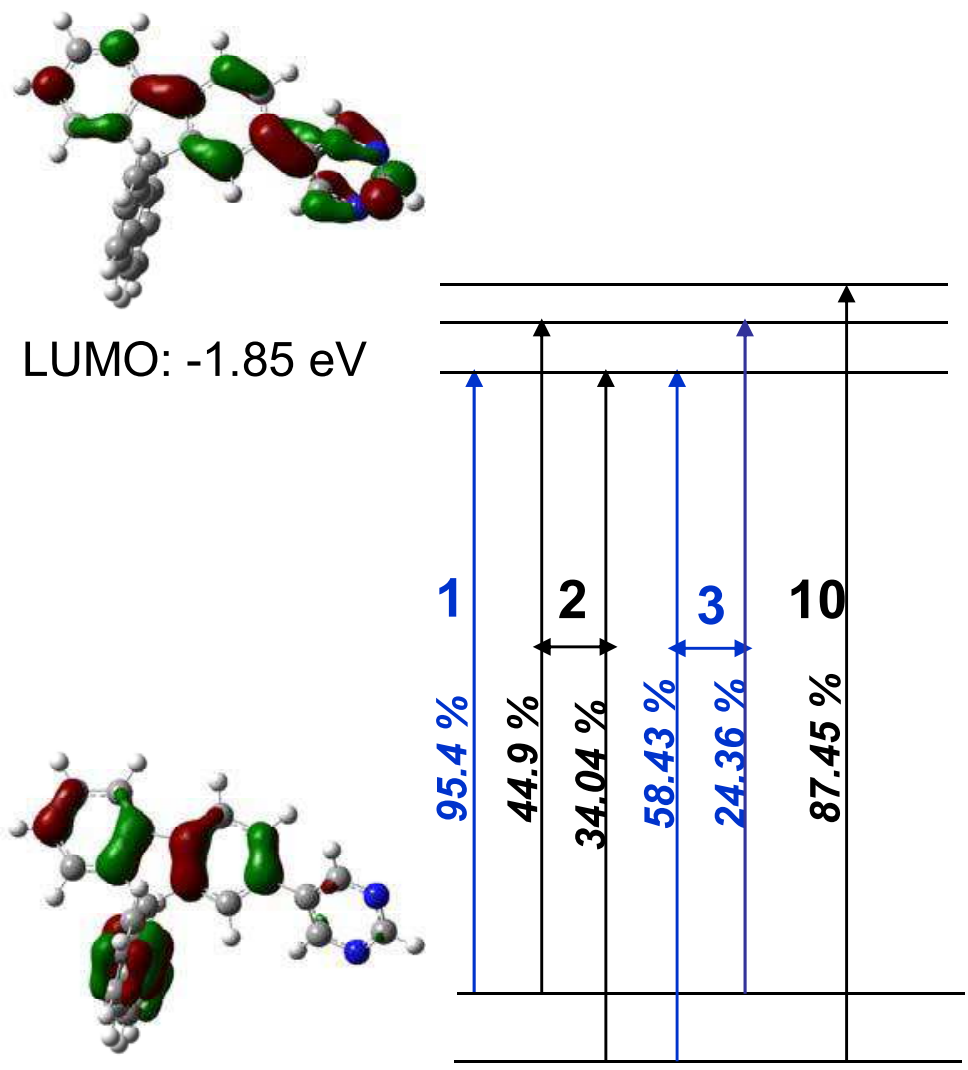

Excited state 1

$\lambda: 327.18 \mathrm{~nm}$

f: 0.1677

Excited state 2

$\lambda: 304.91 \mathrm{~nm}$

LUMO: -1.85 eV

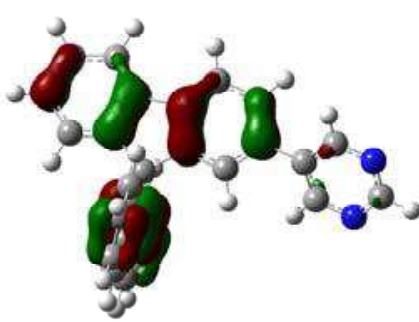

HOMO: $-6.13 \mathrm{eV}$

f: 0.1553

Excited state 3

$\lambda: 304.41 \mathrm{~nm}$

f: 0.239

Excited state 10

$\lambda: 272.97 \mathrm{~nm}$

f: 0.1497

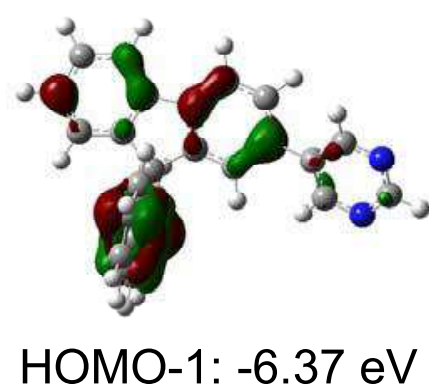

S 23 Calculated frontier molecular orbitals by DFT and the 6th first calculated electronic transitions by TD-DFT of 2-5Pm-SBF, after geometry optimization with DFT B3LYP/6-311G+(d,p), show with an isovalue of 0.04 


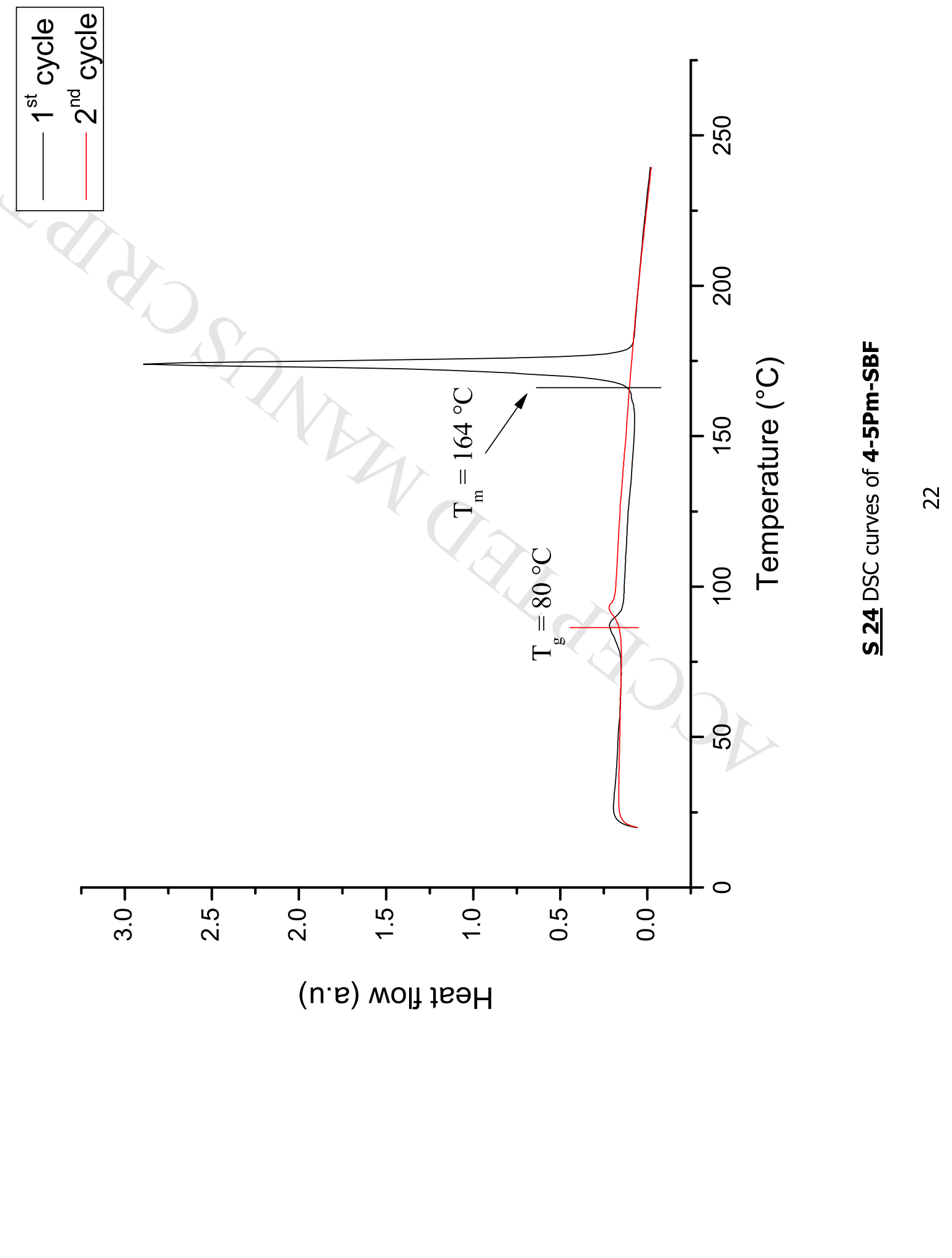




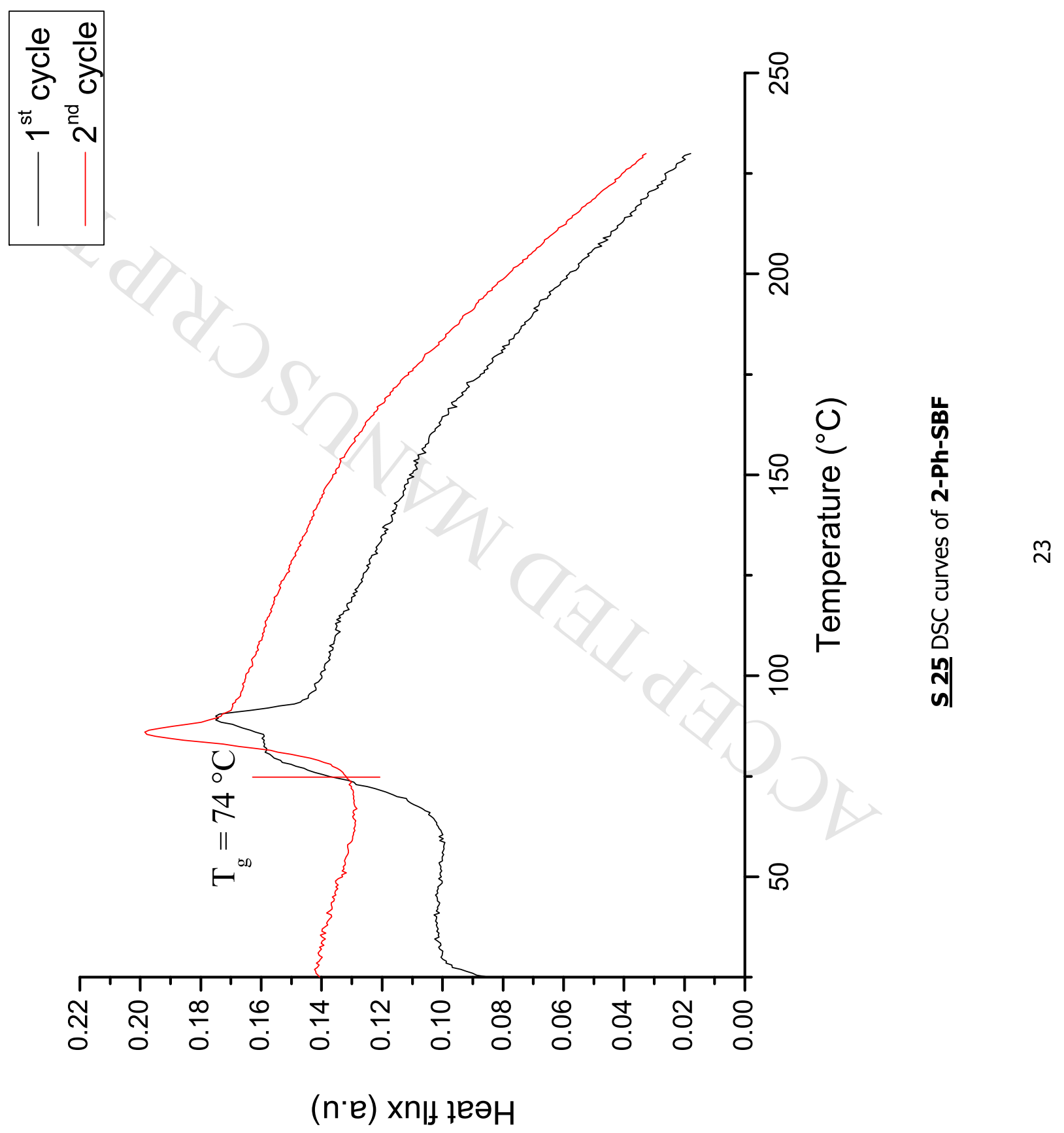




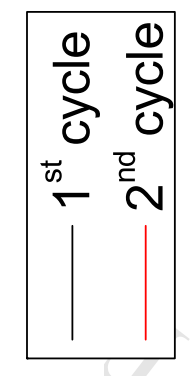

뉴ำ

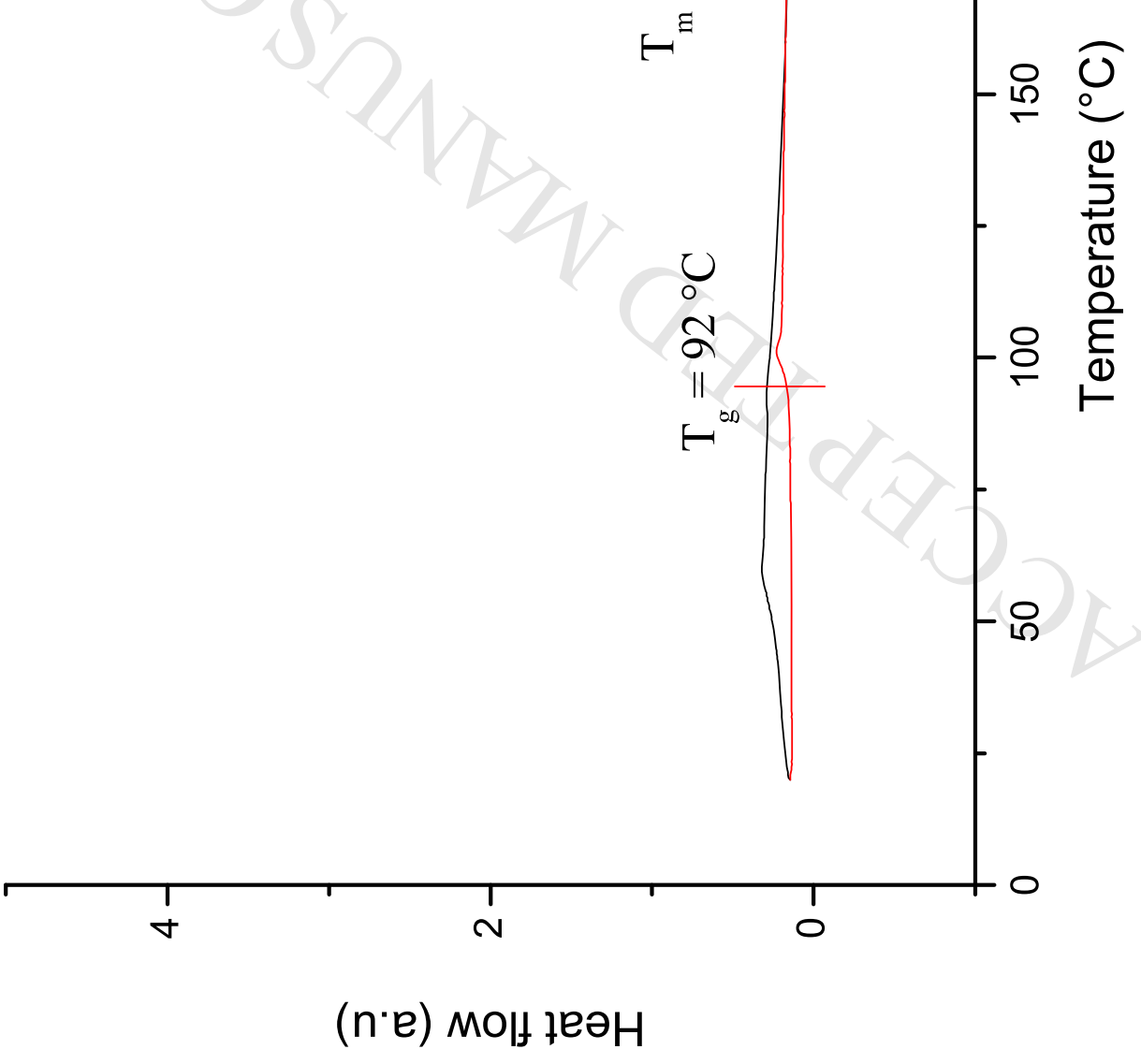

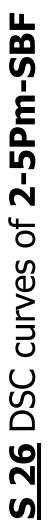




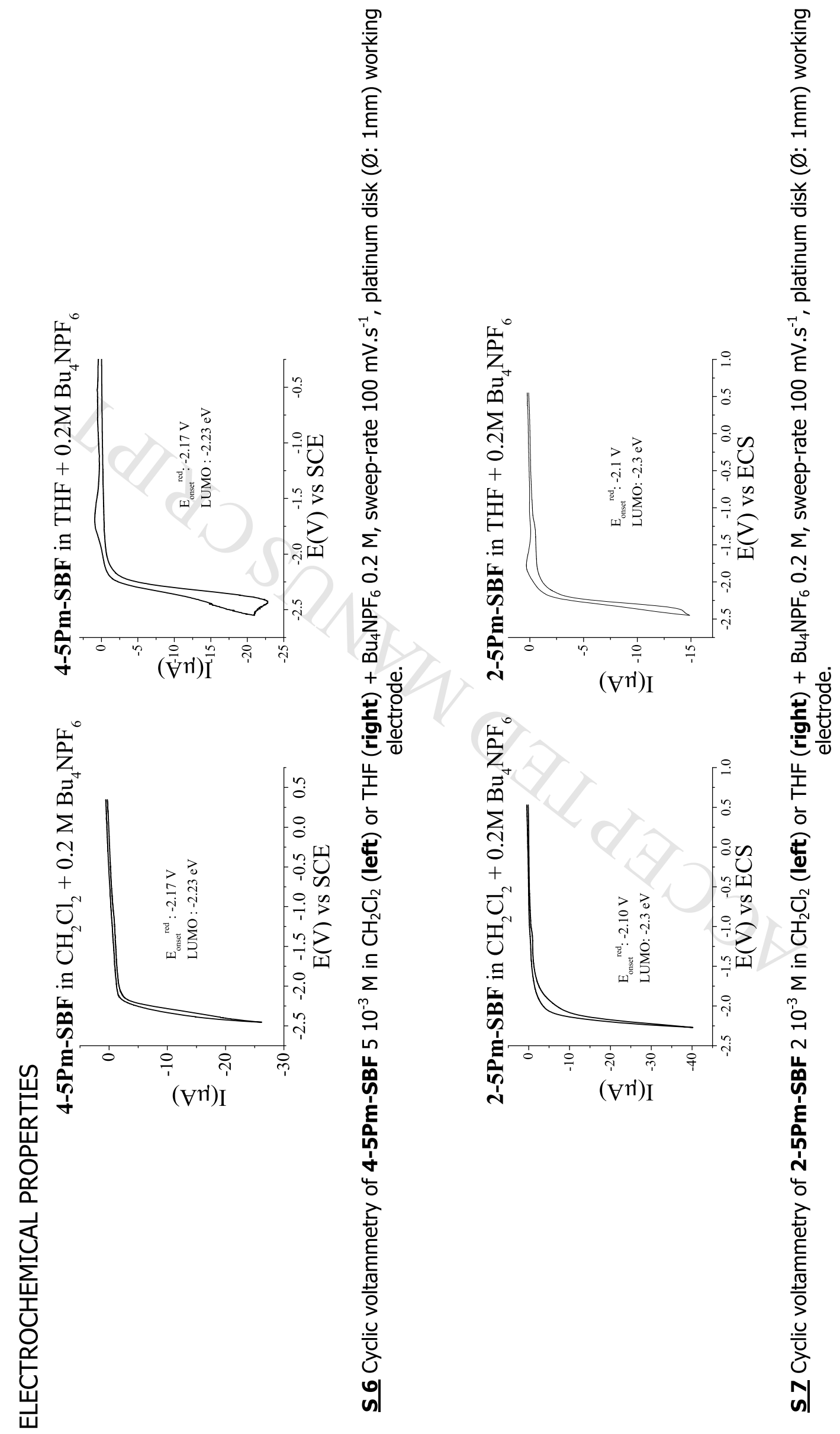




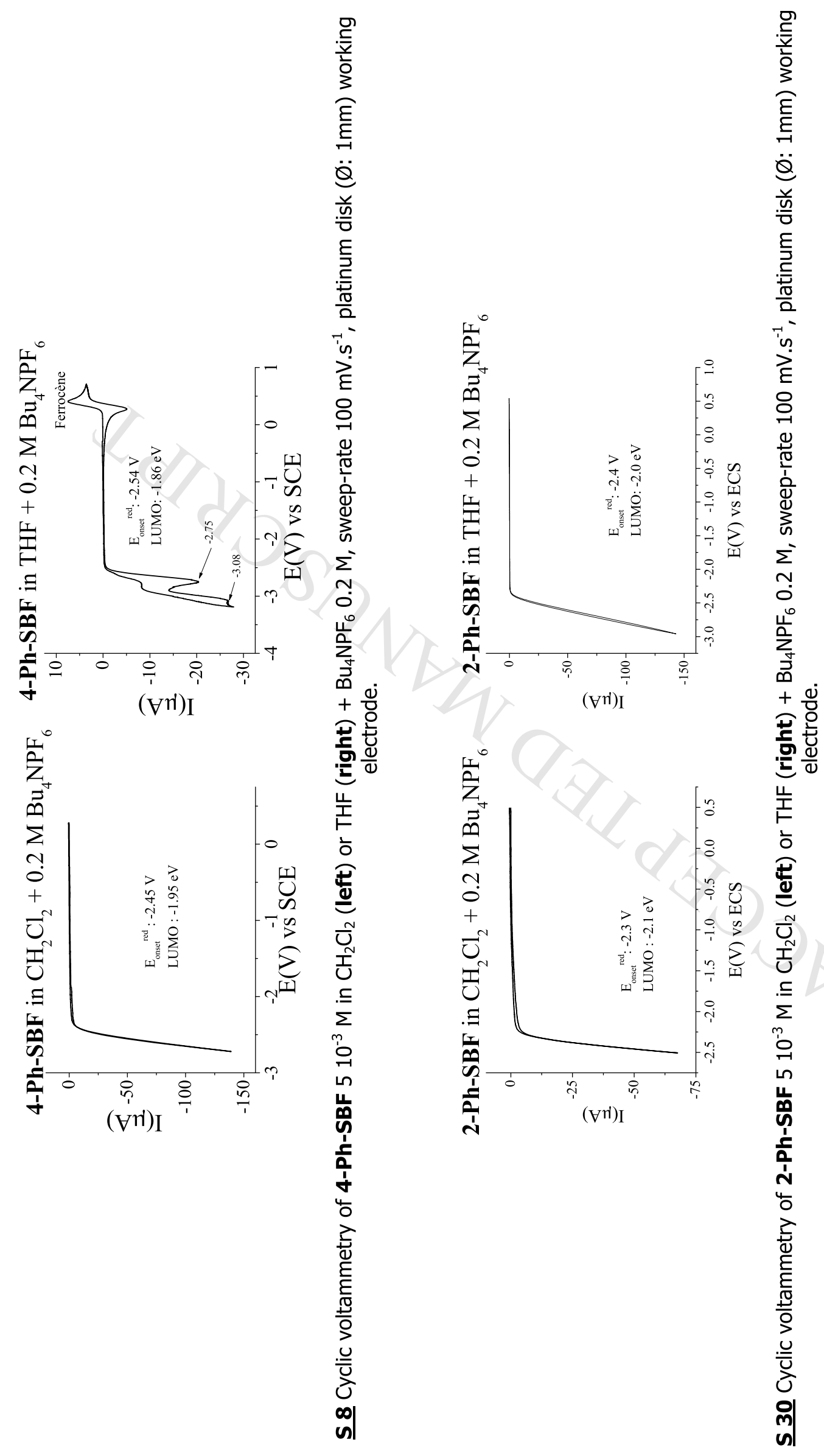



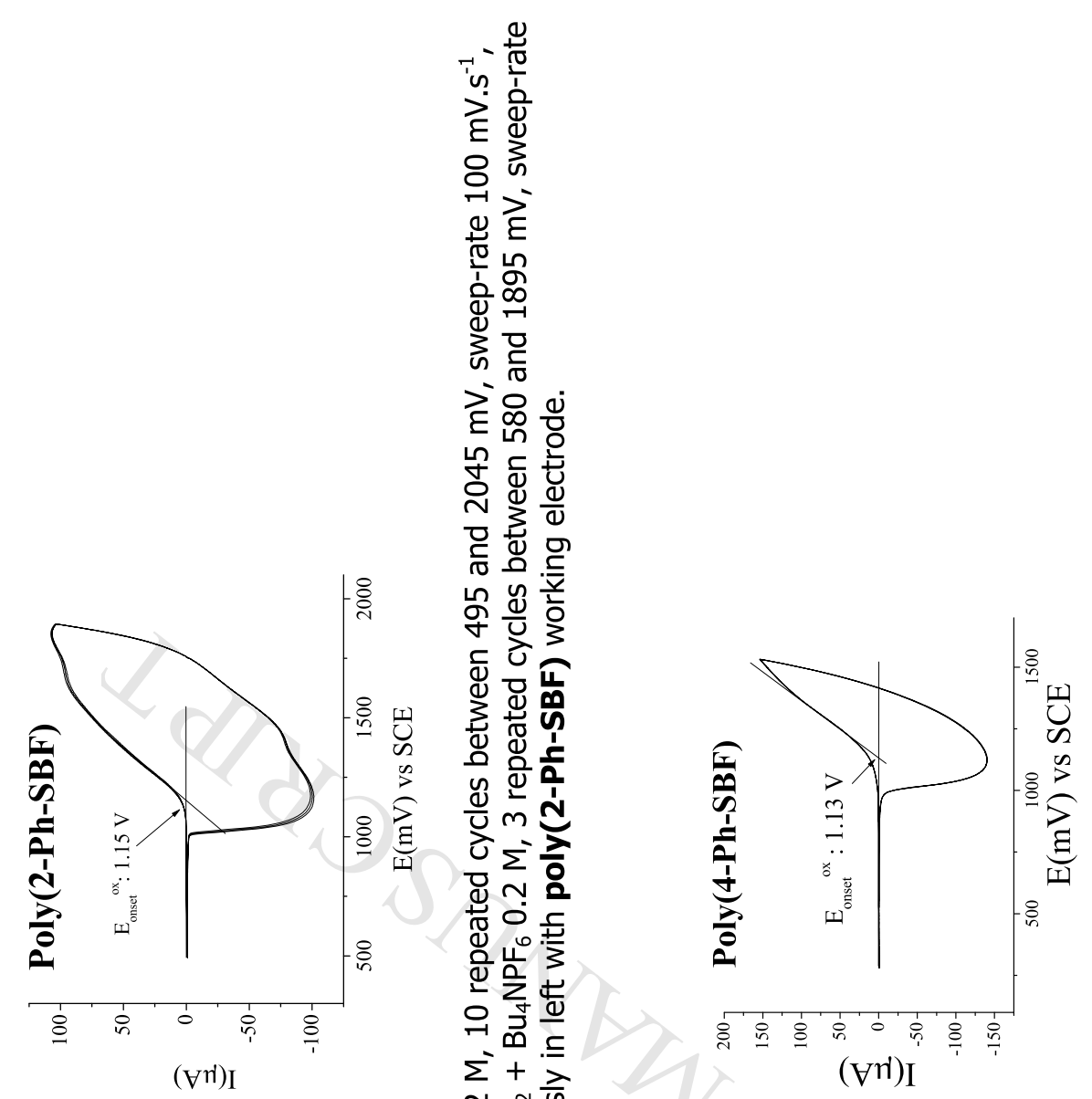

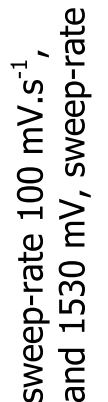

ㄱㅇㅇ 융

노웛

둥

त̄

원인

ఖ

苋荝

䢔

원흔

ปั

这文

区웅

닌눙

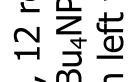

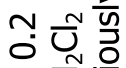

นᄂ
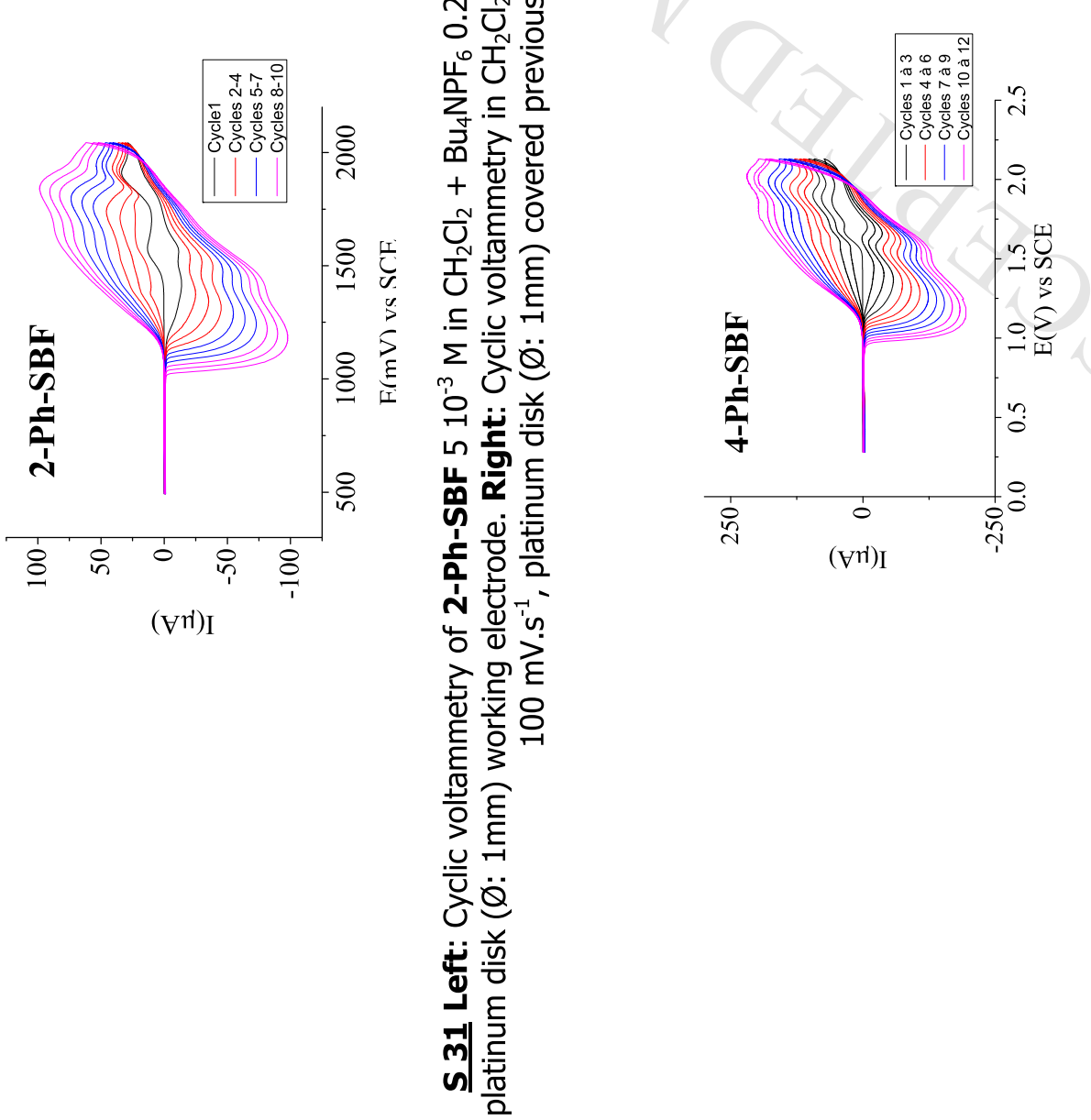

$\sum^{2}+\frac{\lambda}{v}$

능 ज

นㄴํㄴ원

$\lesssim$

$\sum_{0} \leq \frac{1}{2}$

0 잉

+ ए

Nㅡㅇ

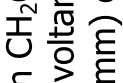




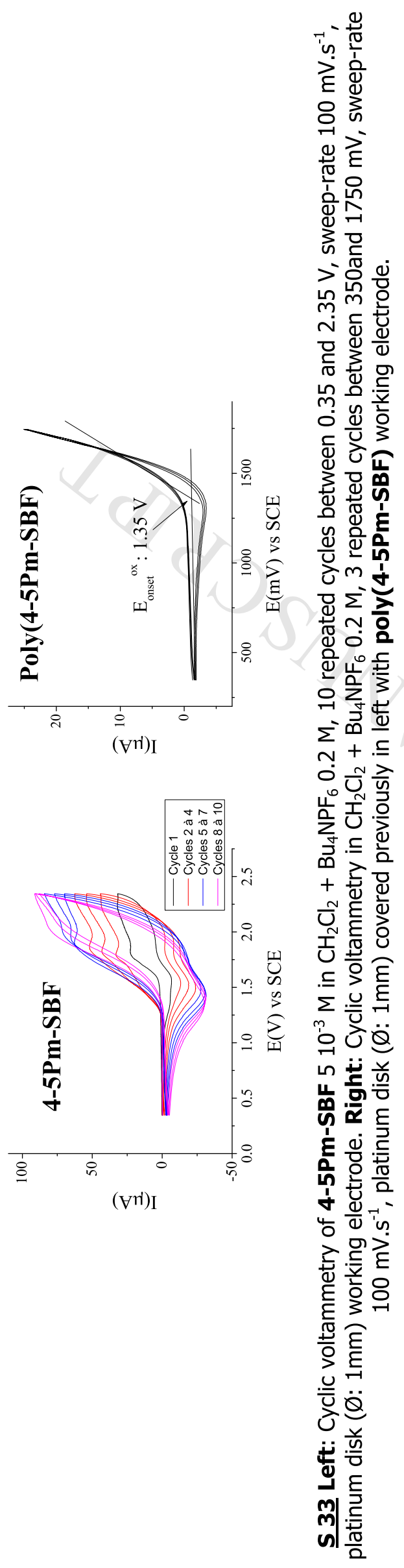




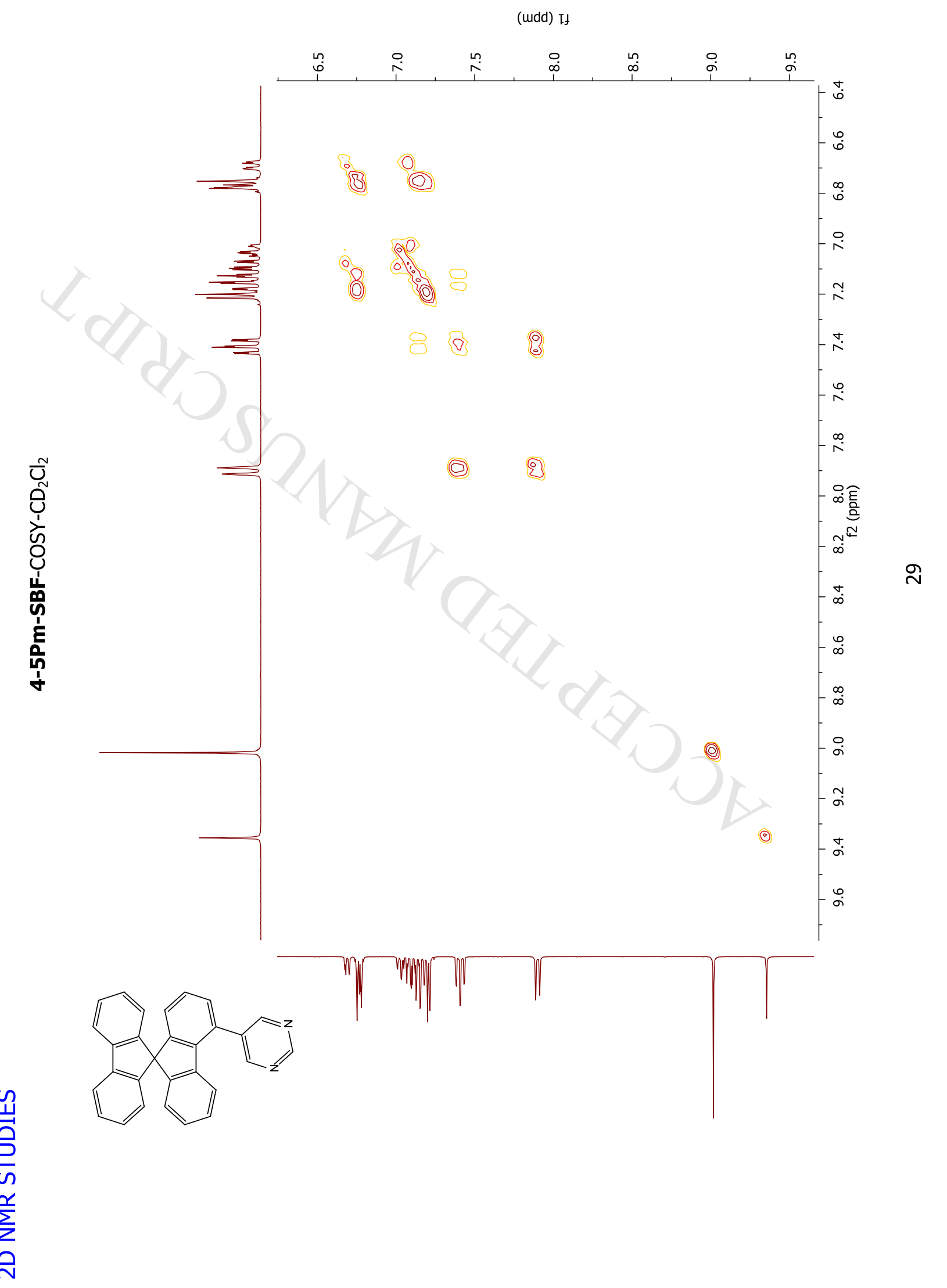




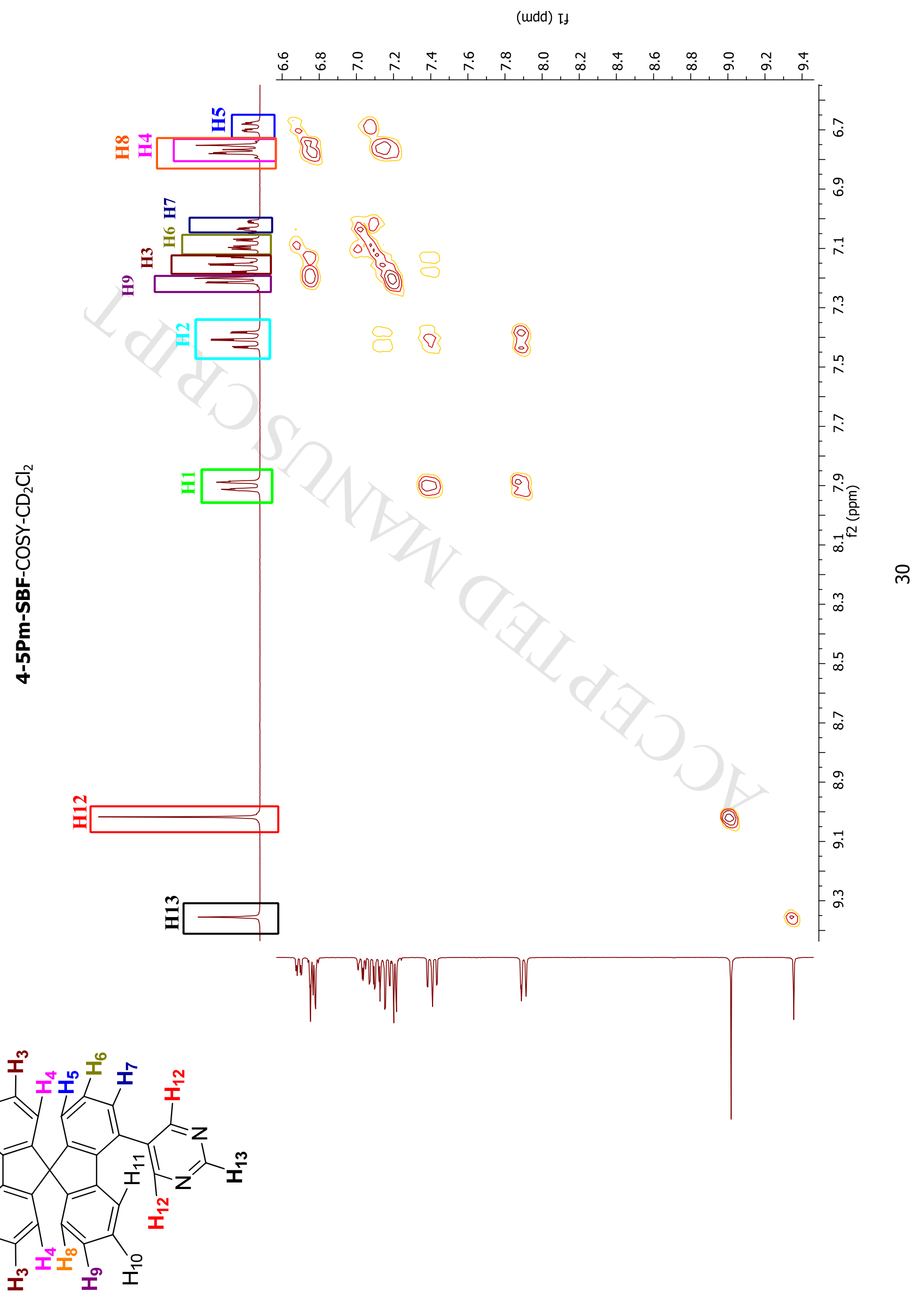




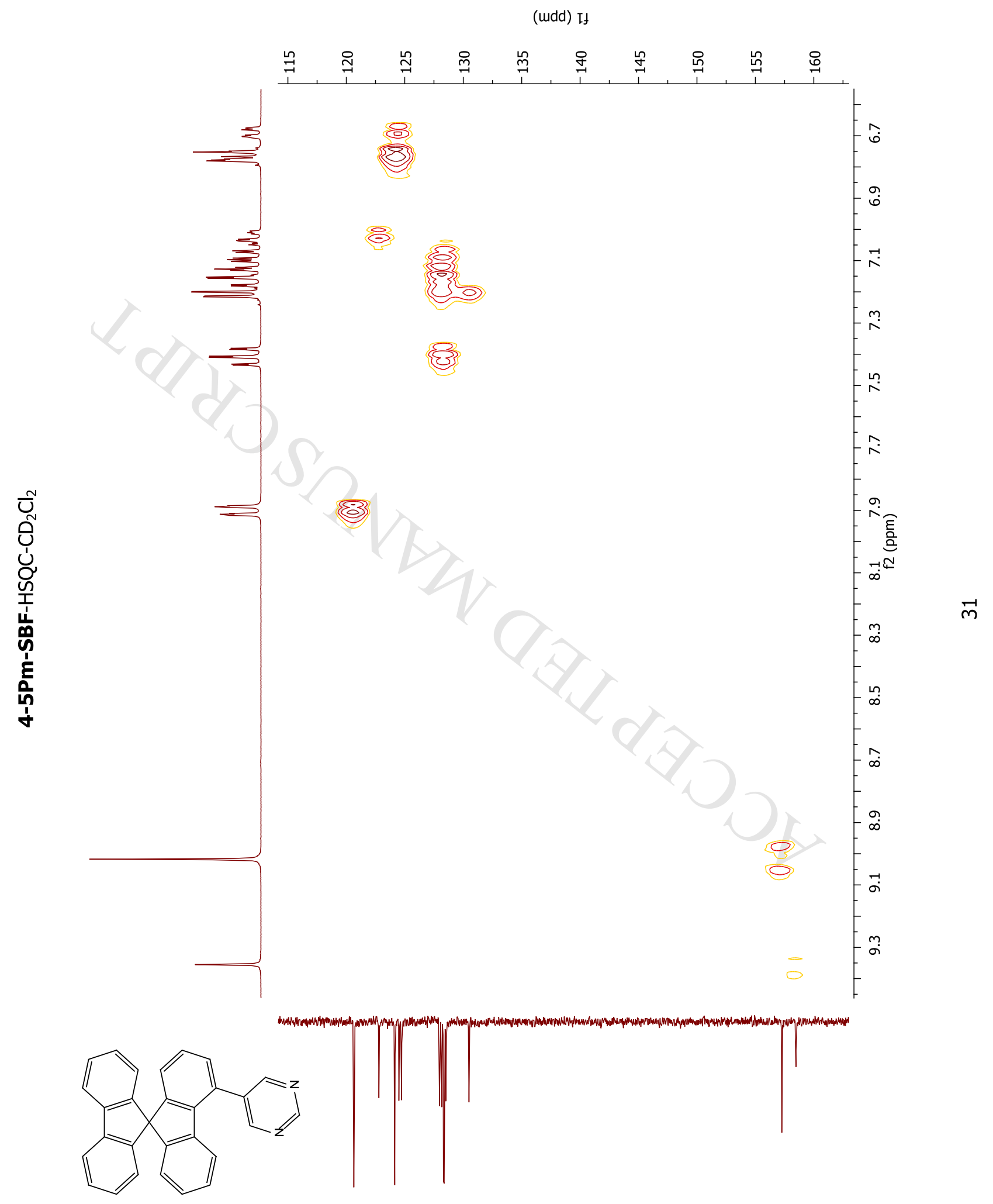




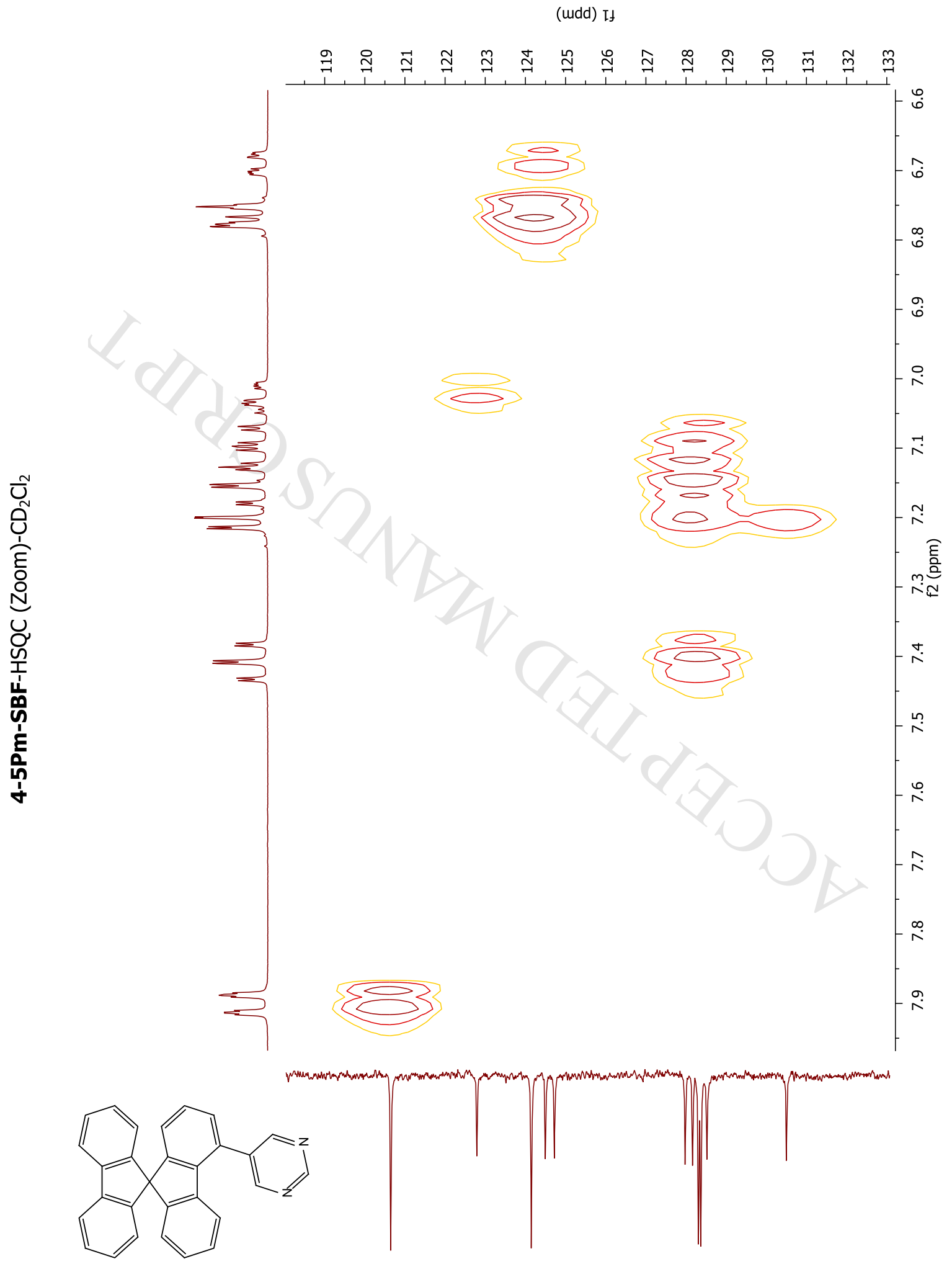




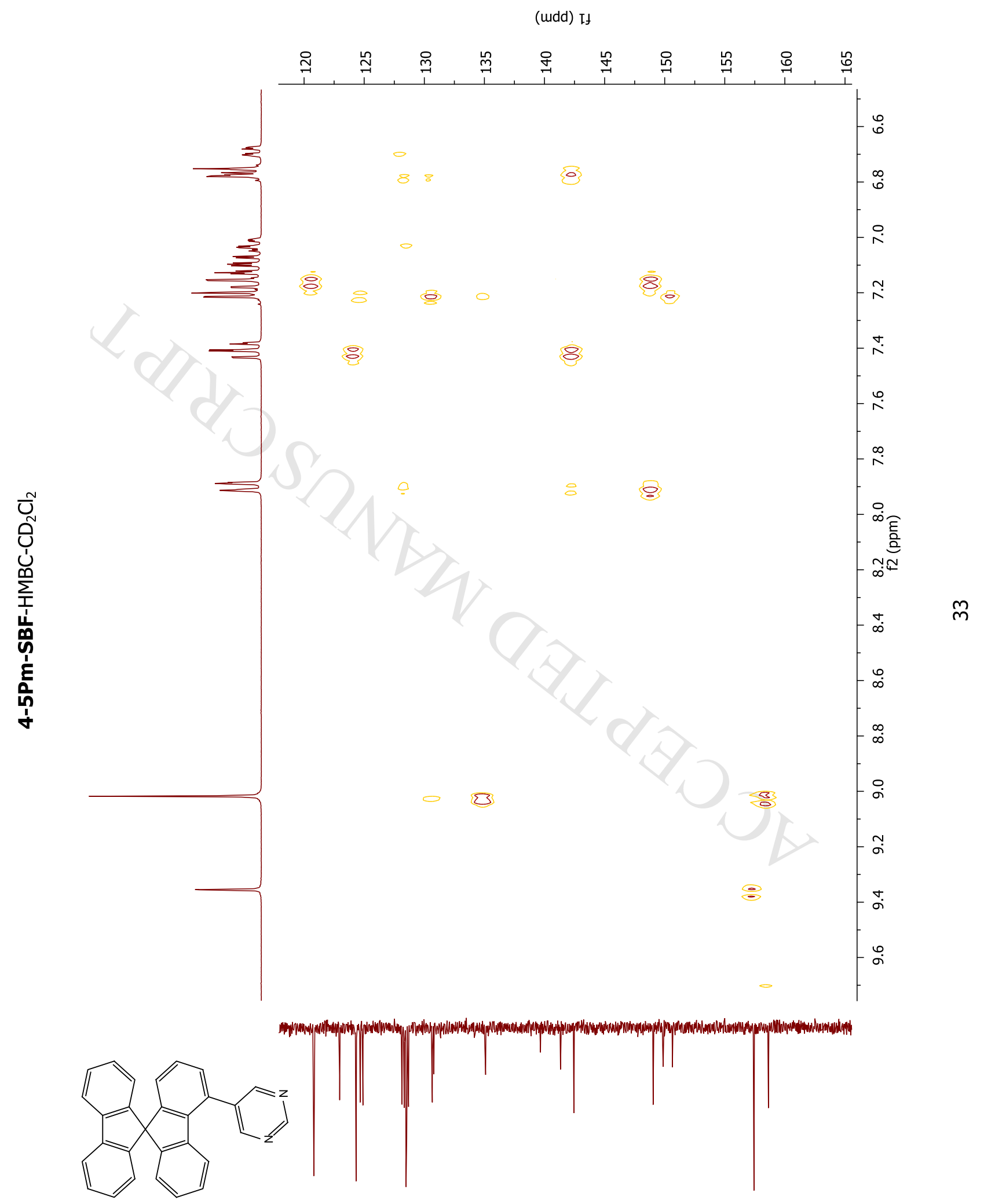




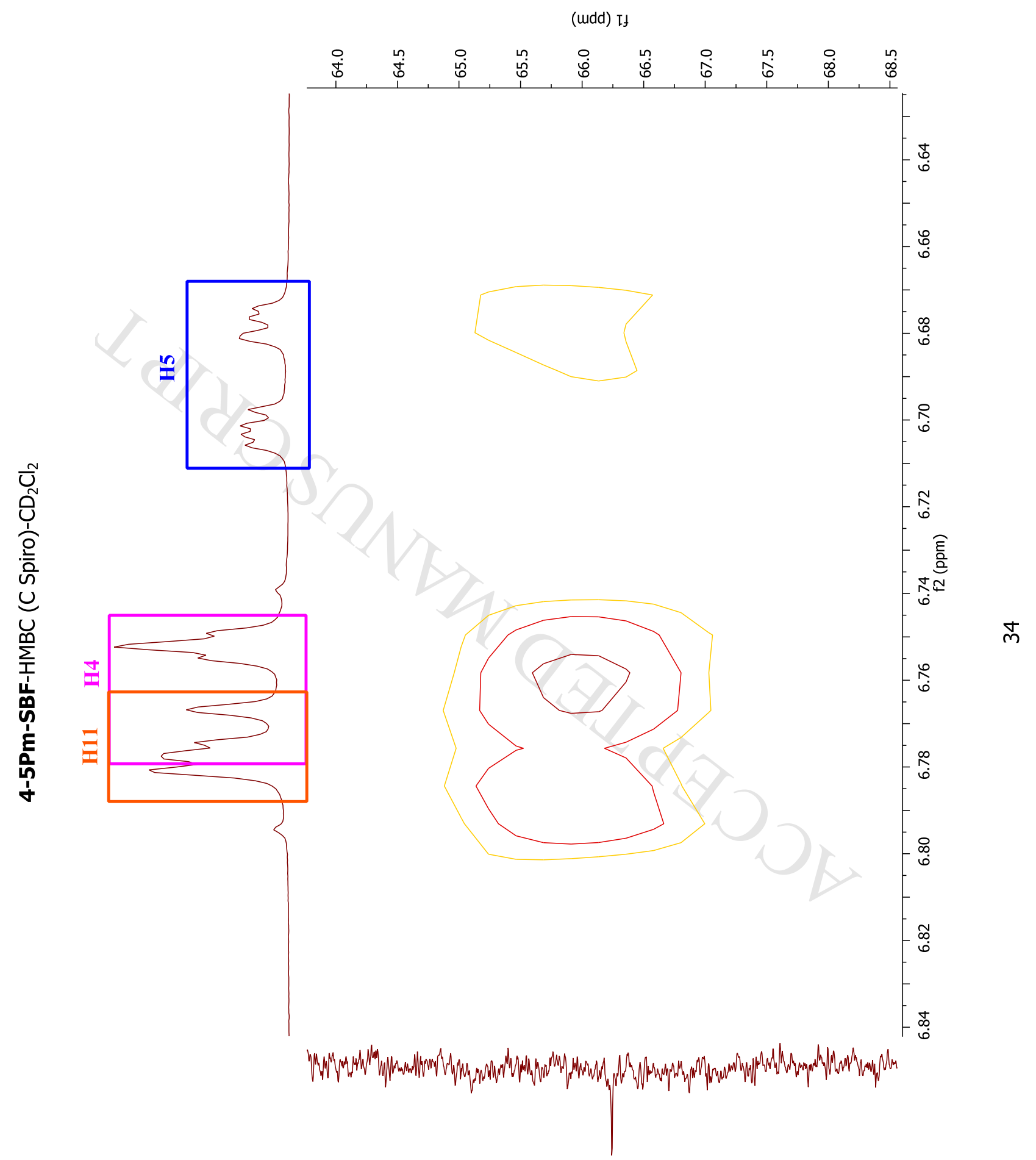




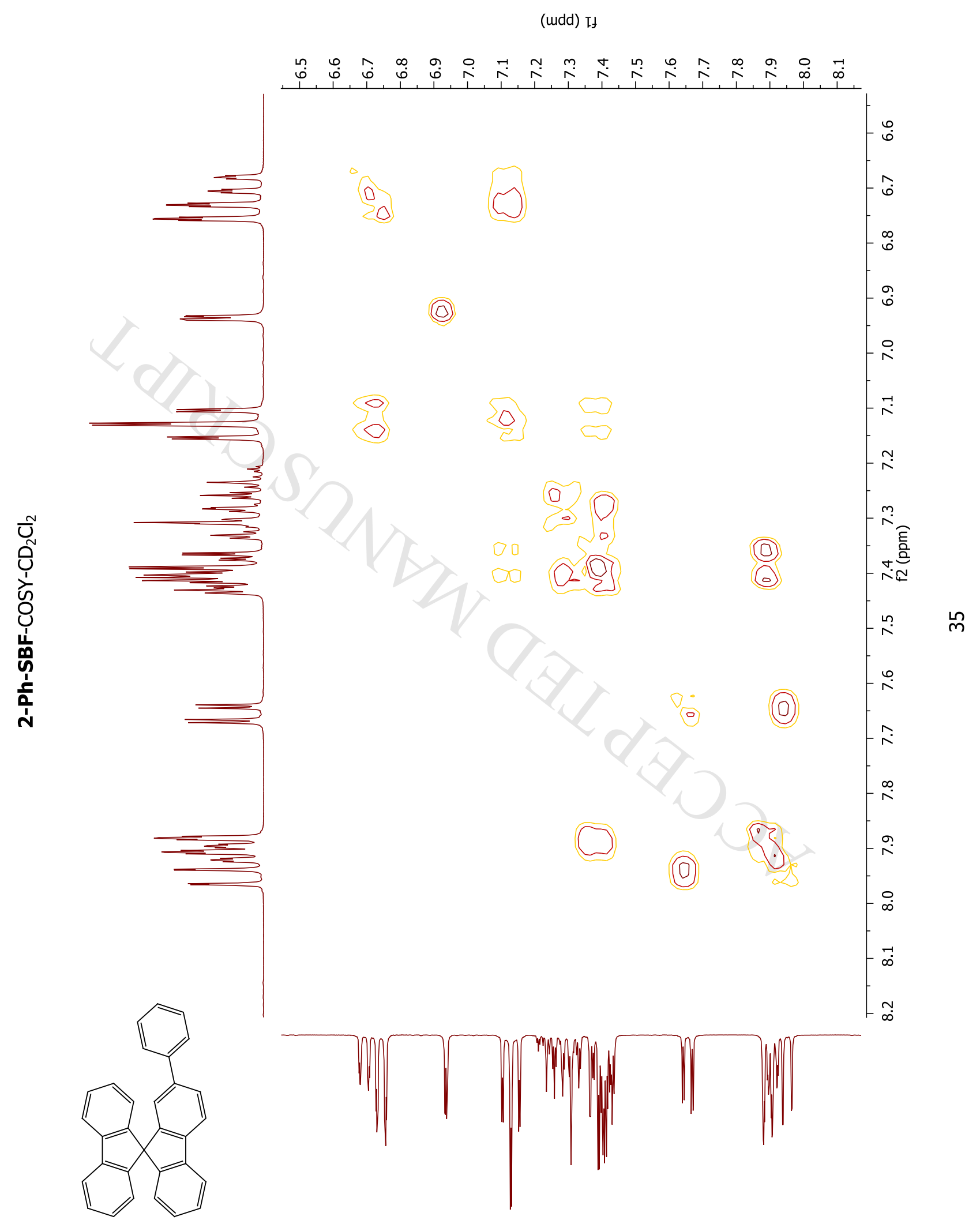




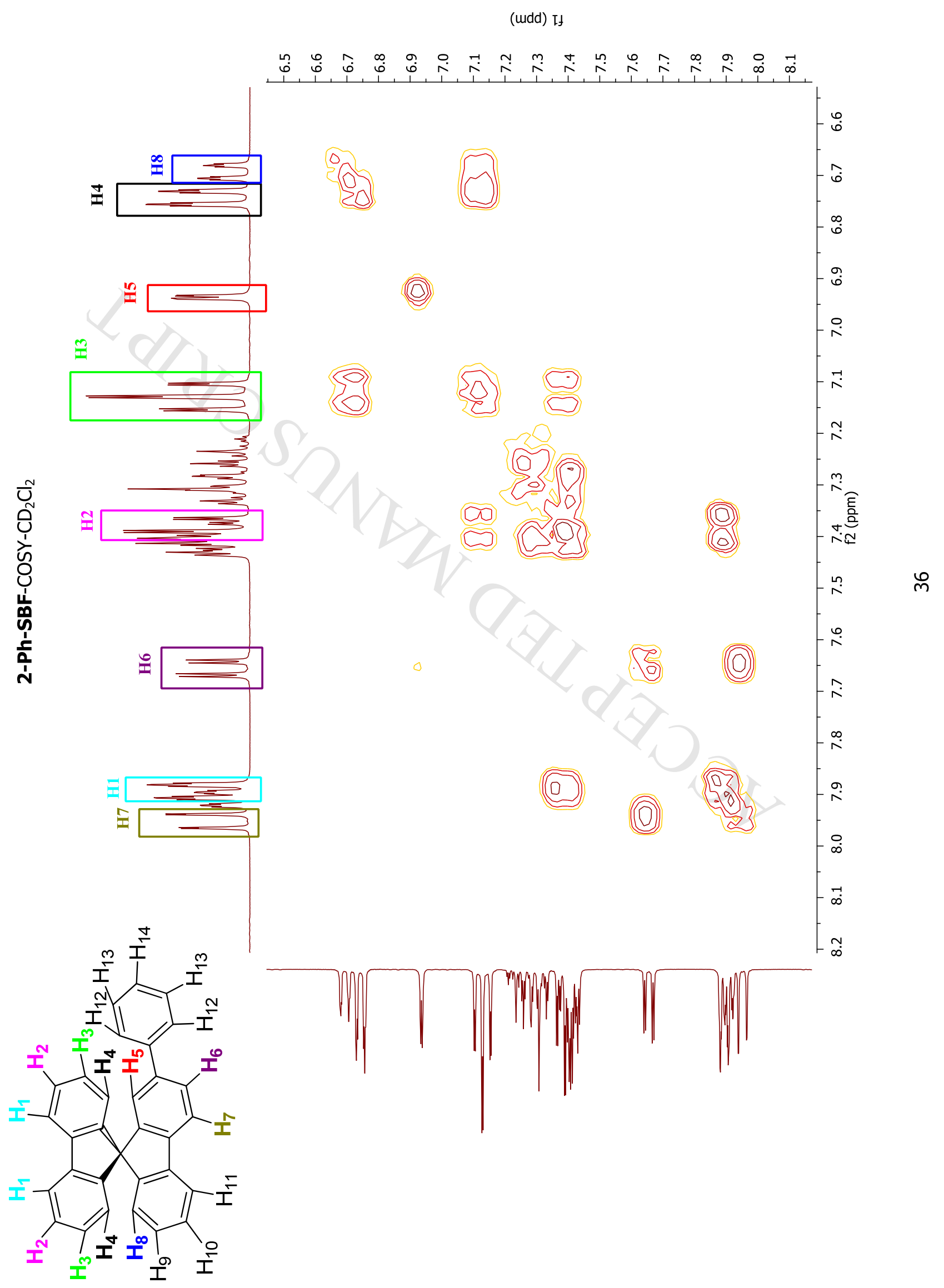




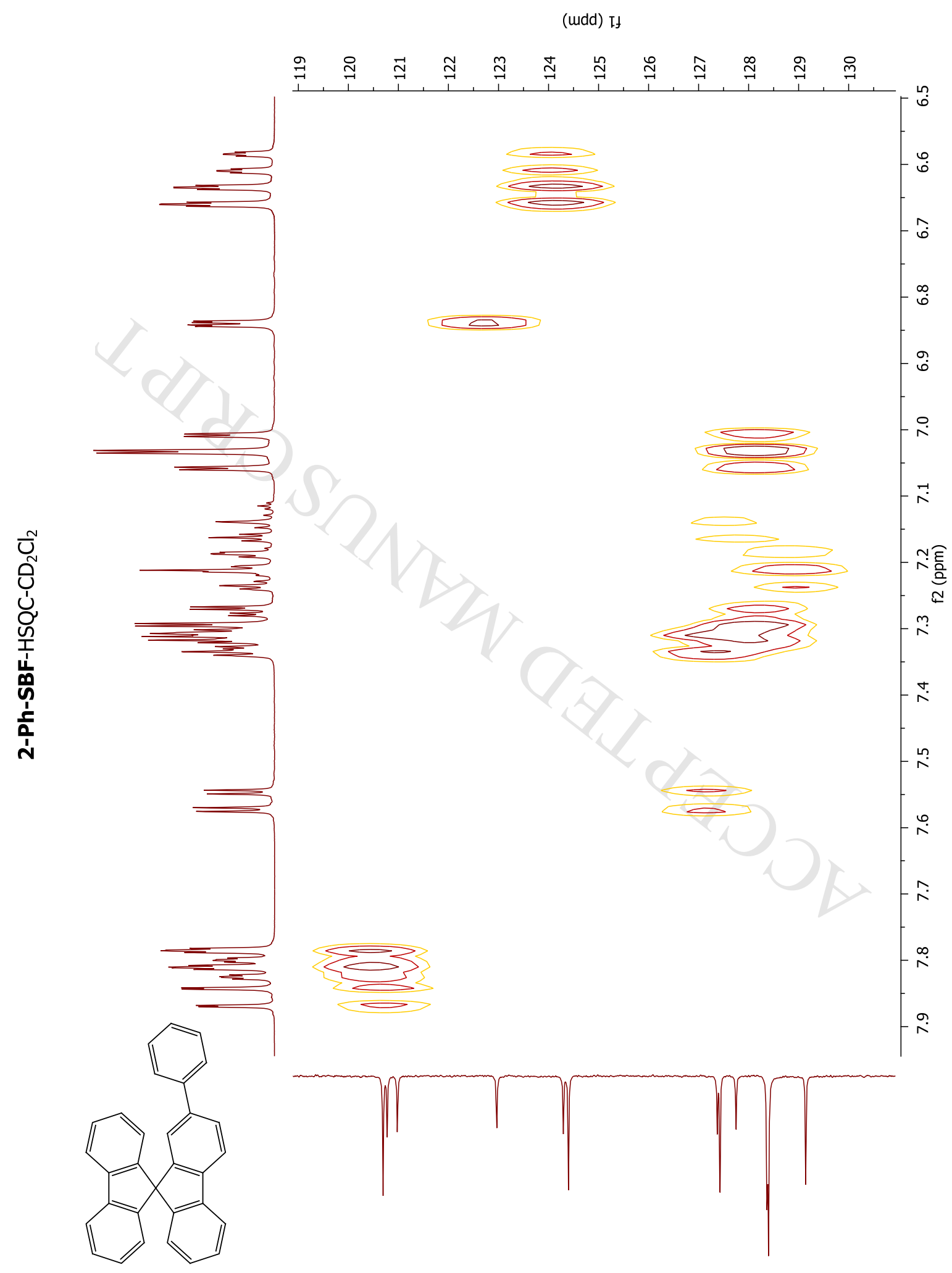

$\hat{m}$ 


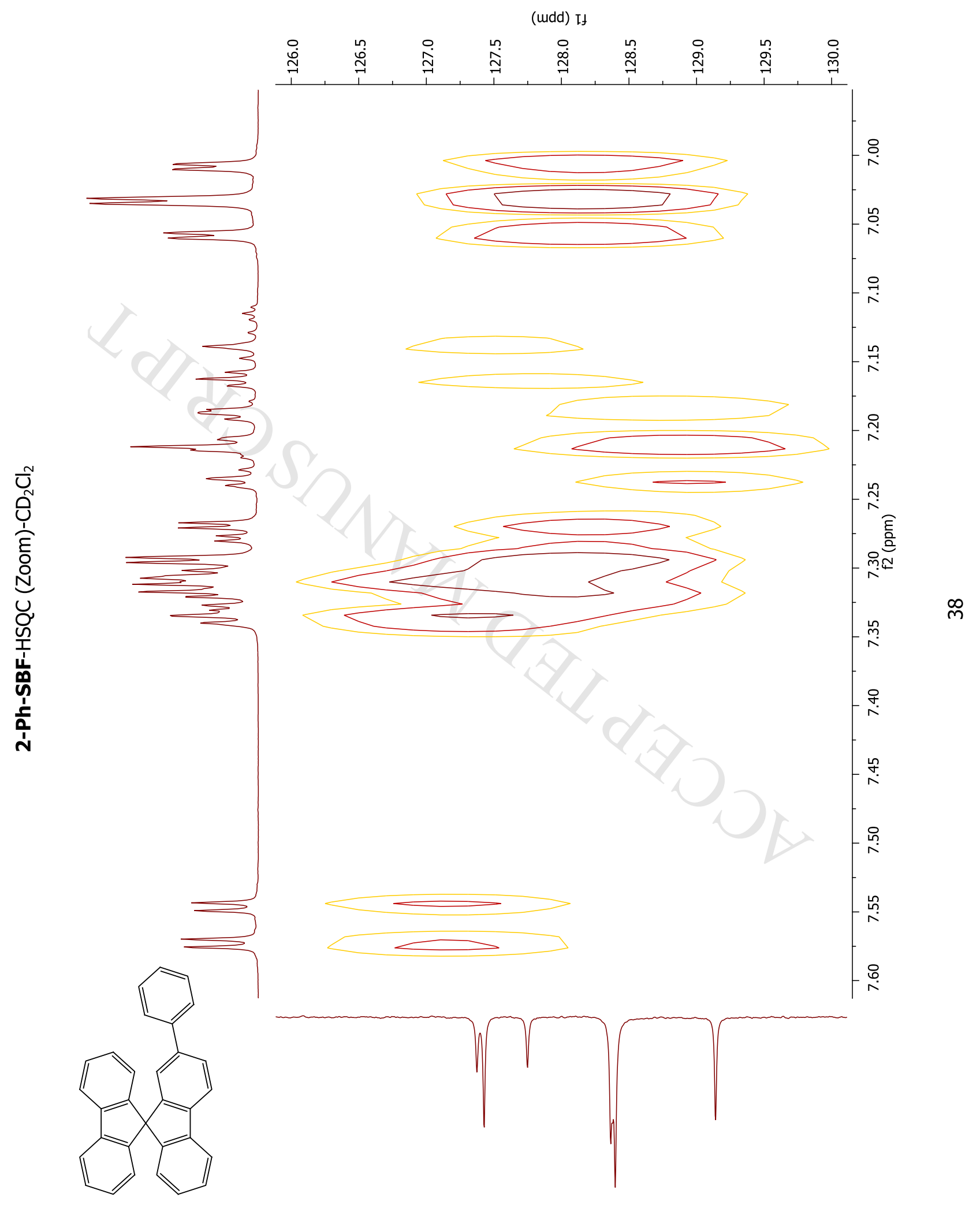




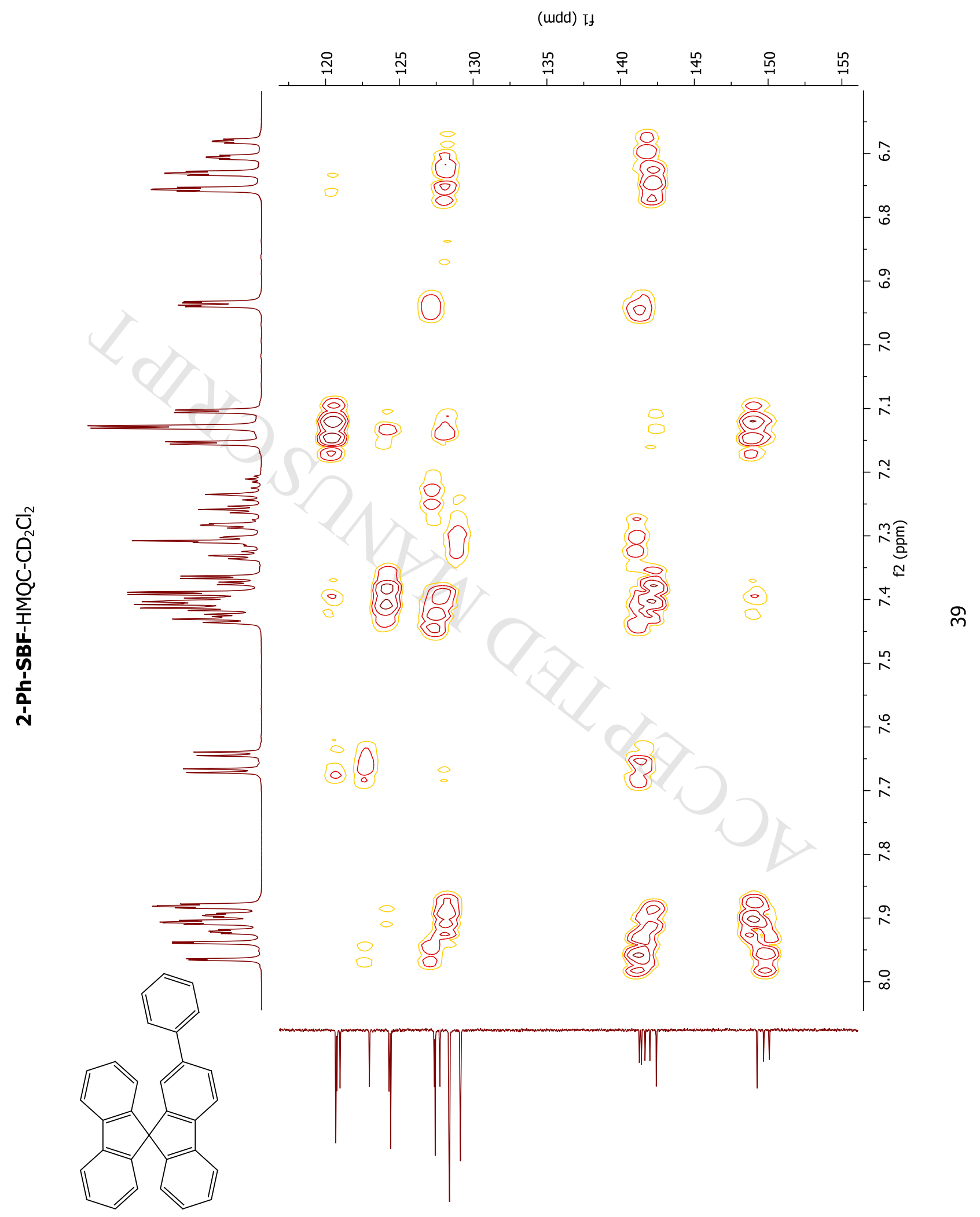




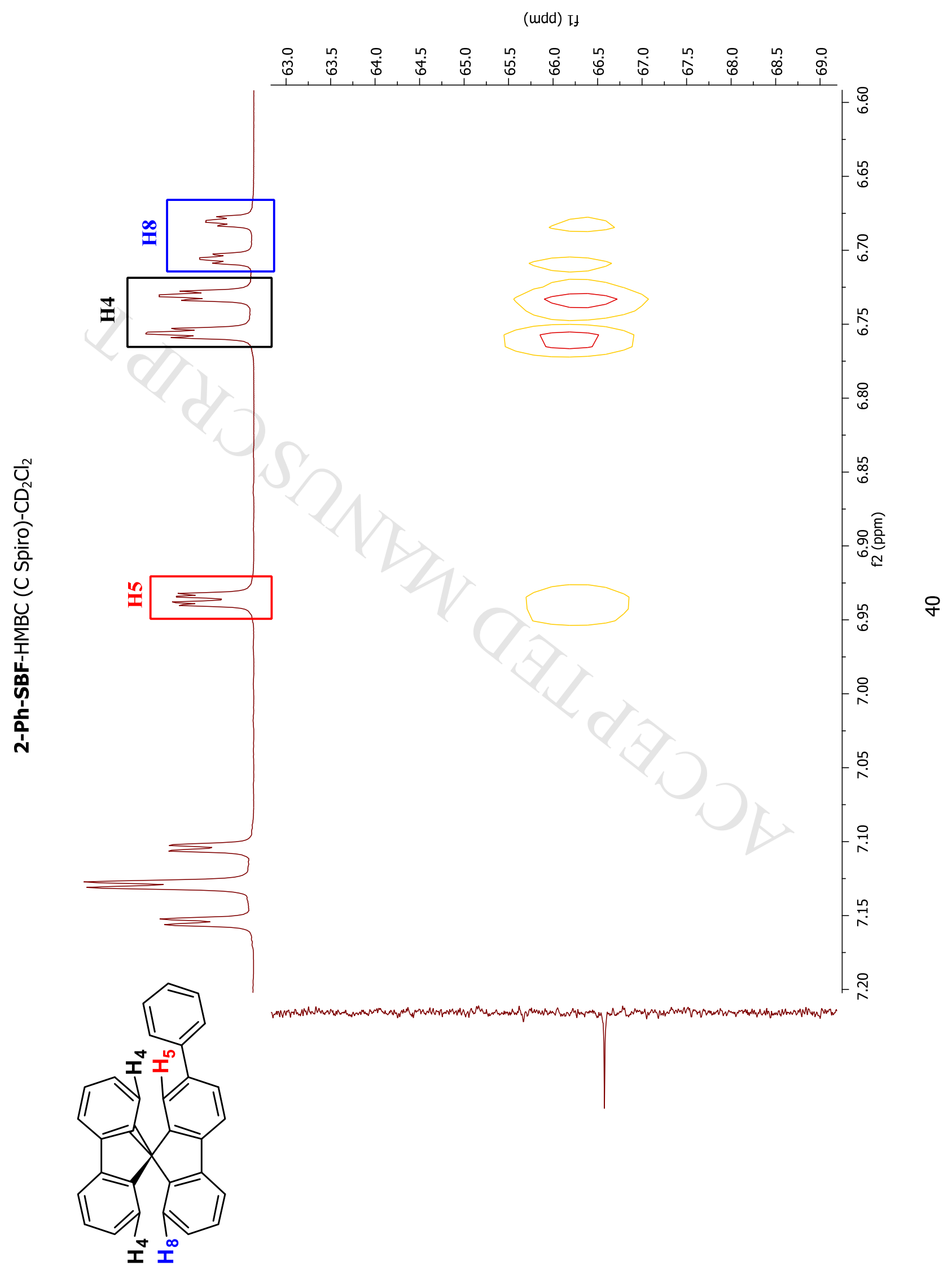




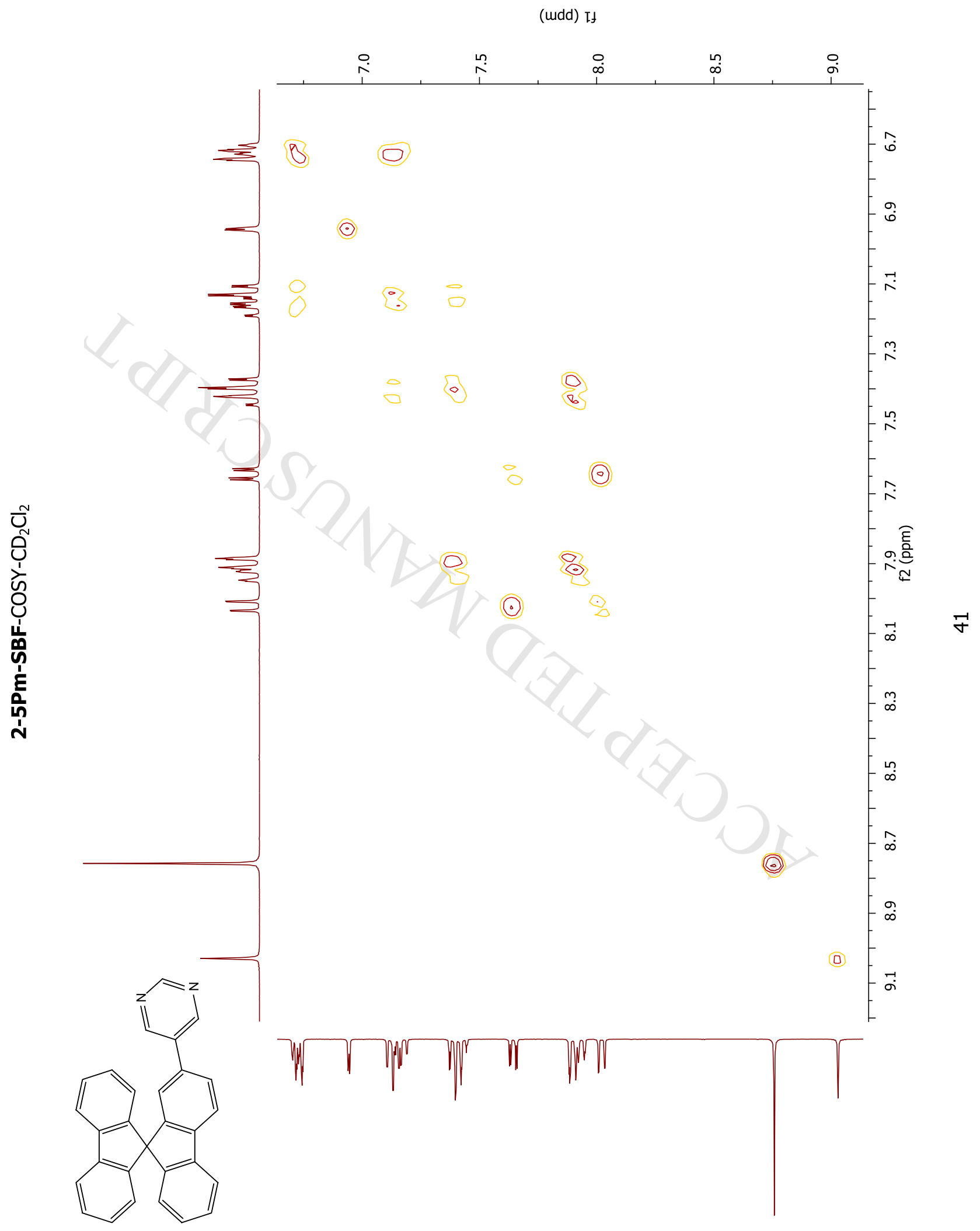




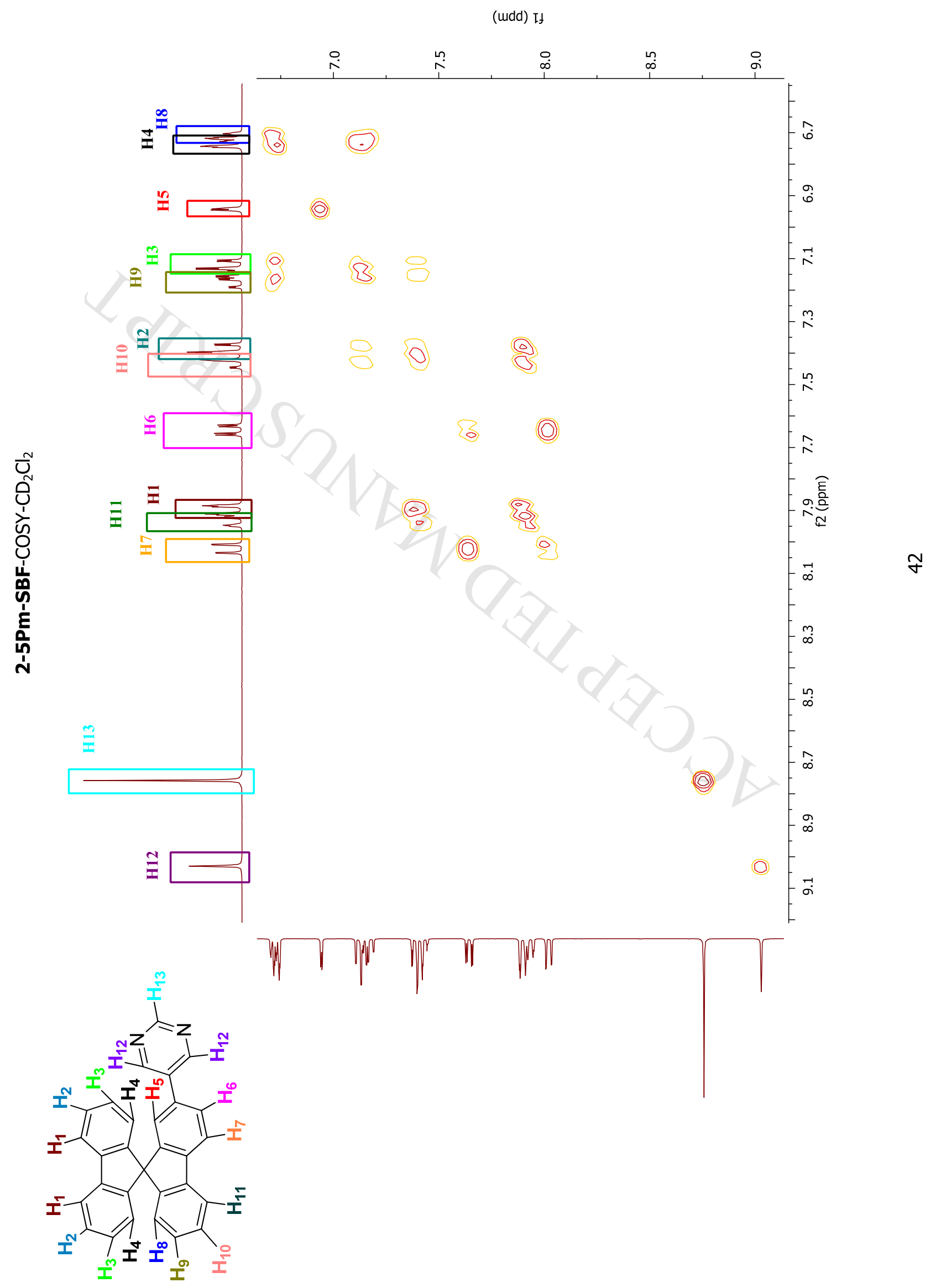




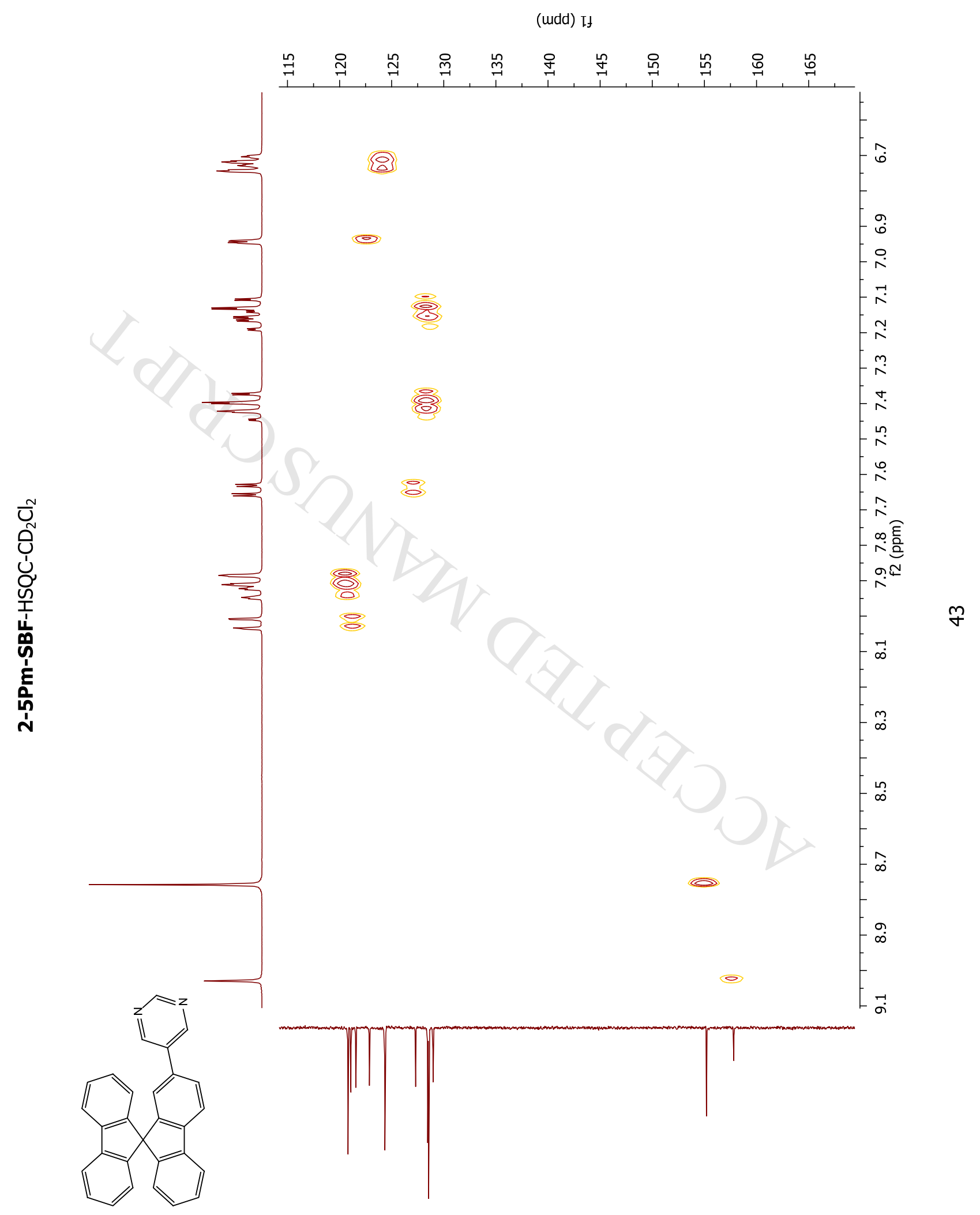




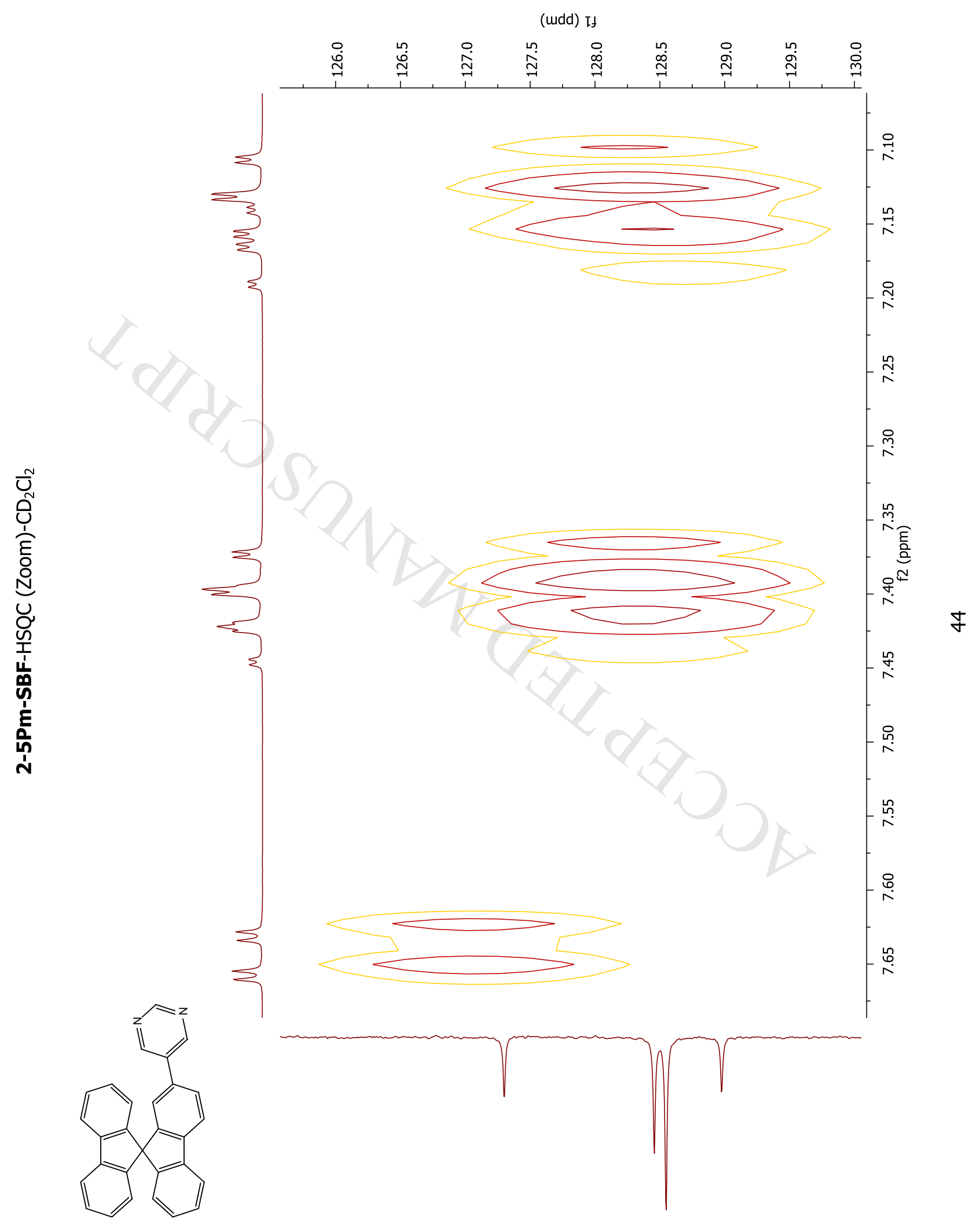




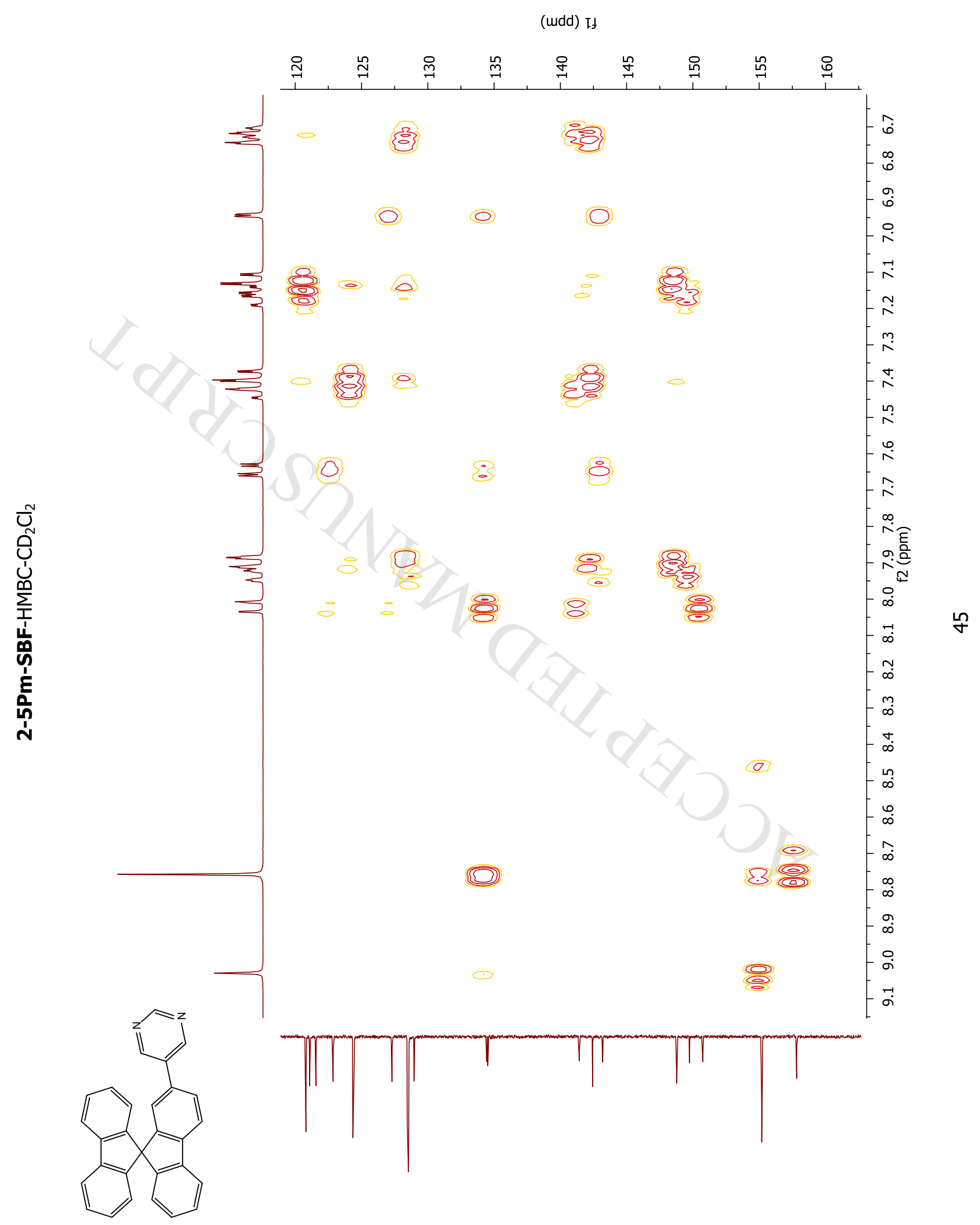


(udd) If
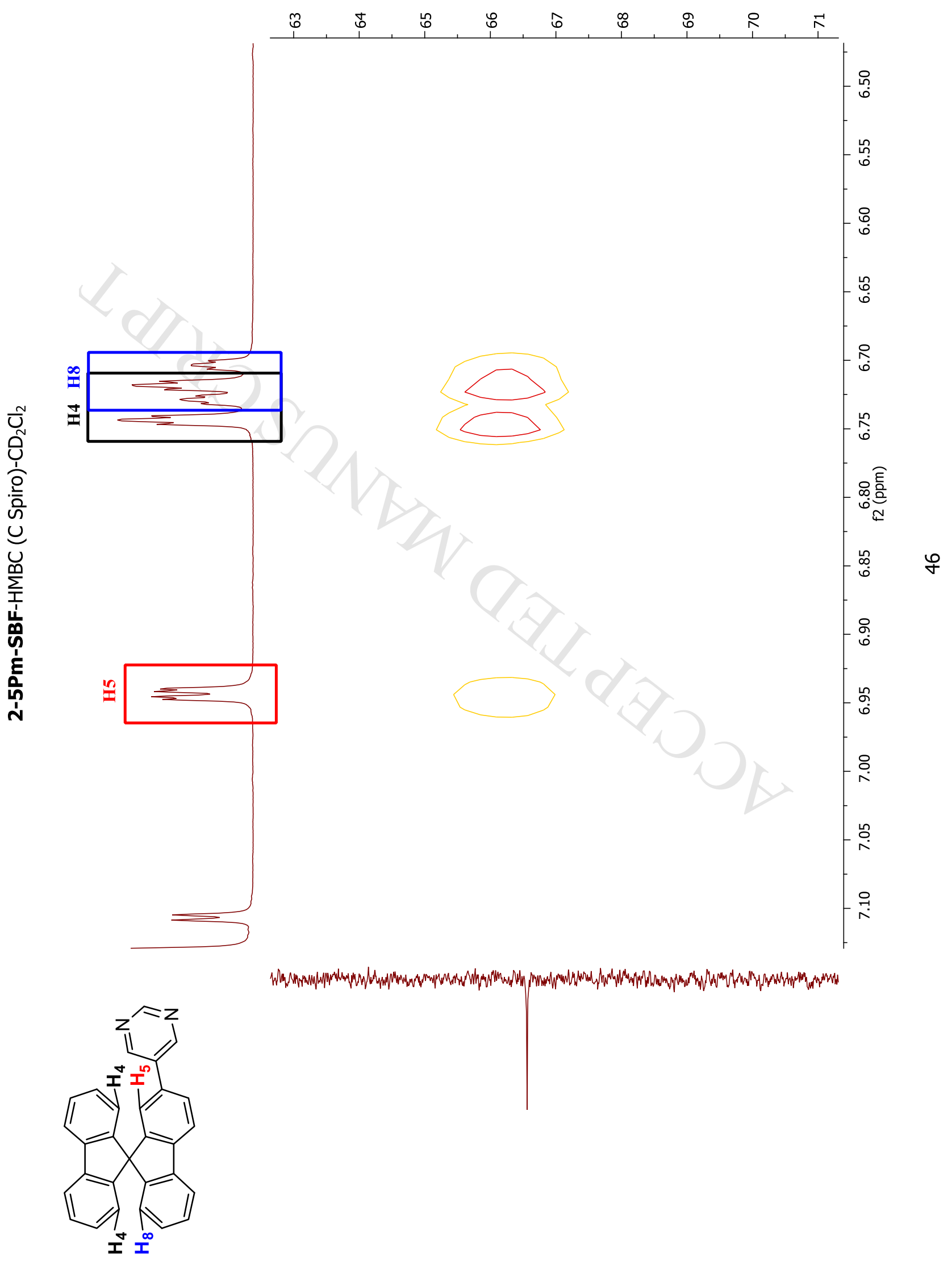

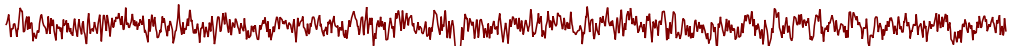




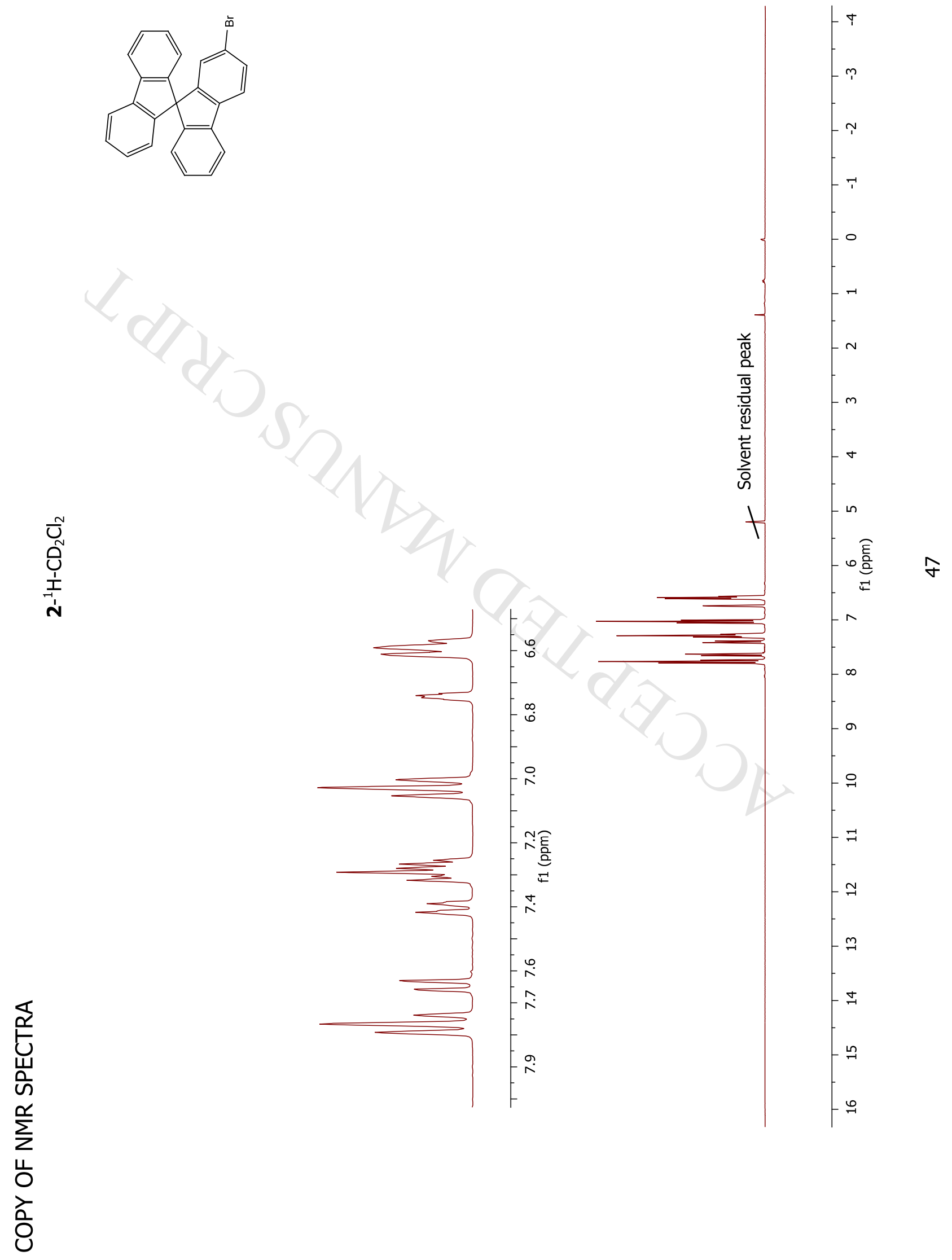




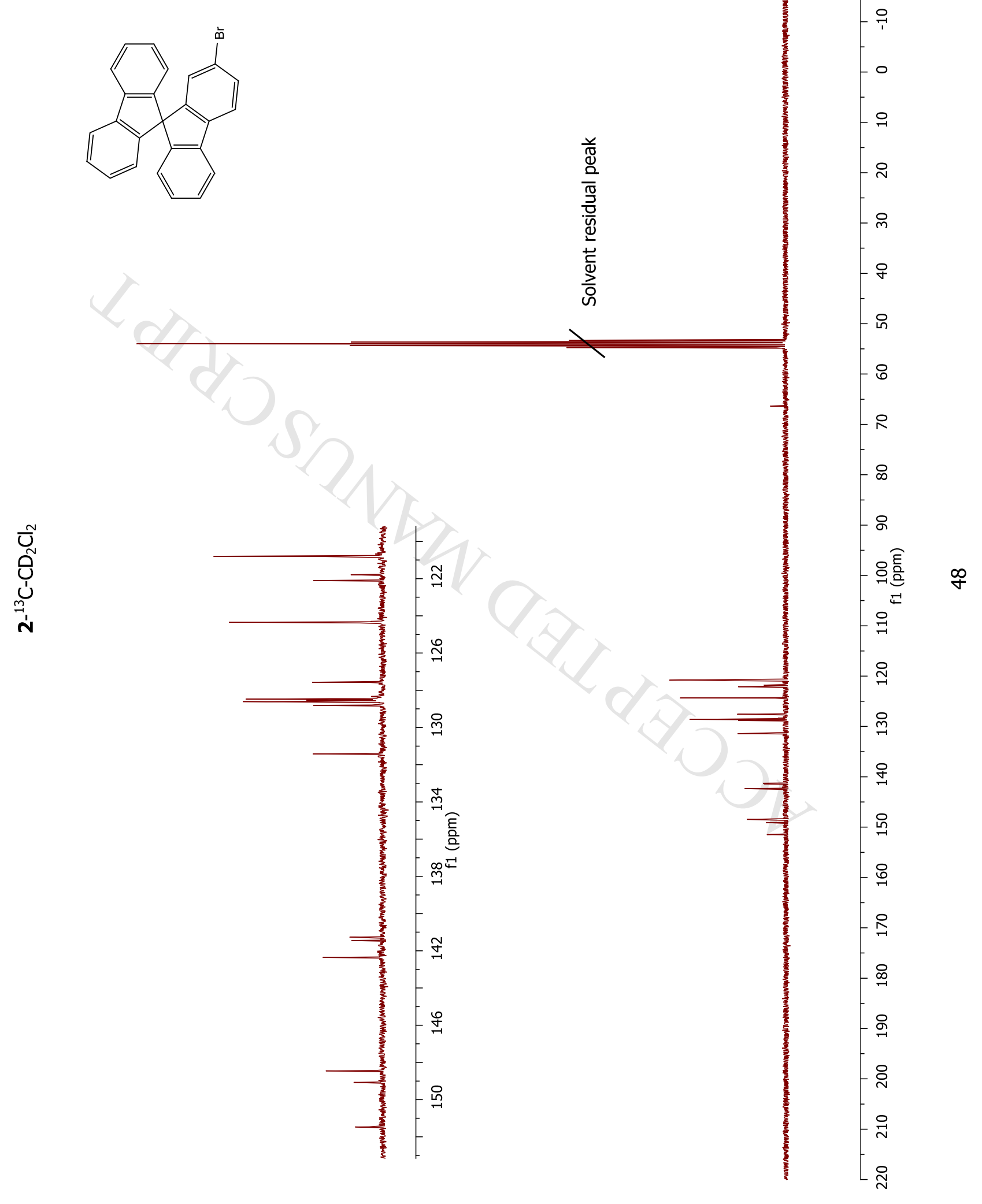




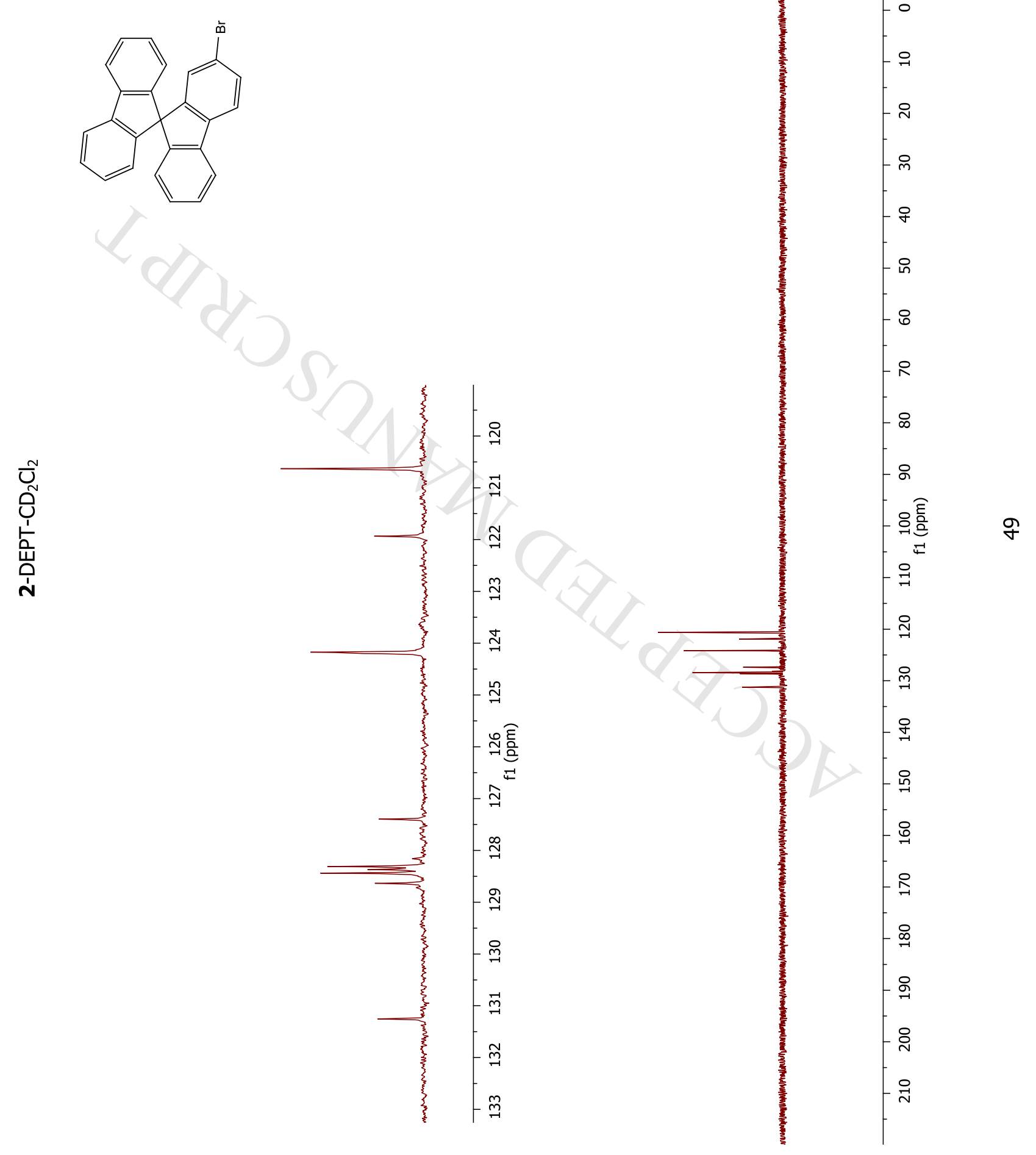




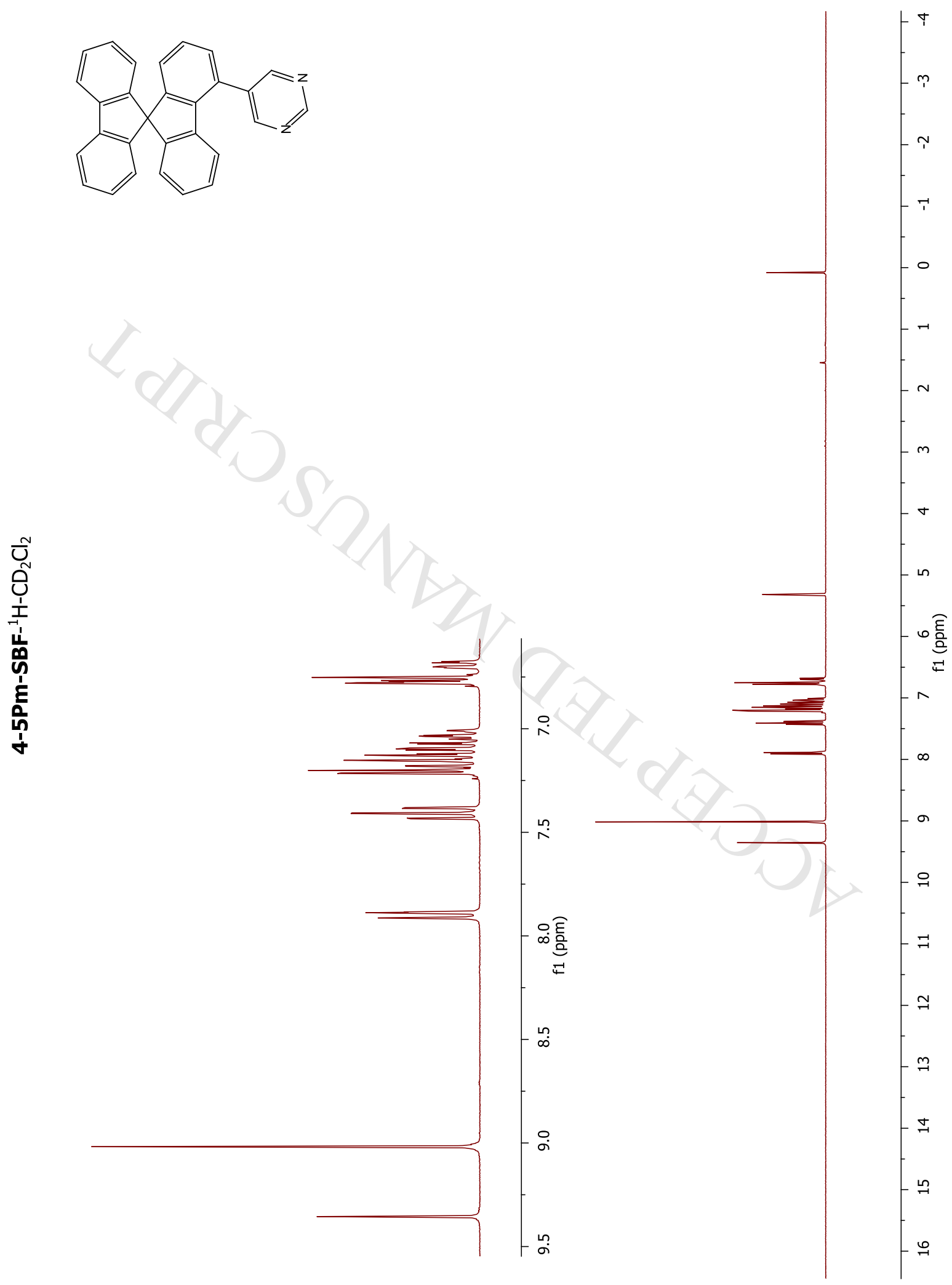




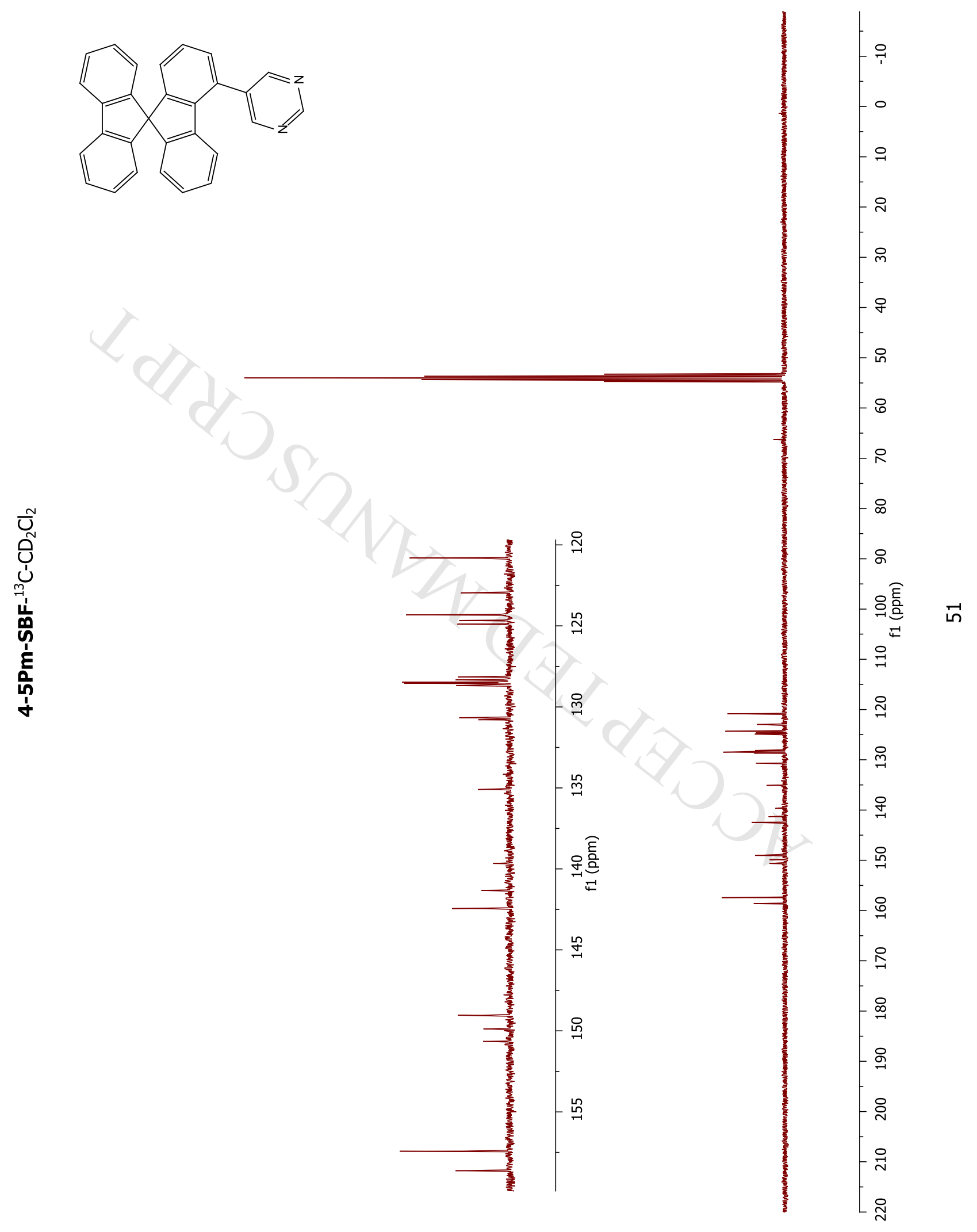




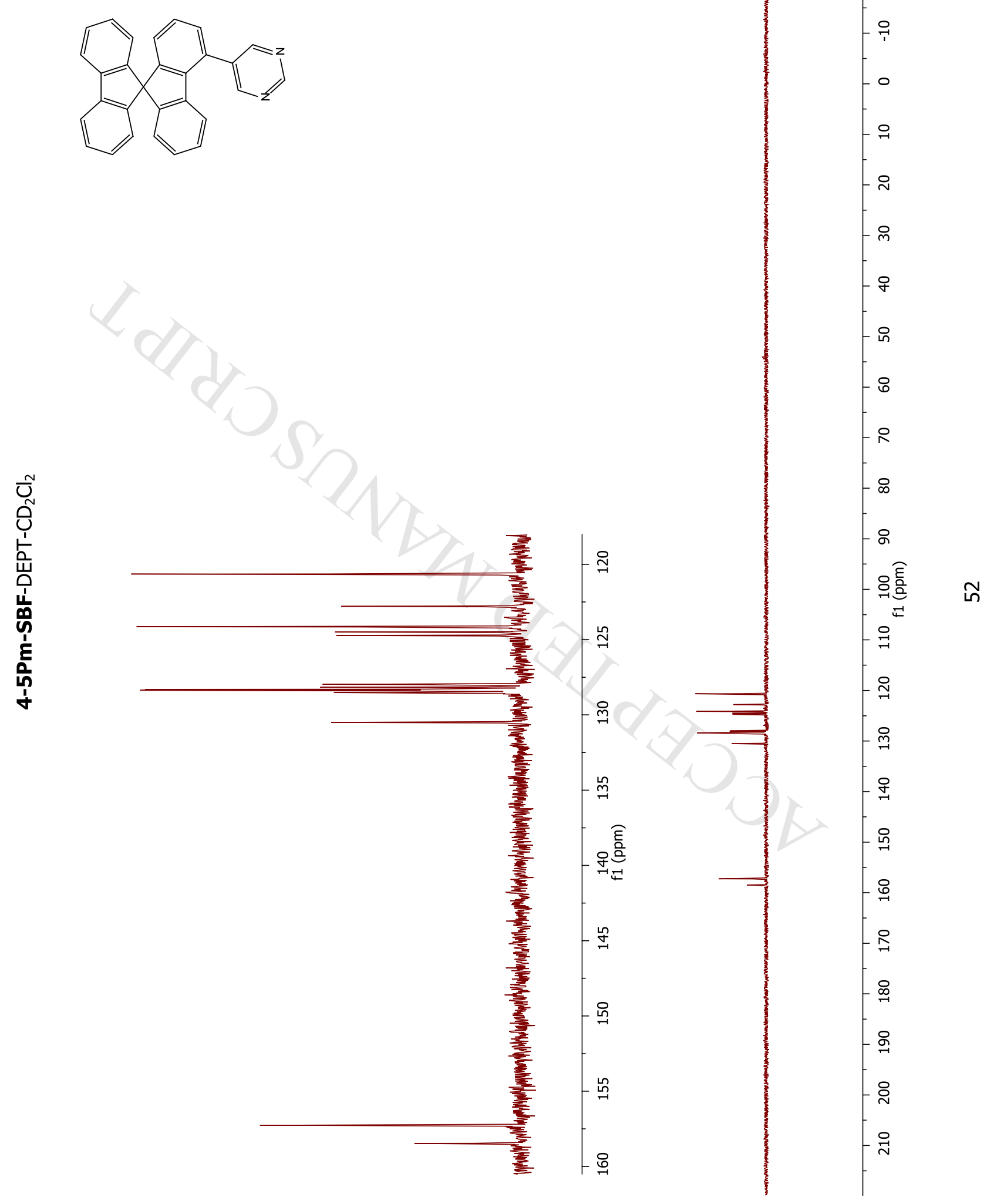




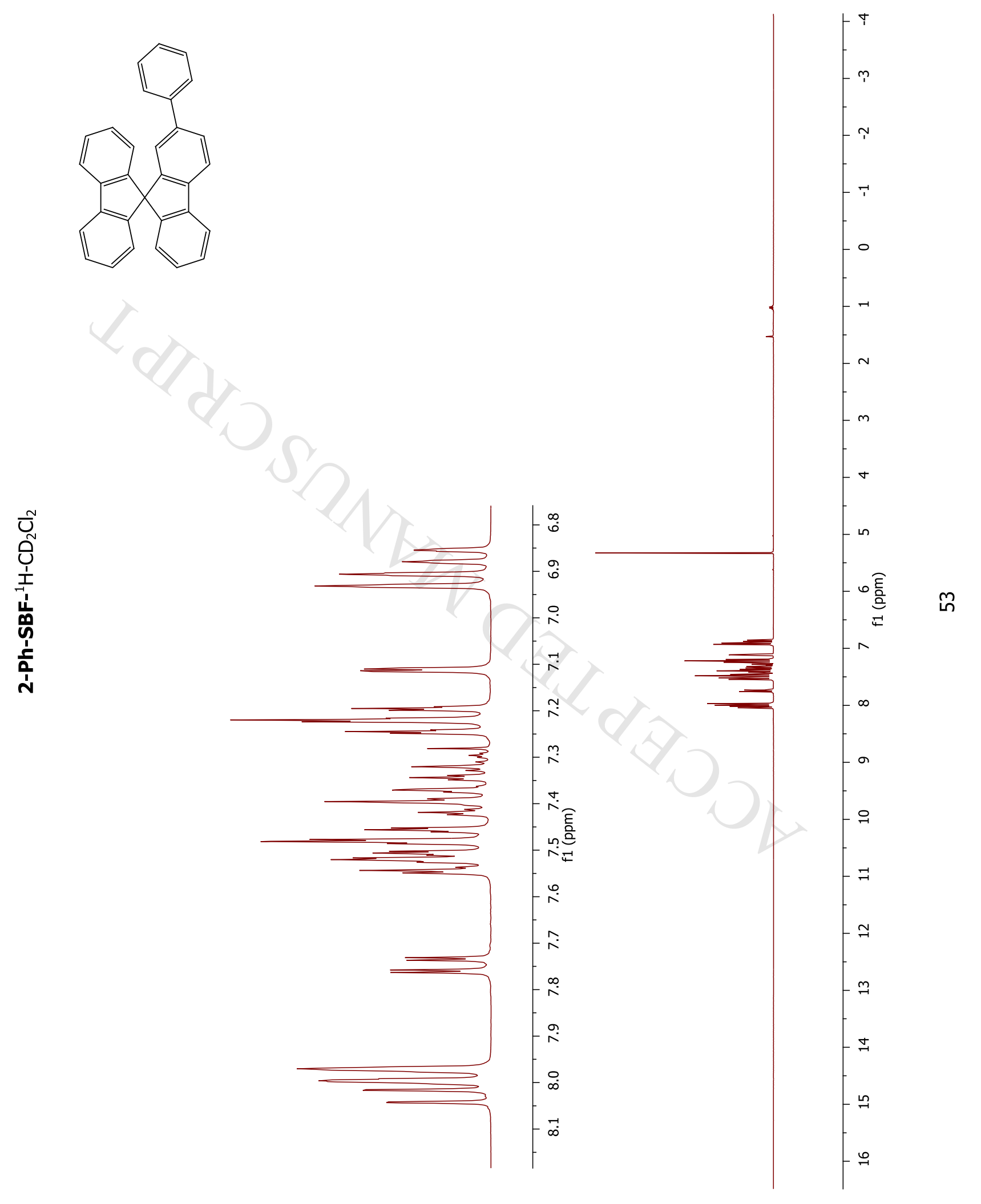




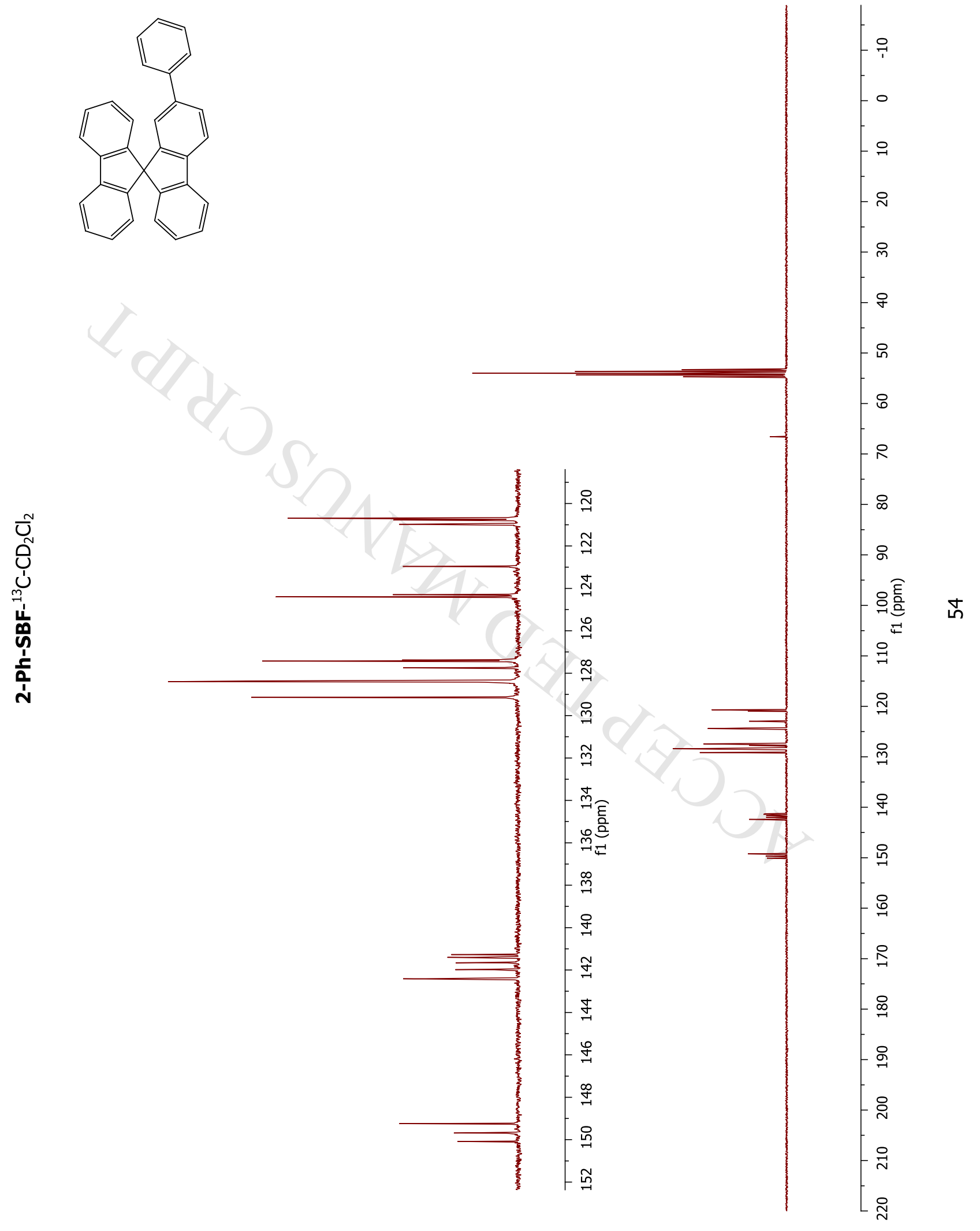




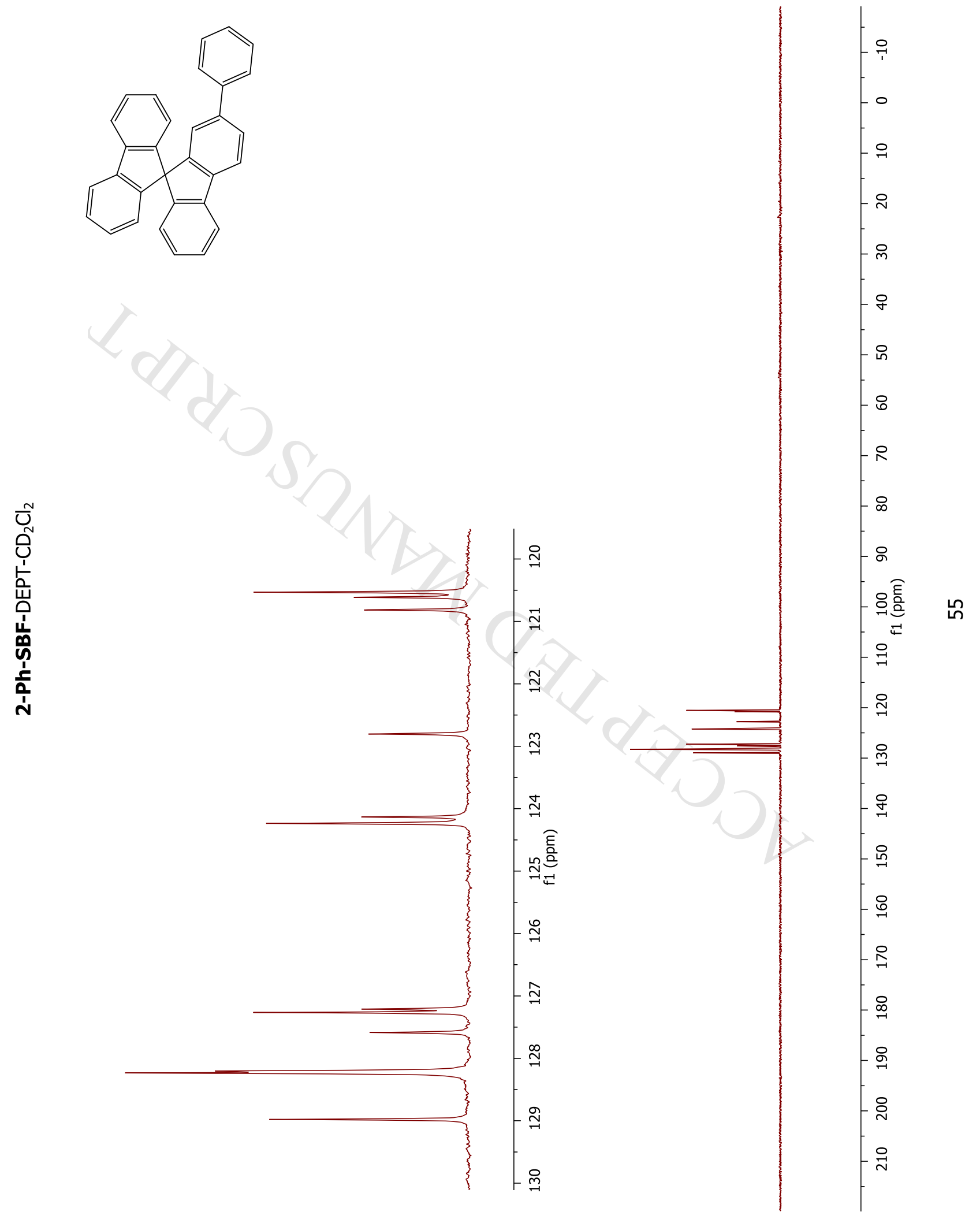



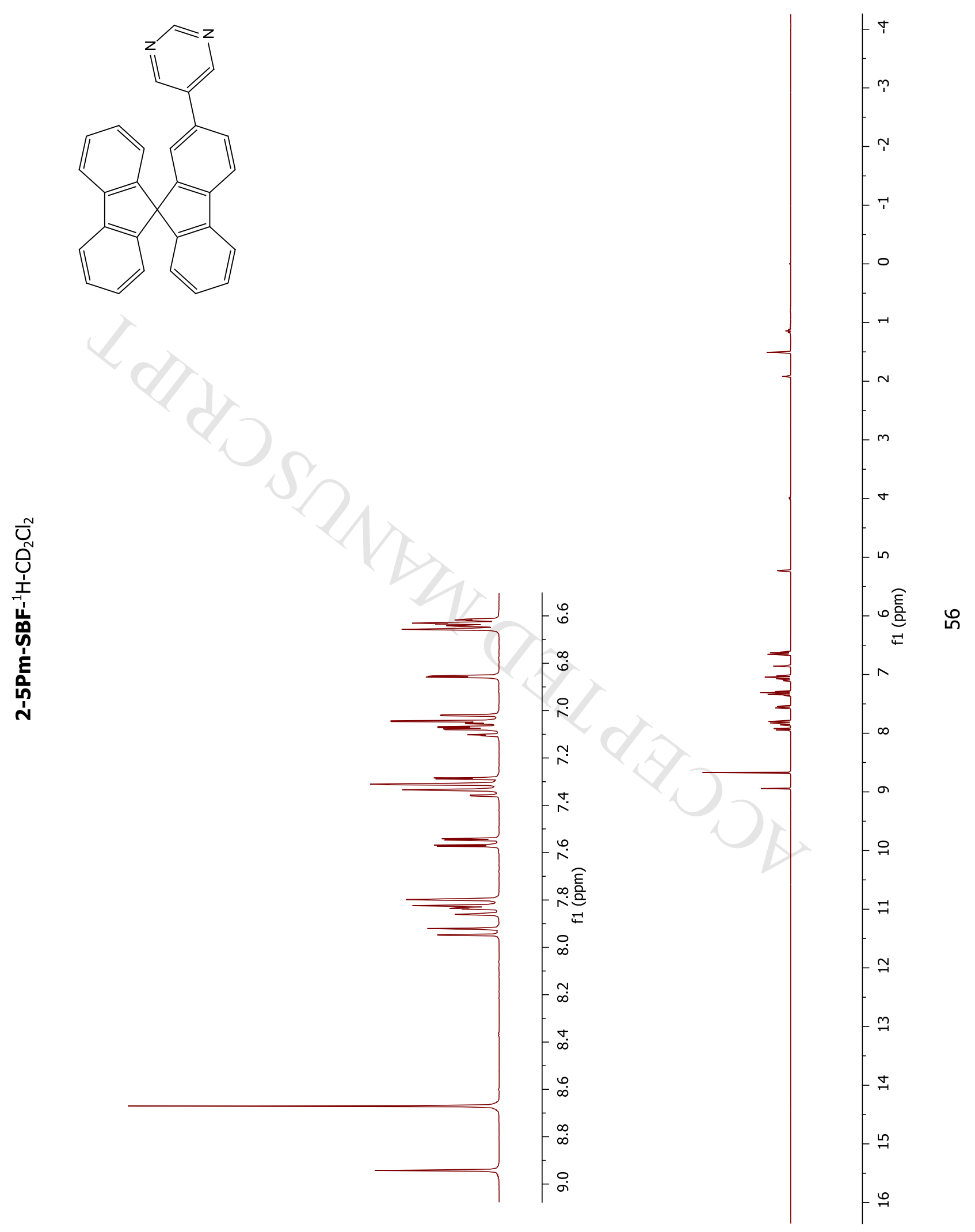


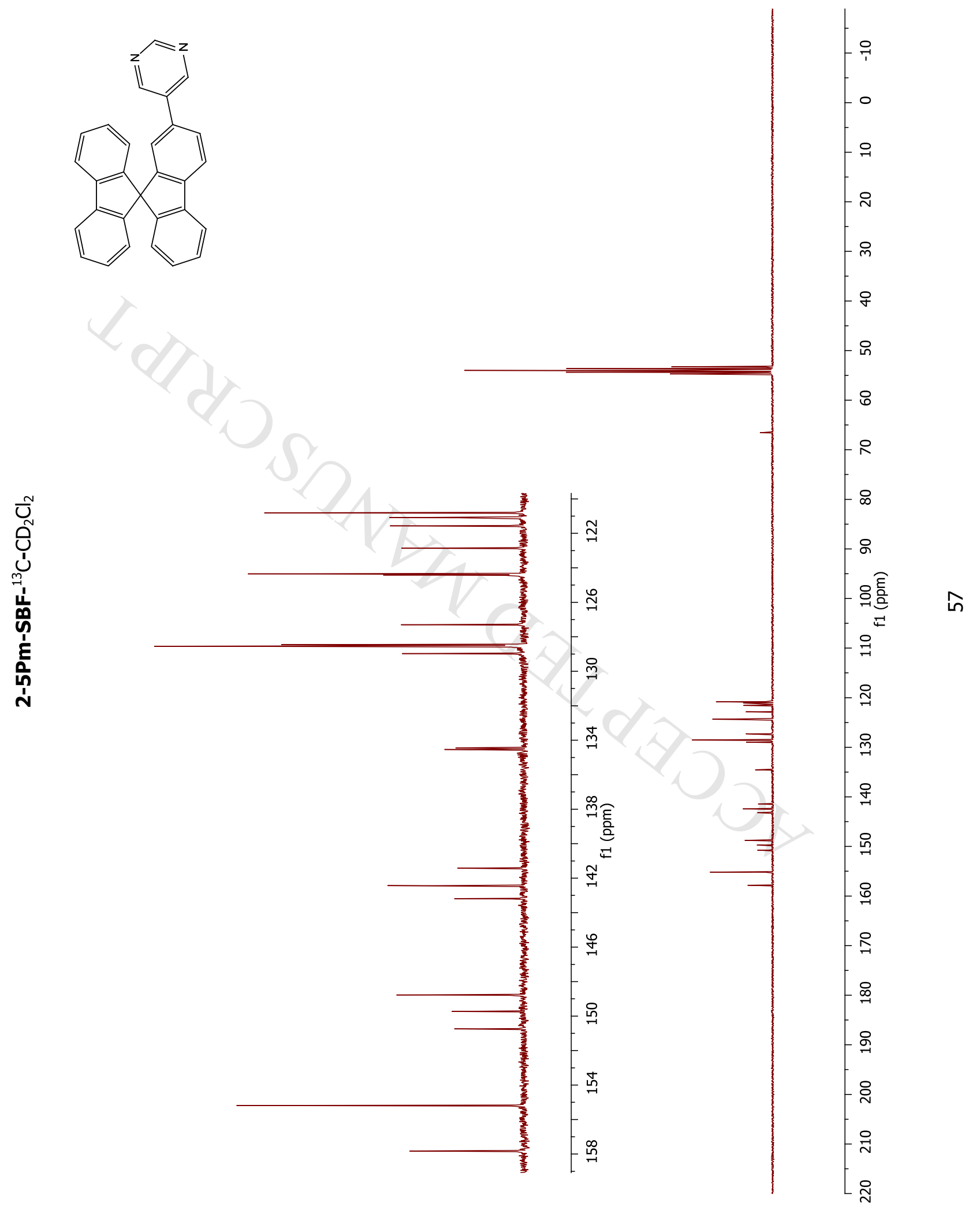




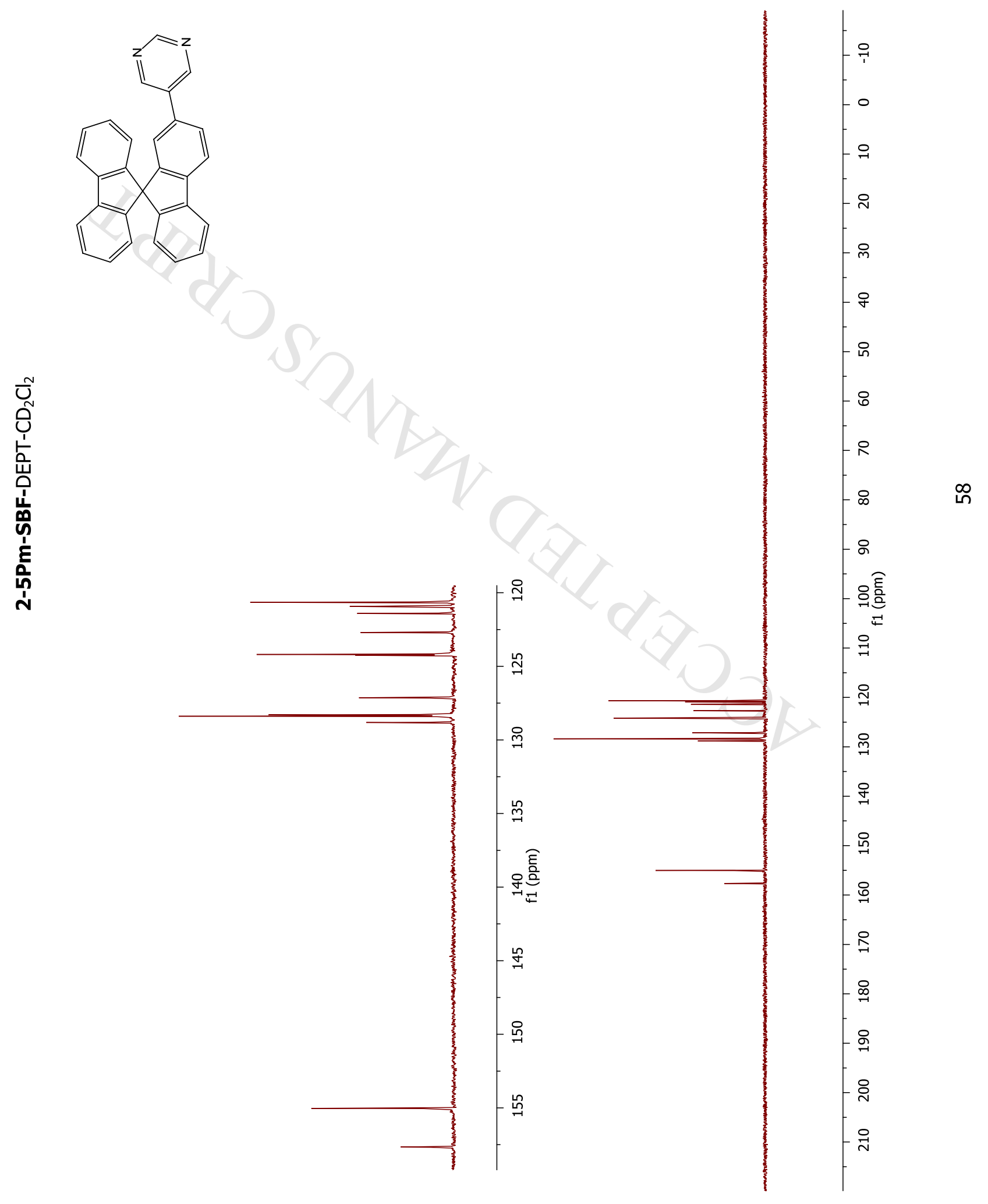




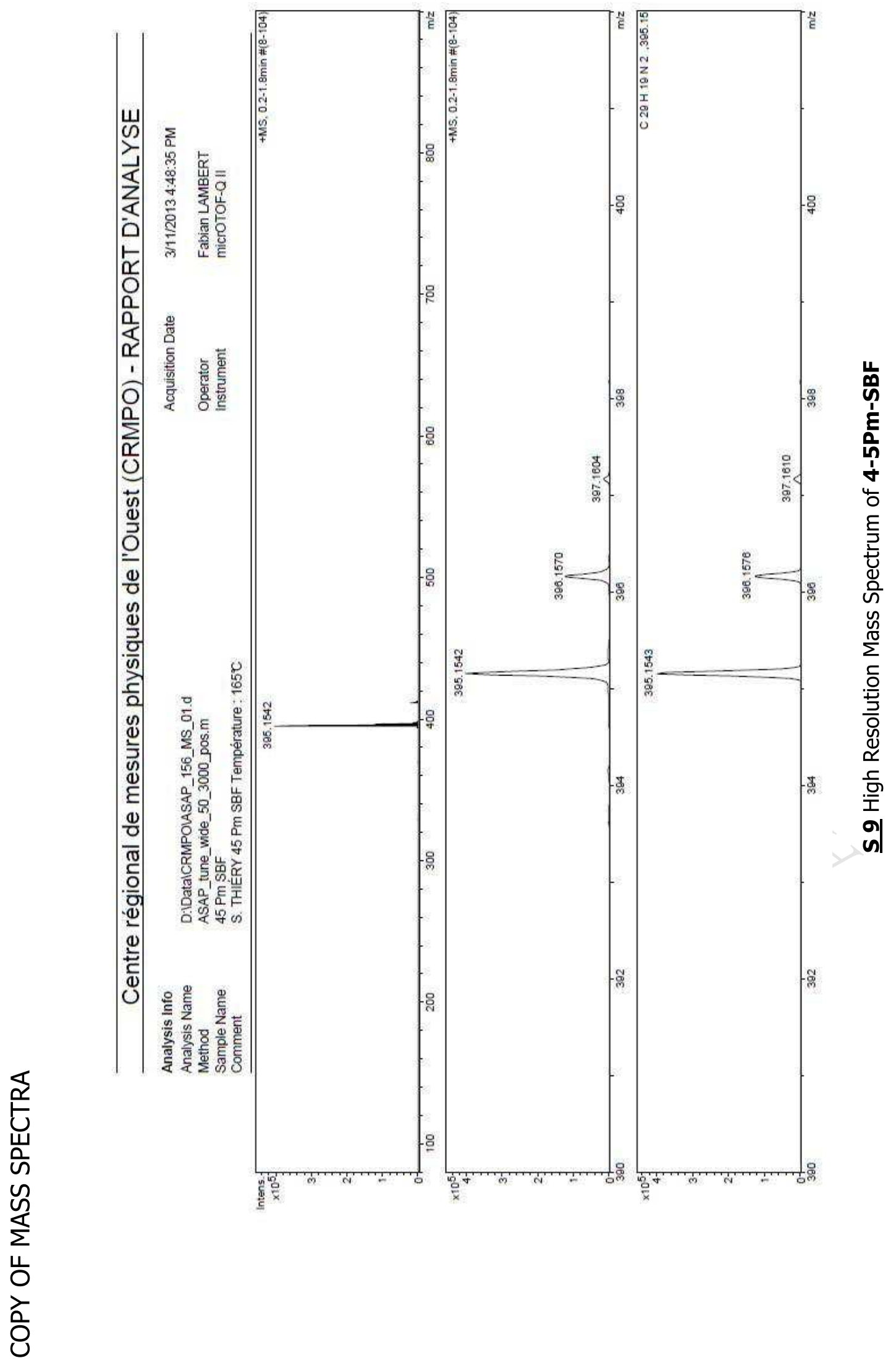

